RODRIGO DE ALBUQUERQUE PACHECO ANDRADE

\title{
Análise e melhoria de um sistema não invasivo de monitoramento da pressão intracraniana
}

\author{
Dissertação apresentada à Escola de \\ Engenharia de São Carlos, da \\ Universidade de São Paulo como \\ parte para obtenção do título de \\ mestre em Engenharia Mecânica \\ Área de Concentração: Manufatura \\ Orientador: Prof. Titular Dr. Reginaldo \\ Teixeira Coelho
}



RODRIGO DE ALBUQUERQUE PACHECO ANDRADE

\section{Análise e melhoria de um sistema não invasivo de monitoramento da pressão intracraniana}

Dissertação apresentada à Escola de Engenharia de São Carlos, da Universidade de São Paulo como parte para obtenção do título de mestre em Engenharia Mecânica

Área de Concentração: Manufatura Orientador: Prof. Titular Dr. Reginaldo Teixeira Coelho

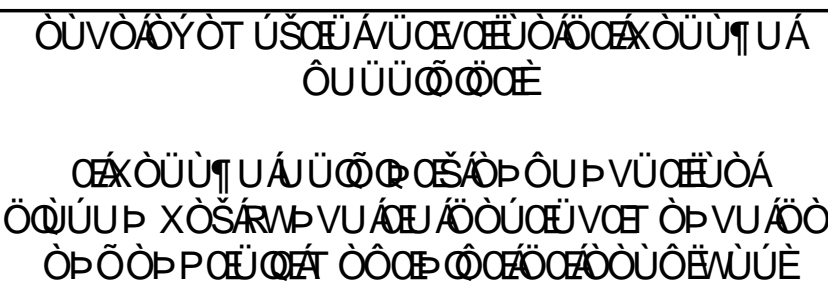


AUTORIZO A REPRODUÇÃO TOTAL OU PARCIAL DESTE TRABALHO, POR QUALQUER MEIO CONVENCIONAL OU ELETRÔNICO, PARA FINS DE ESTUDO E PESQUISA, DESDE QUE CITADA A FONTE.

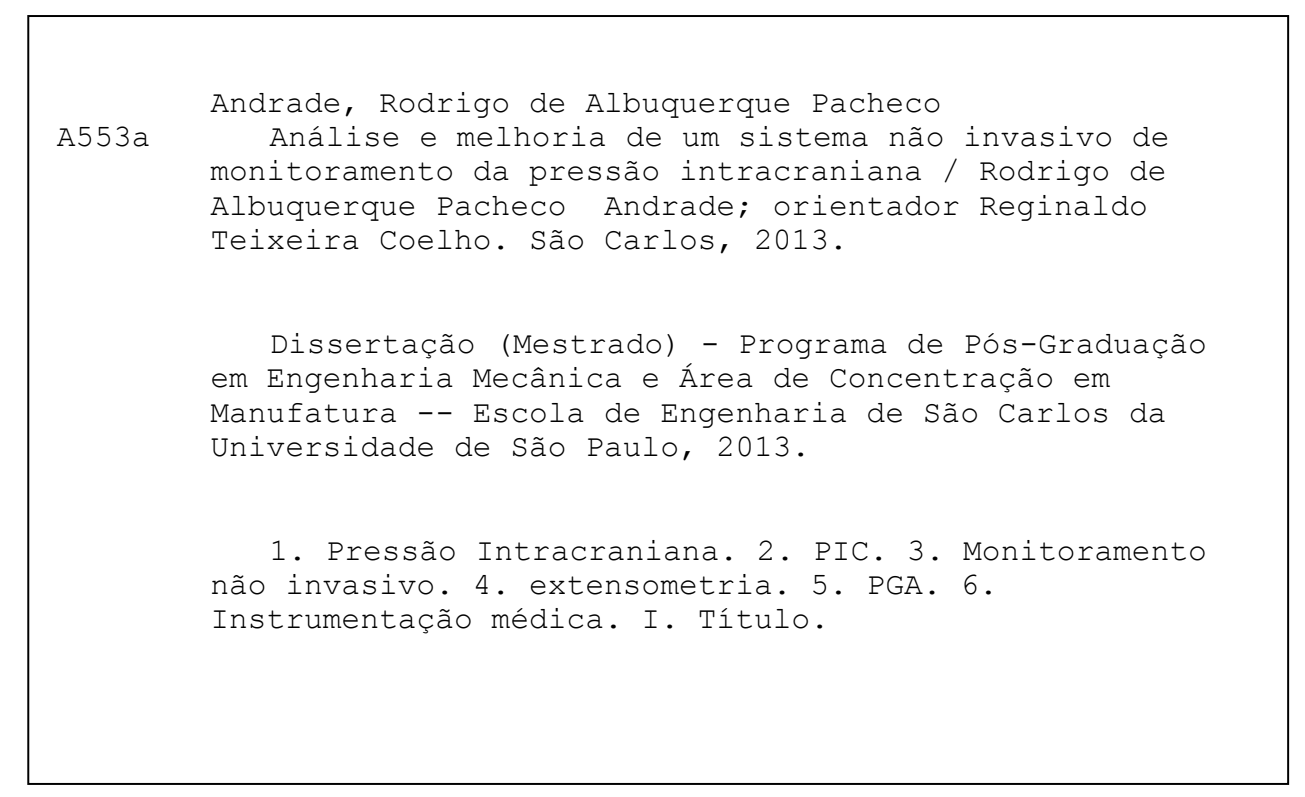




\section{FOLHA DE JULGAMENTO}

Candidato: Engenheiro RODRIGO DE ALBUQUERQUE PACHECO ANDRADE.

Título da dissertação: "Análise e melhoria de um sistema não invasivo de monitoramento da pressão intracraniana".

Data da defesa: 03/10/2013

\section{Comissão Julgadora:}

Prof. Titular Reginaldo Teixeira Coelho (orientador)

(Escola de Engenharia de São Carlos/EESC)

Prof. Dr. Roberto Mario Machado Verzola

(Universidade Federal de São Carlos/UFSCar)

Prof. Dr. Alberto Tannús

(Instituto de Física de São Carlos/IFSC)
Resultado:
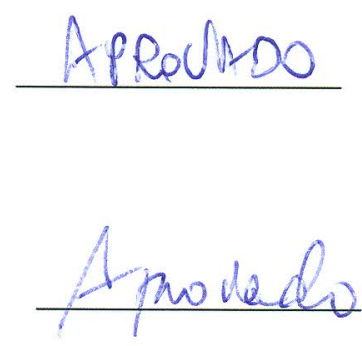

APROVADO

Coordenador do Programa de Pós-Graduação em Engenheira Mecânica:

Prof. Associado Marcelo Areias Trindade

Presidente da Comissão de Pós-Graduação:

Prof. Titular Denis Vinicius Coury 

Dedicatória

Dedico este trabalho aos meus Pais

Paulo Braz de Andrade e Maria Lêda de Albuquerque Pacheco 



\section{Agradecimentos}

Ao Professor Reginaldo Teixeira Coelho pela orientação, incentivo e apoio desde sempre.

Ao Professor Sérgio Mascarenhas pela amizade, orientação, carinho e pela oportunidade de trabalhar nesse projeto.

Ao grande amigo Gustavo Frigieri pela amizade, confiança, orientação, companheirismo e suporte no desenvolvimento deste trabalho.

Ao Danilo Cardim, Charles Wang, e Brenno pelo imenso apoio durante os testes experimentais.

Ao Dinho pela amizade, suporte e apoio durante todo desenvolvimento deste trabalho.

Ao Professor James e à Aeroálcool Tecnologia pela doação das chapas de Alumínio.

Aos professores, Toshiaki Takeya, Sergio Delijaicov, Luis Vareda, Ernesto Massaroppi e Luiz Carlos Casteletti por todos os ensinamentos em extensometria e materiais.

Aos amigos do grupo de pesquisa da PIC de São Carlos, Carol Rizzatti, Carol Cardim, Damiano, Lígia, Maria Vicentini e aos demais pela parceria e aprendizados compartilhados.

Ao técnico Adolfo e ao colega Arai pelo apoio durante os ensaios experimentais no OPF.

Ao colegas do OPF Aldo, Alex, André, Arai, Cláudia, Cleiton, José Eduardo, Prof. Eraldo,Prof. Maíra, Mary e Vanda, pelo companheirismo, suporte e amizade desde a minha chegada ao laboratório. 
Aos colegas de trabalho da Sensoft, Carlos Moritz, Carlos Milhor, Danilo Americano, Fábio Ferraz e Leandro Rondon por toda a ajuda, suporte e apoio neste projeto.

À Professora Yvonne que sempre me apoiou, orientou e incentivou todos os meus passos, sempre com muito carinho.

À Yvoninha, a mãe que a vida generosamente colocou no meu caminho e que não tenho palavras para agradecer seu carinho e preocupação comigo, sempre apoiando e incentivando meus passos.

Ao Paulinho, por toda a confiança, amizade e carinho desde sempre.

À Janaina por todo apoio e carinho.

A toda família Mascarenhas, a qual já me sinto incluído, pela oportunidade de fazer parte do dia a dia de vocês sempre com muito amor e carinho.

Aos meus amigos de São Carlos e de Muriaé, pela maravilhosa convivência.

Aos meus irmão, pelo carinho e amizade de sempre.

Aos meus Tios Feliciano, Tia Cassinha e Tia Meméia, pela confiança em mim depositada e pela oportunidade ofertada. Meu eterno carinho, admiração e agradecimento.

Aos meus Padrinhos Tio Beto e Tia Jacira, pelo apoio, incentivo e carinho.

À minha querida madrinha Solange e à minha grande irmã Monique, pelo amor e companheirismo.

À Camila, minha namorada, pelo grande amor, ternura, companheirismo e apoio. Te amo.

Ao meu Pai, Paulo, pelos ensinamentos, sempre com muita simplicidade, humildade e carinho.

À minha querida mãe, a pessoa mais linda, carinhosa e importante desse mundo. Minha eterna gratidão e amor, por todos os ensinamentos, carinho e dedicação. Te amo muito. 


\section{Resumo}

ANDRADE, R. A. P. (2013). Análise e melhoria de um sistema não invasivo de monitoramento da pressão intracraniana. 151 p. Dissertação (Mestrado) Escola de Engenharia de São Carlos, Universidade de São Paulo, São Carlos, 2013.

A Pressão intracraniana (PIC) é um dos principais parâmetros fisiológicos em animais e humanos e sua morfologia é extremamente importante. Entretanto, todos os métodos de monitoramento existentes no mercado são invasivos, existindo uma ampla demanda por sistemas não invasivos, expandindo assim o campo de pesquisas acerca desse importante parâmetro neurológico, que só não é melhor estudado devido a forma invasiva de ser monitorado. A motivação é fazer com que o monitoramento da PIC seja tão comum e tão essencial quanto é hoje o monitoramento da pressão arterial, facilitando o diagnóstico e até prognóstico de diversas doenças. Este trabalho analisa e implementa melhorias de um sistema não invasivo de monitoramento da pressão intracraniana, baseado em extensometria. Um dos objetivos, no que tange o desenvolvimento do produto, é analisar o equipamento como um todo - Sensor, Hardware, Firmware e Software - e propor melhorias a partir dos testes realizados. Os testes realizados In vivo mostraram uma boa correlação do sinal com um sistema Gold Stardard, evidenciando o potencial promissor do método.

Palavras-chave: Pressão Intracraniana, PIC, Monitoramento não invasivo, extensometria, PGA e Instrumentação médica. 


\section{Abstract}

ANDRADE, R. A. P. (2013). Analysis and improvement of a non-invasive intracranial pressure monitoring system. 151 p. Master Of Science Thesis Escola de Engenharia de São Carlos, Universidade de São Paulo, São Carlos, 2013.

The intracranial pressure (ICP) is one of the main physiological parameters in animals and humans and its morphology is extremely important. However, all monitoring methods available in the market are invasive and there is a large demand for non-invasive systems, thus expanding the scope of research on this important neurological parameter, that just is not further studied because of the invasive method of monitoring. The motivation is to make monitoring the ICP as common and as essential, as monitoring the blood pressure is nowadays, facilitating diagnosis and even prognosis of various diseases. This paper analyzes and implements improvements in a non-invasive intracranial pressure monitoring system based on extensometer. One of the goals, regarding product development, is to analyze the unit as a whole - Sensor, Hardware, Firmware and Software - and propose improvements from the tests. The In vivo tests showed a good correlation with a Gold Stardard system signal showing the promising potential of the method.

Keywords: Intracranial Pressure, ICP, noninvasive monitoring, extensometer, PGA and Medical Instrumentation 


\section{Lista de Figuras}

Figura 1 - Circulação do Líquor no Sistema Nervoso Central - (MACHADO, 2004) 1

Figura 2 - Curva de Langfitt - Pressão versus Volume intracraniano. 4

Figura 3 - Traço da PIC mostrando três distintos picos. Em cérebros não complacentes, a amplitude de P2 é superior a P1 (ADAMS, BELL,MCKINLAY, 2010) 8

Figura 4 - Ondas A de Lundberg - Pressão Intracraniana $(\mathrm{mmHg})$ versus Tempo (minutos) (ADAMS, BELL,MCKINLAY, 2010)

Figura 5 - Ondas B de Lundberg - Pressão Intracraniana $(\mathrm{mmHg})$ versus Tempo (minutos) (ADAMS, BELL,MCKINLAY, 2010) ........................................... 10

Figura 6 - Corpo Deformável (HIBBELER, 2004) ................................... 12

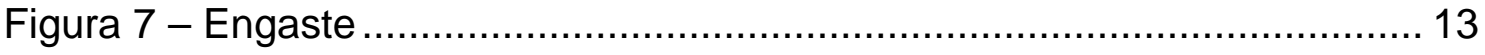

Figura 8 - Seção transversal da Haste ................................................... 15

Figura 9 - Área da seção transversal da Haste ......................................... 15

Figura 10 - (a) Haste em Tração, (b) segmento da haste antes do carregamento, (c) segmento da haste após o carregamento e (d) tensões normais na haste. 17 Figura 11 - Inter-relações de variáveis na solução de problemas de mecânica dos materiais (CHEN,SALEEB, 1994) ............................................ 21

Figura 12 - Diagramas tensão-deformação convencional e real para material dúctil (aço estrutural) (sem escala) (HIBBELER, 2004) ............................... 22

Figura 13 - Força de cisalhamento $V$ e momento fletor $M$ em uma viga ......... 24

Figura 14 - Diagrama de Força Cisalhante............................................... 25

Figura 15 - Diagrama de Momento Fletor............................................. 25

Figura 16 - Concentração de tensão em uma chapa em flexão (PETERSON,

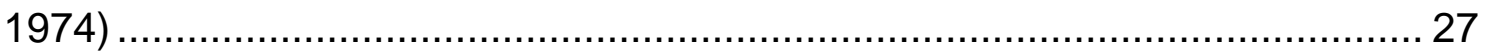

Figura 17 - Fator de Concentração de Tensão para chapa fina com entalhes perpendiculares à flexão. (Baseado nas análises matemáticas de SHIOYA, G. H.

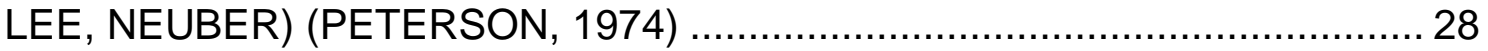

Figura 18 - Deflexão da viga em balanço ................................................. 29

Figura 19 - Strain gauge de fio (ANDOLFATO, 2004) ............................. 31

Figura 20 - Visão transversal do strain gauge de fio (ANDOLFATO, 2004) .... 31

Figura 21 - Strain gauge de lâmina (ANDOLFATO, 2004) ........................... 31 
Figura 22 - Visão transversal do strain gauge de lâmina (ANDOLFATO, 2004)

Figura 23 - Extensômetros uniaxiais (KYOWA, 2013) ................................. 35

Figura 24 - Extensômetros uniaxiais com grade à 45 (KYOWA, 2013).......... 35

Figura 25 - Extensômetros uniaxiais de 5 elementos ..................................... 35

Figura 26 - Extensômetros biaxiais (rosetas de 2 elementos) (KYOWA, 2013)

Figura 27 - Extensômetros triaxiais (rosetas de 3 elementos) (KYOWA, 2013)

Figura 28 - Extensômetros de diafragma (tangencial e radial) (KYOWA, 2013)

Figura 29 - Evolução do creep do material da célula de carga (DELIJAICOV, 2012). 38

Figura 30 - Evolução do creep do material do strain gauge (DELIJAICOV, 2012).

Figura 31 - Compensação dos crepes (DELIJAICOV, 2012) ........................ 39

Figura 32 - Código de creep (HBM) …................................................ 40

Figura 33 - Representação clássica da Ponte de Wheatstone ...................... 42

Figura 34 - Tipos de pontes extensiométricas - (a) 1/4 de ponte - (b) 1/2 ponte (c) ponte diagonal - (d) ponte completa............................................ 45

Figura 35 - Processo de lixação de uma superfície...................................... 47

Figura 36 - 1/4 de ponte simples ......................................................... 49

Figura 37 - Meia ponte com Dummy …............................................. 50

Figura 38 - Meia ponte ativa - lados opostos - (+-) .............................. 51

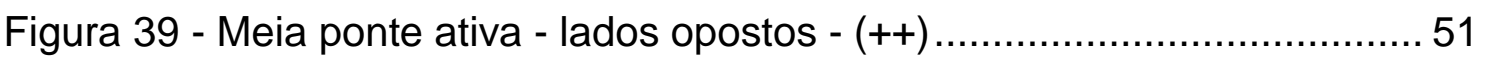

Figura 40 - Ponte completa com dois Dummys - Força Normal ................... 52

Figura 41 - Ponte completa - Momento Fletor ..................................... 52

Figura 42 - Sistema Minimamente invasivo de monitoramento da PIC (VILELA,

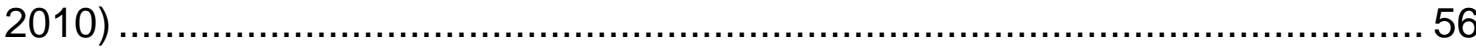

Figura 43 - Sistema para medir a deformação óssea. (MASCARENHAS et al.,

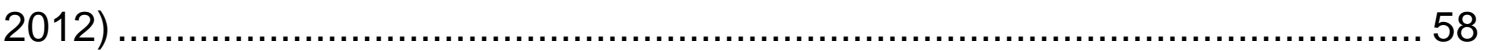

Figura 44 - Gráfico da relação entre expansão craniana (mV) e pressão intracraniana $(\mathrm{mmHg})$ de um crânio específico. (MASCARENHAS et al., 2012) e (VILELA, 2010). 58 
Figura 45 - Simulação de hidrocefalia em ratos Wistar através de injeção de solução salina 0.9\% no canal raquial.(VILELA, 2010). 59

Figura 46 - Brain Helmet - Simulação de uso do primeiro protótipo desenvolvido

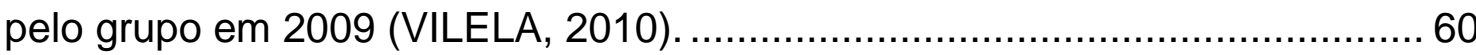

Figura 47 - Amostra do sinal captado pelo sensor Brain Helmet....................60

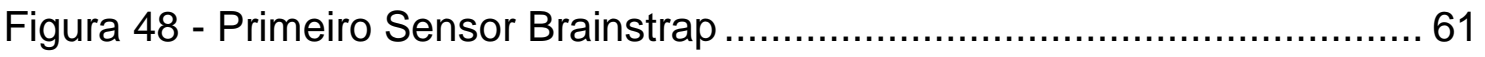

Figura 49 - Posicionamento do sensor Brainstrap na cabeça ........................62 62

Figura 50 - Esquema simplificado da primeira barra sensora (marrom extensômetro; amarelo - ponta que toca o couro cabeludo) desenvolvida pelo grupo.

Figura 51 - Sensor montado no interior da caixa que irá receberá faixa elástica para ser posicionada na cabeça do paciente. 63

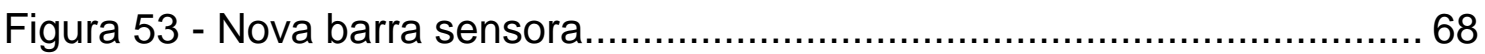

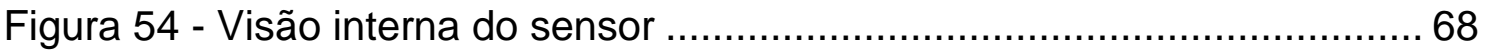

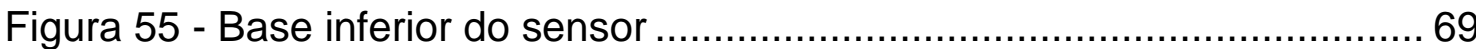

Figura 56 - Sistema atual de monitoramento da PIC - Hardware e Sensores. . 71 Figura 57 - Bloco de ganhos da PGA309

Figura 58 - Software Braincare v1.0 (DAQ - Sinal Bruto; PIC - Sinal da Pressão Intracraniana; Respiração - Avaliação da frequência respiratória; BPM -

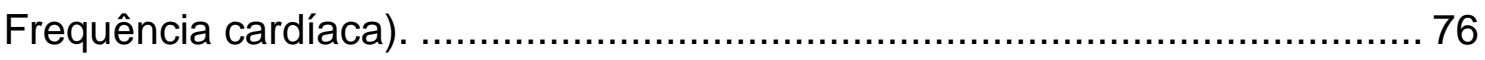

Figura 59 - Diagrama de bloco com os filtros implementados...................... 77

Figura 60 - Diagrama de bloco com os FFTs implementados ....................... 77

Figura 61 - Configuração dos Filtros e FFTs da respiração (Esquerda e Direita). 78

Figura 62 - Organização do Formato TDMS ......................................... 79

Figura 63 - Armazenamento dos dados dinâmicos via TDMS ..................... 80

Figura 64 - Tela de monitoramento da nova versão do software. .................. 81

Figura 65 - Teste do Sistema com dois Sensores não invasivos Brainstrap.... 81

Figura 66 - Fluxograma completo do sistema .......................................... 82

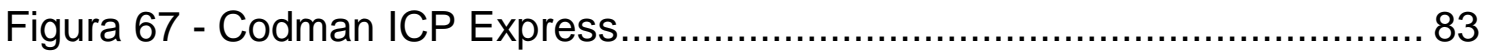

Figura 68 - Diagrama original digitalizado de conexão do CODMAN (JOHNSON

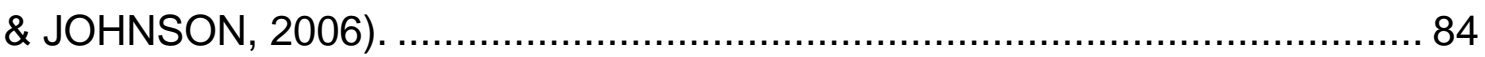

Figura 69 - Cabo de conexão Braincare-Codman .................................. 84

Figura 70 - Pinagem Conexão Braincare-Codman...................................... 85 
Figura 71 - Sistema Braincare de monitoramento da PIC (NI - Canal 01; Codman

- Canal 02)......

Figura 72 - Malhas das barras sensoras - Antiga com entalhe retangular (Superior) e atual com entalhe semicircular (Inferior)............................. 86

Figura 73 - Hermle modelo C $800 \mathrm{U}$....................................................... 88

Figura 74 - Sensor de Posicionamento Heidenhain MT 1200 ....................... 89

Figura 75 - Sistema de aquisição do sensor não invasivo e do sensor de

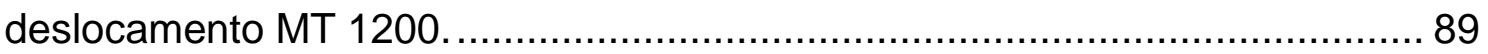

Figura 76 - Barra usinada usada para movimentar os dois sensores............. 90

Figura 77 - Posicionamento dos Sensores no teste .................................. 91

Figura 78 - Voluntário ativo durante atividade aeróbica em uma bicicleta

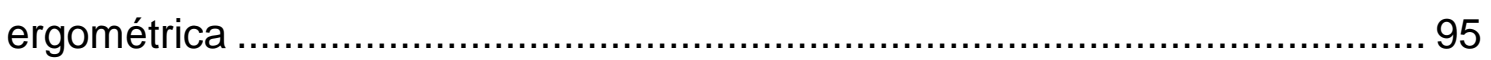

Figura 79 - Montagem do teste de infusão - (1) Haste Estereotáxica, (2) Agulha de infusão, (3) Sensor Invasivo CODMAN, (4) Sensor Não Invasivo............... 97 Figura 80 - Detalhe do posicionamento do SENSOR NI e do CODMAN na

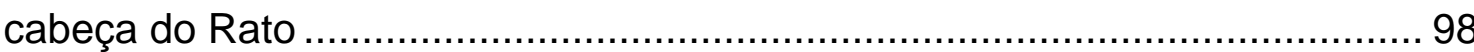

Figura 81 - Barra sensora com entalhe retangular - Análise da deformação no

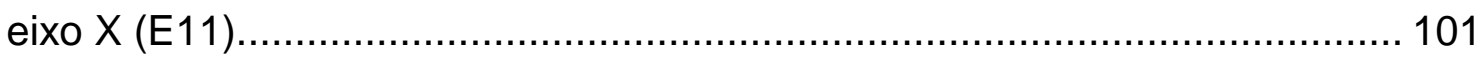

Figura 82 - Barra sensora com entalhe semicircular - Análise da deformação no

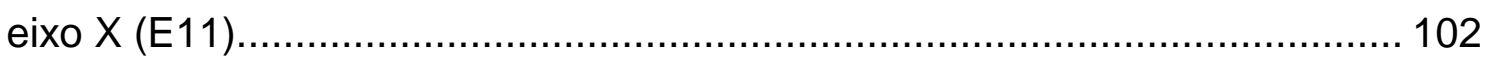

Figura 83 - Deformações Plásticas na barra com entalhe retangular............ 102

Figura 84 - Detalhe da deformação plástica......................................... 103

Figura 85 - Ausência de Deformação Plástica na nova barra sensora (entalhe semicircular) ....................................................................... 103

Figura 86 - Deslocamento da barra com entalhe semicircular. ................... 104

Figura 87 - Análise dos ciclos de teste Sensor Brain 11 .......................... 105

Figura 88 - Gráfico comparativo da média da amplitude dos pulsos por ciclo referentes às deflexões de $15 \mu \mathrm{m}$ lidos dos três sensores BrainStrap........... 106 Figura 89 - Histograma da distribuição dos valores .................................. 108 Figura 90 - Janela de leitura do monitoramento fisiológico com sensor não invasivo Brainstrap ............................................................. 109

Figura 91 - Pulso da PIC medido invasivamente - PIC (mmHg) versus tempo (s) (WAGSHUL, EIDE,MADSEN, 2011) ........................................ 110 
Figura 92 - Comparação entre as formas de onda do Sistema Invasivo (Esquerda) contra o Sistema Não Invasivo de monitoramento da PIC (Direita) de indivíduos distintos.

Figura 93 - Ruído de Zero Drift

Figura 94 - Monitoramento da pressão arterial periférica durante exercício aeróbico. O Gráfico mostra a pressão sendo aferida a cada 60 segundos. A linha mostra a média e a barra mostra o erro quadrático entre os valores medidos da PA para os participantes de cada grupo. O primeiro gráfico mostra os resultados do grupo ativo (Militares de 19 anos de idade) e o segundo gráfico mostra o grupo dos sedentários (Homens de 27士 6 anos de idade).

Figura 95 - Monitoramento da Pressão Intracraniana utilizando o sensor não invasivo BrainStrap. A linha mostra a média e a barra mostra o erro quadrático entre os valores medidos da PA para os participantes de cada grupo. O primeiro gráfico mostra os resultados do grupo ativo (Militares de 19 anos de idade) e o segundo gráfico mostra o grupo dos sedentários (Homens de $27 \pm 6$ anos de idade).

Figura 96 - Infusão aguda - Rato 01: Série temporal para a PICi (mmHg) e PICni (V) durante infusão aguda de solução salina. A correlação de Pearson foi calculada para o sinal original e para o sinal corrigido.

Figura 97 - Três infusões agudas - Rato 02: Série temporal para a PICi (mmHg) e PICni (V) durante sequência de infusões agudas de solução salina. A correlação de Pearson foi calculada para o sinal original e para o sinal corrigido.

Figura 98 - Infusão aguda - Rato 03: Série temporal para a PICi (mmHg) e PICni (V) durante infusão aguda de solução salina. A correlação de Pearson foi calculada para o sinal original e para o sinal corrigido. 116 Figura 99 - Infusão aguda - Rato 04: Série temporal para a PICi (mmHg) e PICni (V) durante infusão aguda de solução salina. A correlação de Pearson foi calculada para o sinal original e para o sinal corrigido.

Figura 100 - Duas infusões agudas - Rato 05: Série temporal para a PICi (mmHg) e PICni (V) durante infusão aguda de solução salina. A correlação de Pearson foi calculada para o sinal original e para o sinal corrigido. 118 


\section{Lista de Tabelas}

Tabela 1 - Condições onde o monitoramento da PIC deveria utilizado.

Tabela 2 - Lista de verificação da aplicação para escolha adequada do extensômetro. (HOFFMANN, 1989) Tradução livre. .................................. 34

Tabela 3 - Coeficientes térmicos comerciais para strain gauges (HBM) .......... 37

Tabela 4 - Sensibilidade do SG de acordo com a liga metálica utilizada. ........ 41

Tabela 5 - Comparativo entre os formatos de arquivo suportados pelo LabVIEW ${ }^{\circledR}$

Tabela 6 - Tabela de propriedade do material Alclad Aluminum 2024 T3 de $0.4 \mathrm{~mm}$ de espessura (MATWEB, 2013)........................................... 87

Tabela 7 - Resultados estatísticos do Teste dos Sensores BrainStrap.......... 106 


\section{Lista de Abreviaturas e Siglas}

ASTM American Society for Testing and Materials

CNC Computer Numeric Control

COBEA Colégio Brasileiro de Experimentação Animal

FC Frequência Cardíaca

FFT Fast Fourier Transform

HPN Hidrocefalia de pressão normal

LabVIEW Laboratory Virtual Instrument Engineering Workbench

SNC Sistema nervoso central

MATLAB MATrix LABoratory

MEF $\quad$ Método dos Elementos Finitos

NI Não Invasivo

PA Pressão Arterial

PAM Pressão Arterial Média

PGA Amplificador de ganho programavel

PIC Pressão Intracraniana

PICi Pressão Intracraniana invasiva

PICni Pressão Intracraniana não invasiva

PPC Pressão de Perfusão Cerebral

FSC Fluxo Sanguíneo Cerebral

RAP Correlação linear entre a amplitude da PIC e o valor da PIC média

RCV Resistência Cerebrovascular

EESC Escola de Engenharia de São Carlos

TCLE Termo de consentimento livre esclarecido

TDMS Technical Data Management - Streaming

USB Universal Serial Bus 
USP Universidade de São Paulo 


\section{Lista de Símbolos}

$\alpha$

coeficiente de expansão térmica

$\epsilon$

deformação

$\delta \quad$ Aumento no comprimento

$\Omega \quad$ ohms

$\rho \quad$ resistividade

$\sigma \quad$ tensão mecânica

$v \quad$ coeficiente de Poisson

E módulo de Young

$\mathrm{cm}^{3} \quad$ centímetros cúbicos

$m^{2} \quad$ metros quadrados

$\mathrm{mmHg} \quad$ milímetros de mercúrio

$\min \quad$ minutos

$\mathrm{Pa} \quad$ Pascal

$N / m^{2} \quad$ Newtons por metro ao quadrado

MPa Mega Pascal

$\mathrm{N} / \mathrm{mm}^{3} \quad$ Newtons por milímetro cúbico

$w(s) \quad$ carga linear distribuida

$F_{R} \quad$ Força Resultante 


\section{Sumário}

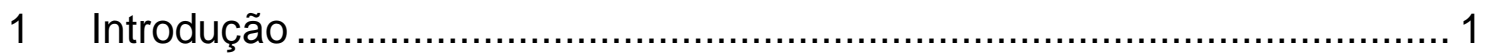

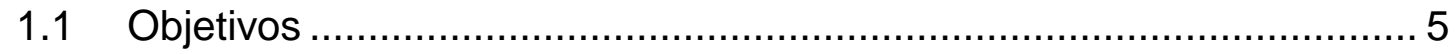

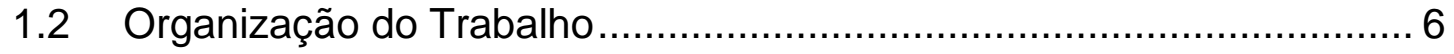

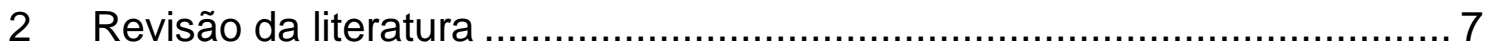

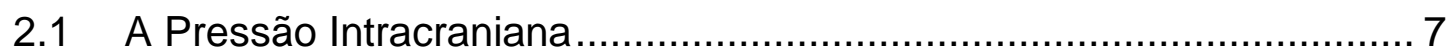

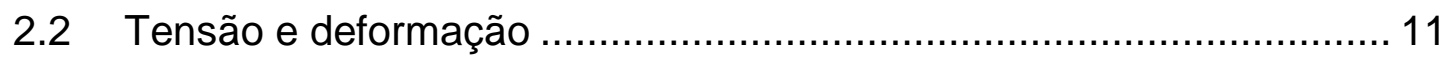

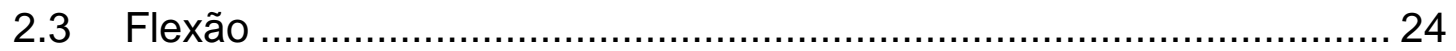

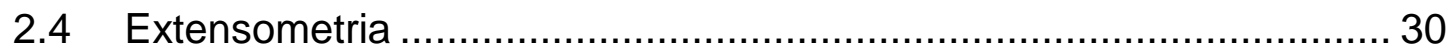

2.5 Ponte de Wheatstone ............................................................. 42

2.6 Materiais utilizados na montagem de strain gauges ....................... 46

2.7 Técnicas de redução de erros de medição em pontes....................... 49

2.8 Medição dinâmica da deformação da viga em flexão. ...................... 53

2.9 Medidas biológicas utilizando strain gauges ............................... 54

2.10 O Strain gauge e seu uso em biomecanismos.......................... 55

3 Propostas de Método para monitorar a PIC .................................... 57

3.1 Análise e melhoria do sensor de expansão craniana à base de

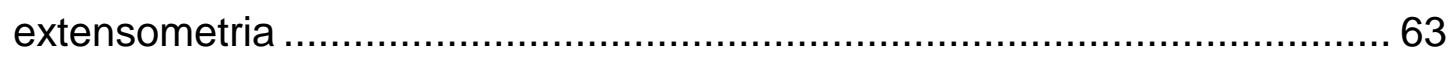

3.2 Sistema de aquisição e condicionamento dos sinais ...................... 70

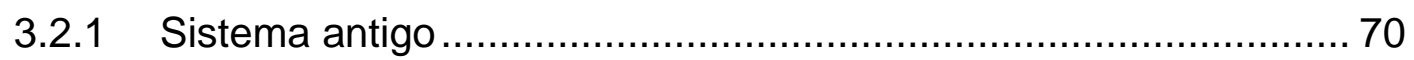

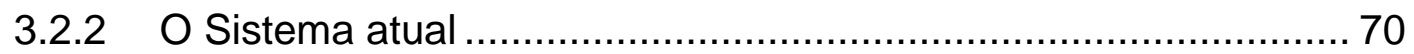

3.2.3 Descrição do sistema atual.................................................. 72

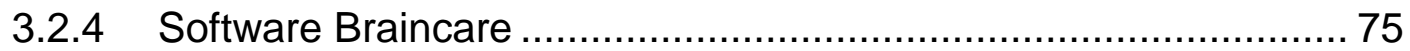

3.3 Preparação do equipamento para comparação do método NI com outros

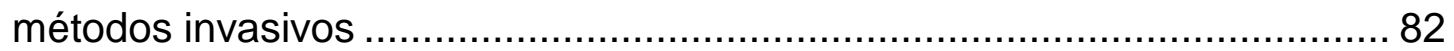

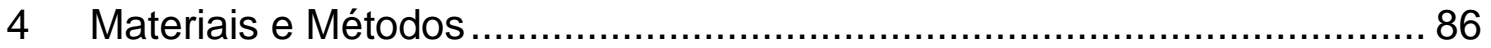




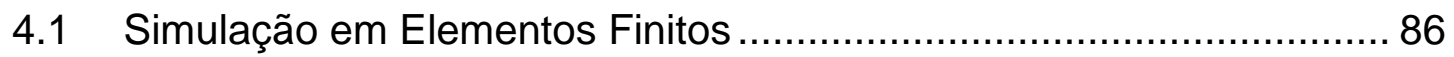

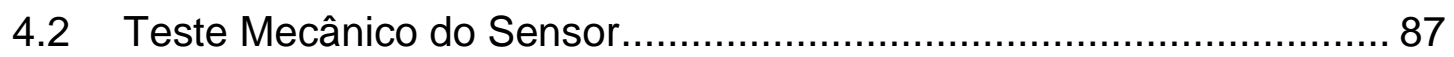

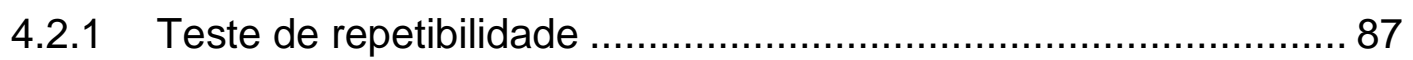

4.3 Metodologia do Teste do Equipamento de Amplificação e Aquisição de

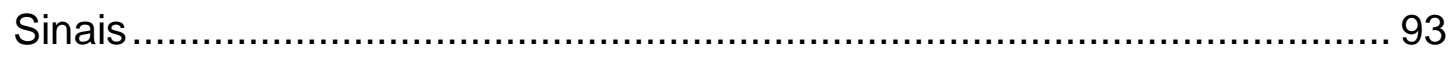

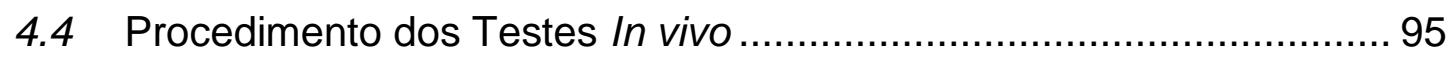

4.4.1 Metodologia de teste durante exercício físico.............................. 95

4.4.2 Metodologia dos testes com sensor $\mathrm{NI}$ e sensor invasivo Codman

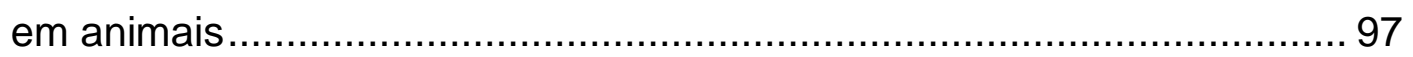

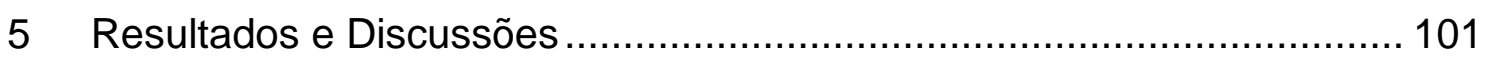

5.1 Análise da Simulação em Elementos Finitos .................................... 101

5.2 Análise mecânica do sensor ...................................................... 105

5.3 Teste do Equipamento de Amplificação e Aquisição de Sinais ......... 109

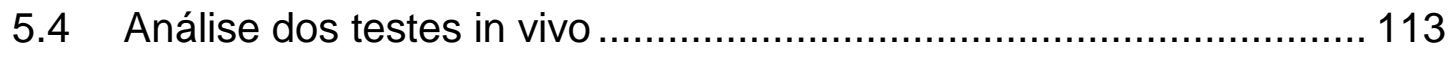

5.4.1 Testes durante exercício físico ………………...................... 113

5.4.2 Análise da comparação do sensor não invasivo com o CODMAN em animais 115

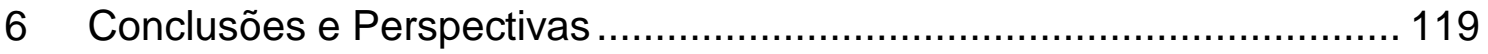

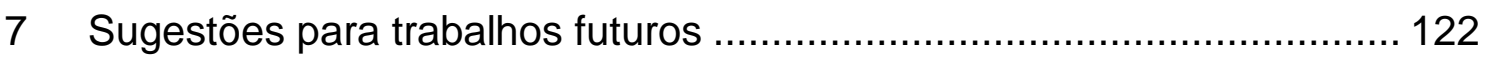

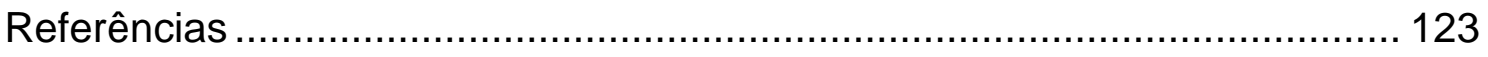




\section{Introdução}

A maior parte dos órgãos humanos apresenta pressão ambiente de perfusão sanguínea próxima à pressão atmosférica ou menor (CZOSNYKA,PICKARD, 2004). Entretanto, no sistema nervoso central (SNC) mostrado na Figura 1, que inclui o encéfalo e a medula espinhal, a pressão ambiente é diferente por estar circundada e protegida pelo esqueleto axial (cavidade craniana e canal vertebral). Esta pressão circundante é denominada pressão intracraniana (PIC).

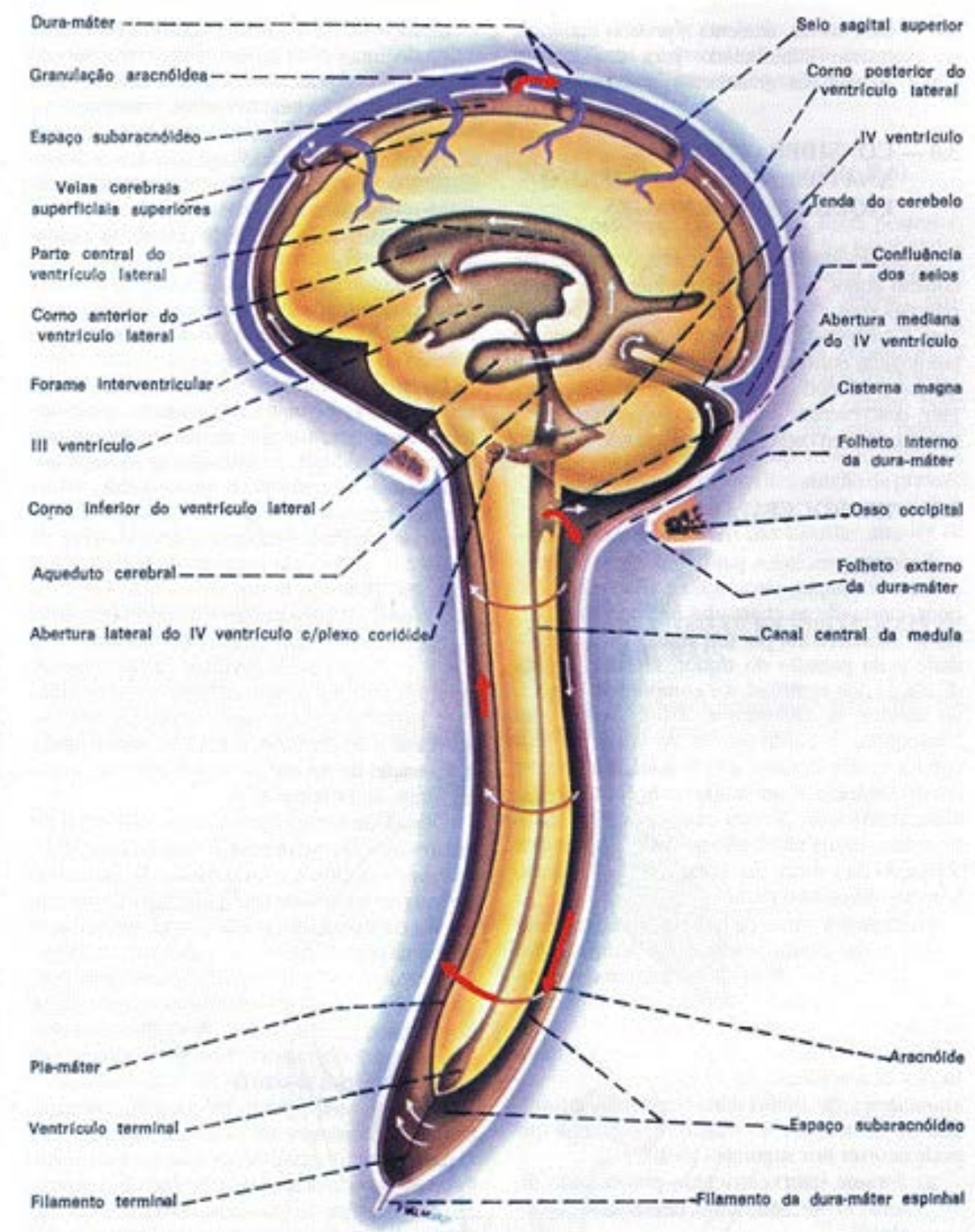

Figura 1 - Circulação do Líquor no Sistema Nervoso Central - (MACHADO, 2004) 
A PIC é normalmente menor que $10-15 \mathrm{mmHg}^{1}$ em adultos, e o compartimento intracraniano é protegido pelo crânio, uma estrutura rígida com um volume interno fixo de 1400 a 1700 ml. Sob condições normais, o conteúdo intracraniano inclui (em volume):

- Parênquima cerebral - 80 a $85 \%$

- $\quad$ Líquido cérebro-espinhal (líquor) - 5 a 10\%

- $\quad$ Sangue - 8 a $12 \%$

O Líquor cefalorraquidiano, conhecido também como líquido cérebro-espinhal, é um fluido aquoso e incolor, com pequenas quantidades de proteína, potássio, glicose e cloreto de sódio que ocupa o espaço subaracnóideo e as cavidades ventriculares e está representado pelas setas brancas na Figura 1. A função primordial do Líquor é de proteção mecânica do SNC, distribuindo a pressão (seja ela natural ou causado por algum impacto) em virtude do Princípio de Pascal, igualmente em todos os pontos. Dessa maneira o Líquor funciona como um sistema amortecedor dos choques para o sistema nervoso central, pois este, fica totalmente submerso no líquido e de acordo com o Princípio de Arquimedes, o torna muito mais leve, o que reduz drasticamente o risco de traumatismo do encéfalo resultantes do contato direto com os osso do crânio. Se o encéfalo ou os vasos sanguíneos que o irrigam aumentam de volume, o líquor é drenado e diminui-se a pressão intracraniana, para manter o volume constante sendo este fenômeno chamado de autorregulação. O Volume total do líquor em adultos é de 100 a $150 \mathrm{~cm}^{3}$, renovando-se completamente a cada oito horas (MACHADO, 2004).

Um dos aspectos mais importantes da cavidade craniana, do ponto de vista neurológico, é o fato de ser uma cavidade completamente fechada que não permite uma expansão significativa de seu conteúdo. Sendo assim, o aumento de volume de qualquer componente da cavidade craniana reflete-se sobre os demais, levando a um aumento da pressão intracraniana. Tumores, hematomas

\footnotetext{
${ }^{1}$ Acima da pressão atmosférica
} 
e outros processos expansivos intracranianos comprimem não só as estruturas em sua vizinhança imediata, mas também todas as estruturas da cavidade crânio-vertebral (MACHADO, 2004).

As causas do aumento da PIC podem ser diversas. O monitoramento da pressão intracraniana por ainda ser invasivo é indicado em apenas alguns casos. A Tabela 1 mostra as condições onde o monitoramento da PIC deveria ser realizado.

\begin{tabular}{|c|}
\hline Lesões Traumáticas na Cabeça \\
\hline Hemorragia Intracerebral \\
\hline Hemorragia Subaracnóidea \\
\hline Hidrocefalia \\
\hline Infarto Maligno \\
\hline Edema Cerebral \\
\hline Infecções do Sistema Nervoso Central \\
\hline Encefalopatia hepática \\
\hline
\end{tabular}

Se o encéfalo tem o seu volume aumentado (tumor, hematoma, edema, etc.), alguma quantidade de sangue ou líquor deverá escapar de dentro do crânio para que a pressão não se eleve. Quando isto não puder mais ocorrer, a PIC irá se elevar acima de seu valor fisiológico (10 -15 mmHg). Normalmente, a resposta inicial é uma redução no volume de líquor do crânio. O líquor é desviado do crânio para dentro do saco espinhal (GIBRAIL, 2013). Desta forma, a PIC é inicialmente controlada. Se o processo patológico inicial progride com mais aumento de volume, o sangue venoso dos seios e eventualmente mais líquor podem ser forçados a sair do crânio. Quando este mecanismo de compensação é exaurido, qualquer aumento maior de volume intracraniano irá causar um rápido aumento da PIC.

As relações entre as variações de volume e de pressão dentro do crânio são representadas na Figura 2. Ela indica que um aumento no volume com pouca mudança de pressão ocorre até certo ponto, quando pequenos aumentos de 
volume acarretam grandes aumentos de pressão. Este ponto geralmente indica que os mecanismos de compensação se tornaram exauridos e uma fase de aumento da PIC compensada foi sucedida por uma fase descompensada.

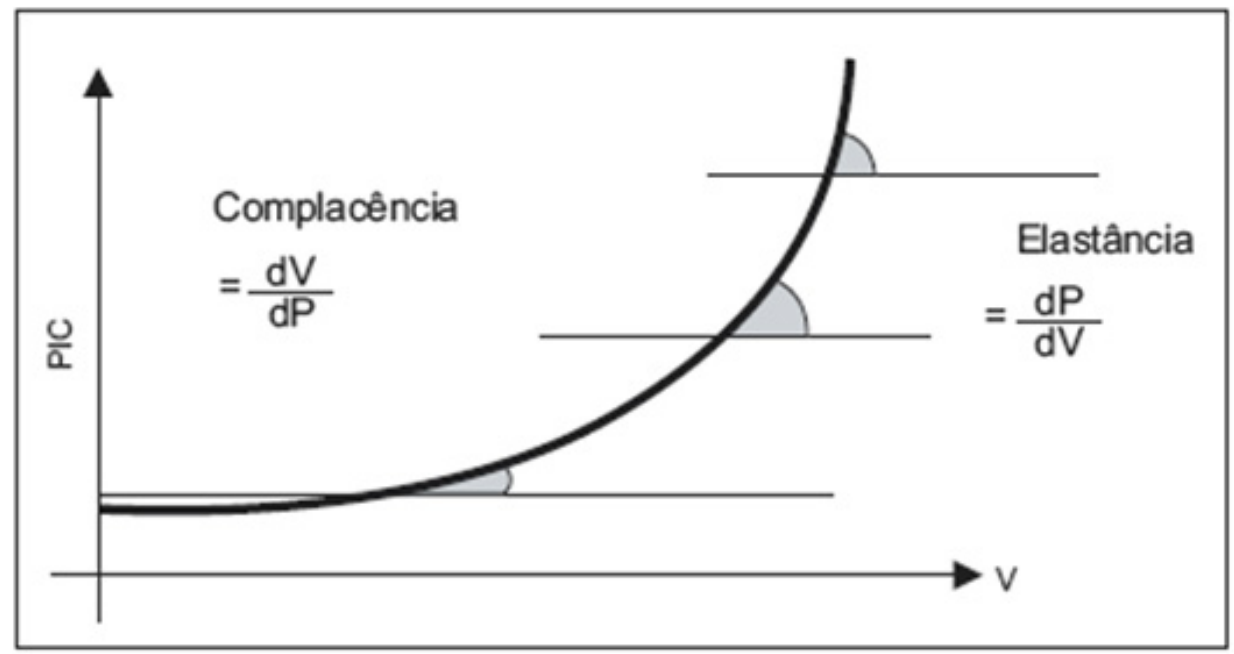

Figura 2 - Curva de Langfitt - Pressão versus Volume intracraniano.

Esta curva clássica representa as alterações de pressão quando um único compartimento dentro do crânio varia, neste caso, o líquor. Na prática, a curva seria menos íngreme caso o aumento do volume cerebral ocorresse por um tumor ou hematoma (ROSSBERG, 2002).

A Pressão intracraniana é um dos principais parâmetros fisiológicos em animais e humanos e significa muito mais do que um simples número. Em neurocirurgia é uma das variáveis mais importantes para definição dos procedimentos a serem adotados. Atualmente, todos os métodos de monitoramento existentes são invasivos, existindo uma ampla demanda por sistemas não invasivos ou minimamente invasivos.

Os métodos de monitoramento convencionais existentes no mercado incluem penetração no crânio e inserção através dele e da dura-máter de um cateter para realização da medida. Este procedimento altamente invasivo inclui riscos de precipitação de hematoma intracraniano, de agravar o edema cerebral, danificar o parênquima, hemorragia intracerebral e promover infecção intracraniana, sendo a última a mais comum das complicações nos pacientes monitorados 
durante mais de uma semana após a cirurgia (PITLYK, PIANTANIDA,PLOEGER, 1985).

Considerando todas as desvantagens mencionadas, a necessidade de monitorar a PIC com um método não invasivo, que elimine as complicações geradas pela penetração dentro do crânio é de extrema importância clínica, pois abrirá um novo campo de pesquisas acerca desse importante parâmetro fisiológico, que só não é mais bem estudado por causa da forma invasiva de ser monitorado.

A motivação para desenvolvimento deste trabalho, além do cunho científico de participar da descoberta de um novo método de monitoramento da PIC, é o forte apelo social fazendo com que o monitoramento da PIC seja tão comum e tão essencial, como é hoje o monitoramento da pressão arterial, facilitando o diagnóstico e até prognóstico de diversas doenças.

\subsection{Objetivos}

Este trabalho tem o objetivo de realizar análises e implementar melhorias em um sistema não invasivo de monitoramento de pressão intracraniana baseado em extensometria. Um dos objetivos, no que tange 0 desenvolvimento do produto, é analisar o equipamento como um todo Sensor, Hardware, Firmware e Software - e propor melhorias a partir dos testes realizados.

Os objetivos específicos são:

- Apresentar os sensores não invasivos desenvolvidos pelo grupo e seu histórico;

- Apresentar e analisar o sensor Brainstrap, fazer uma revisão sobre seu princípio físico e propor melhorias, adequando os novos requisitos ao projeto;

- Apresentar o equipamento e as modificações realizadas no mesmo para aquisição dos sinais dos sensores invasivos - Codman;

- Discutir as melhorias já realizadas e as futuras de acordo com o melhor estudo do sensor e do equipamento. 


\subsection{Organização do Trabalho}

Este trabalho foi organizado e formatado seguindo as diretrizes para apresentação de dissertações da EESC-USP, de forma a manter o padrão para facilitar a leitura e um bom entendimento desse trabalho interdisciplinar. Para tanto este documento é composto pelas seguintes partes:

Capítulo 1: Introdução onde se apresenta os conceitos fundamentais sobre a pressão intracraniana e suas variáveis. Também são apresentados os objetivos do trabalho e sua estrutura.

Capítulo 2: Apresenta a revisão da literatura abordando, alguns conceitos da Pressão Intracraniana, da Mecânica dos Materiais e de extensometria voltados para o desenvolvimento de transdutores à base de extensômetros e um histórico sobre o uso de extensômetros em medidas biológicas e biomecanismos.

Capítulo 3: Apresenta a proposta do método para medir PIC de forma não invasiva desenvolvida pelo grupo, fazendo uma descrição detalhada do sensor e do equipamento desenvolvido.

Capítulo 4: Neste capítulo estão dispostos os materiais, equipamentos e procedimentos utilizados para realizar os testes do sensor e do uso do sensor in vivo.

Capítulo 5: Apresenta as análises e discussões dos resultados obtidos.

Capítulo 6: Composto pelas conclusões e perspectivas.

Capítulo 7: Apresenta as sugestões para trabalhos futuros. 


\section{Revisão da literatura}

\subsection{A Pressão Intracraniana}

A Pressão Intracraniana é derivada da circulação do sangue (componente vascular) e do fluido cérebro-espinhal (componente cérebro-espinhal) com o volume interno do esqueleto axial sendo seu limite (CZOSNYKA,PICKARD, 2004). Porém, não se têm certeza que o operador da fórmula seja uma simples soma como mostrado abaixo:

$$
P I C=P I C_{\text {vascular }}+P I C_{\text {líquor }}
$$

A componente vascular é difícil de ser expressa quantitativamente e provavelmente é derivada da pulsação sanguínea no cérebro que por sua vez é absorvida por mecanismos não-lineares de regulação do volume sanguíneo cerebral.

A componente do Líquor pode ser expressa de acordo com JODAL et al. (1975), usando a equação de Davson onde,

$$
\begin{gathered}
\text { PIC }_{\text {líquor }}=(\text { resistência da saída de líquor }) \times(\text { formação do líquor }) \\
+(\text { pressão no seio sagittal })
\end{gathered}
$$

Qualquer fator, seja ele fisiológico, como a compressão das veias jugulares através da manobra de Queckenstedt (PEARCE, 2006), ou patológico, como edema cerebral, obstrução do caminho do Líquor, etc., pode causar um distúrbio na circulação dos fluidos, podendo provocar um aumento da PIC.

Medidas da PIC são utilizados para estimar a pressão de perfusão cerebral (PPC) à partir da pressão arterial média (PAM) da seguinte forma:

$$
P P C_{\text {Média }}=P A_{\text {Média }}-P I C_{\text {Média }}
$$

A PPC representa o gradiente de pressão que atua ao longo do leito vascular cerebral e, consequentemente, é um fator importante na regulação do fluxo sanguíneo cerebral (FSC) (MILLER, STANEK,LANGFITT, 1972). 
Analogamente à Lei de Ohm, o FSC está diretamente relacionado à PPC e inversamente relacionado à resistência cerebrovascular (RCV) e pode ser representado pela seguinte equação:

$$
F S C=\frac{P P C}{R C V}
$$

O monitoramento da PIC não apenas permite a medição da pressão intracraniana, mas também fornece informações importantes sobre a dinâmica intracraniana e a complacência do cérebro através da avaliação de sua forma de onda. A análise da forma de onda da PIC fornece informações que podem identificar pacientes com baixa capacidade de adaptação (baixa complacência) que estão susceptíveis a um aumento da PIC e uma diminuição do PPC.

O forma de onda normal da PIC como visto na Figura 3 é um traço modificado da pulsação arterial (ADAMS, BELL,MCKINLAY, 2010) e consiste de três picos característicos. O Primeiro pico P1, chamado de percussão, é resultante da pressão arterial sendo transmitida a partir do plexo coróide. O segundo pico P2, chamado de "tidal", varia de acordo com a complacência cerebral, sendo a reverberação de P1. O terceiro pico, P3 é precedido pela curva dicrótica seguida do fechamento da válvula aórtica no coração.

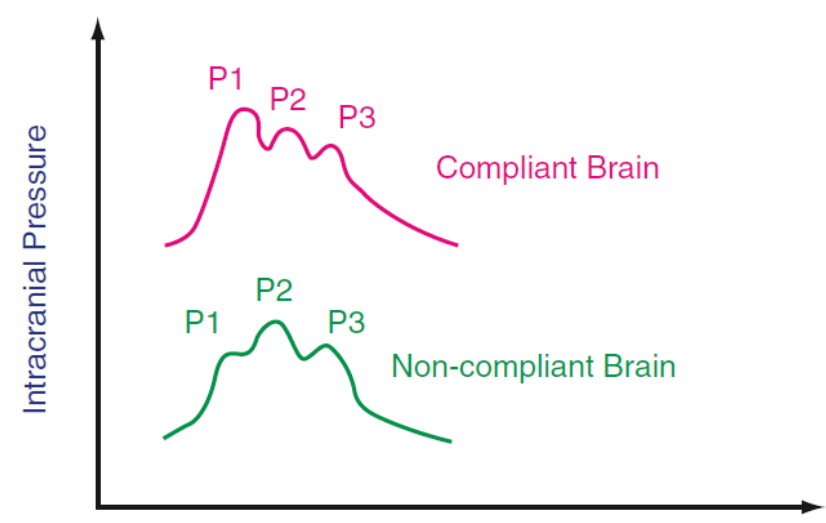

Figura 3 - Traço da PIC mostrando três distintos picos. Em cérebros não complacentes, a amplitude de P2 é superior a P1 (ADAMS, BELL,MCKINLAY, 2010)

Como mostrado na Figura 3, é visual e de fácil diagnóstico o comportamento do traço da PIC. De acordo com (ADAMS, BELL,MCKINLAY, 2010) cérebros complacentes, possuem os picos P1, P2 e P3 decrescentes nesta sequência, 
enquanto nos cérebros que não apresentam boa complacência, o pico P2 é maior que P1 e P3, resultado dessa não complacência.

Além do simples monitoramento da pressão e dos picos característicos, se a PIC for registrada em função do tempo, algumas formas de ondas características se evidenciarão. Conhecidas também por ondas lentas, as "Lundberg Waves" podem ser divididas em três tipos.

- Ondas A - (Platô)

o Amplitude de $50-100 \mathrm{mmHg}$

o Duração 5-20 minutos

o Acompanhado por uma simultânea elevação da PAM

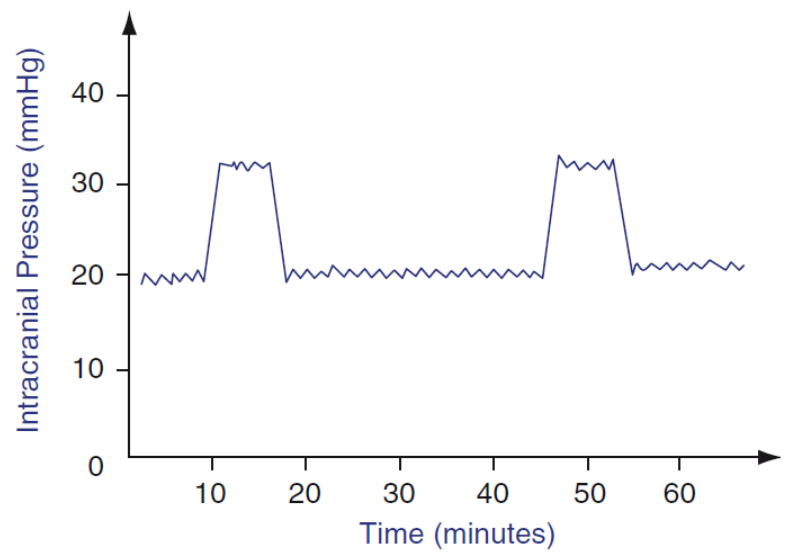

Figura 4 - Ondas A de Lundberg - Pressão Intracraniana (mmHg) versus Tempo (minutos) (ADAMS, BELL,MCKINLAY, 2010)

- Ondas B - (Pulsos)

o Amplitude de $50 \mathrm{mmHg}$

o Freq. 0,5-2/min 


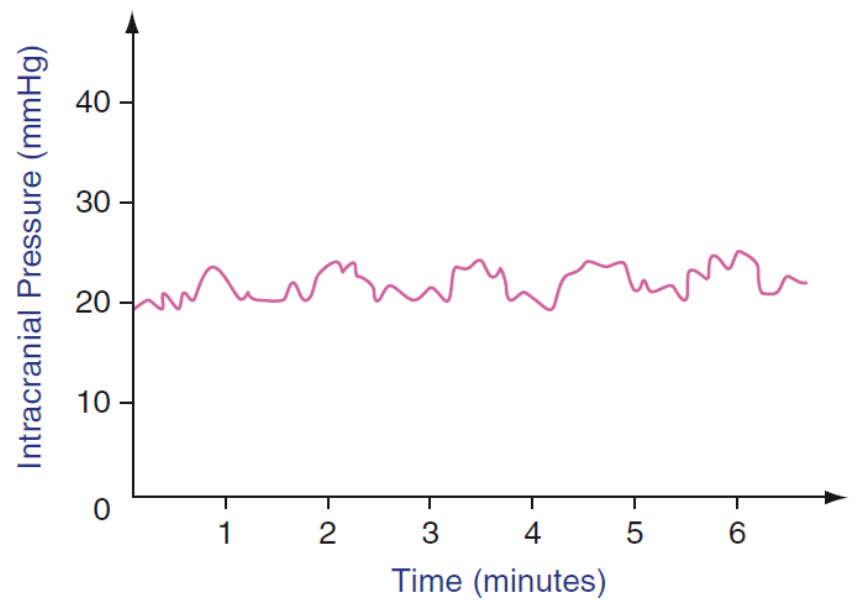

Figura 5 - Ondas B de Lundberg - Pressão Intracraniana $(\mathrm{mmHg})$ versus Tempo (minutos) (ADAMS, BELL,MCKINLAY, 2010)

- Ondas C

o Amplitude de $20 \mathrm{mmHg}$

o Freq. 4-8/min

As ondas A, sempre patológicas, também conhecidas como ondas de platô, são elevações da PIC da ordem de até 100mmHg durante 2 a 20 minutos, com a queda abrupta ao valor basal, possivelmente representando vasodilatação cerebral e um aumento no FSC, em resposta a um PPC baixo, e são interpretados como sinais de grave descompensação da PIC.

As ondas B ocorrem de 0,5 a 2 vezes por minuto com amplitude de até $50 \mathrm{mmHg}$, refletindo a influência do ciclo respiratório sobre a PIC. Estes podem ser observados em indivíduos normais, mas que são indicativos de patologia intracraniana quando a amplitude aumenta acima dos $10 \mathrm{mmHg}$ (RABOEL et al., 2012).

Estas duas ondas são consideradas como sinal de alerta porque demonstram um certo grau de prejuízo da complacência cerebral.

As ondas $\mathrm{C}$ ocorrem de 4 a 8 vezes por minutos e refletem as curvas arteriais de Traube-Hering-Meier. (CZOSNYKA et al., 1999) 


\subsection{Tensão e deformação}

A Mecânica aplicada possui uma área chamada mecânica dos materiais que estuda o comportamento de corpos sólidos sujeitos a diversos tipos de carregamento. O principal objetivo da mecânica dos materiais é determinar as tensões, deformações e deslocamentos em estruturas e seus componentes devido à ação de cargas sobre eles. Podendo-se encontrar essas quantidades para todos os valores das cargas, até as que causam falha, tem-se uma noção completa do comportamento mecânico dessas estruturas. (GERE, 2003)

A Origem da mecânica dos materiais ocorreu no início do século XVII, época em que Galileu realizava experiências para estudar os efeitos de cargas em hastes e vigas feitas de vários materiais. Entretanto, para a compreensão adequada, foi necessário estabelecer descrições experimentais precisas das propriedades mecânicas de um material. O método para tais descrições foi consideravelmente melhorado no início do século XVIII. Naquela época, estudos sobre o assunto, tanto experimentais como teóricos, foram realizados, principalmente na França, por notáveis como Saint-Venant, Poisson, Lamé e Navier. Como seus estudos baseavam-se em aplicações da mecânica a corpos materiais, eles denominaram esses estudos de 'resistência dos materiais'. Atualmente, no entanto, refere-se a eles como 'mecânica de corpos deformáveis' ou simplesmente 'mecânica dos materiais'. (HIBBELER, 2004)

Um entendimento do comportamento mecânico é essencial para o desenvolvimento de sensores à base de extensometria (que será discutido nos próximos capítulos), pois vai-se um passo além ao examinar tensões e deformações de corpos de dimensões finitas que deformam sob cargas. Para determinar essas tensões e deformações usam-se as propriedades físicas dos materiais, bem como várias leis teóricas e conceitos técnicos.

As análises teóricas e os resultados experimentais têm igual importância na mecânica dos materiais. Usa-se a teoria para derivar fórmulas e equações prevendo o comportamento mecânico, mas essas expressões nem sempre podem ser utilizadas em projetos práticos, a menos que as propriedades físicas dos materiais sejam conhecidas. (GERE, 2003) 
A estática é extremamente importante tanto no desenvolvimento como na aplicação da mecânica dos materiais, e é necessário ter uma boa compreensão e visão de seus fundamentos. Por essa razão revisam-se de acordo com (HIBBELER, 2004) e (GERE, 2003) alguns dos principais fundamentos da estática que serão usados ao longo de todo o trabalho.

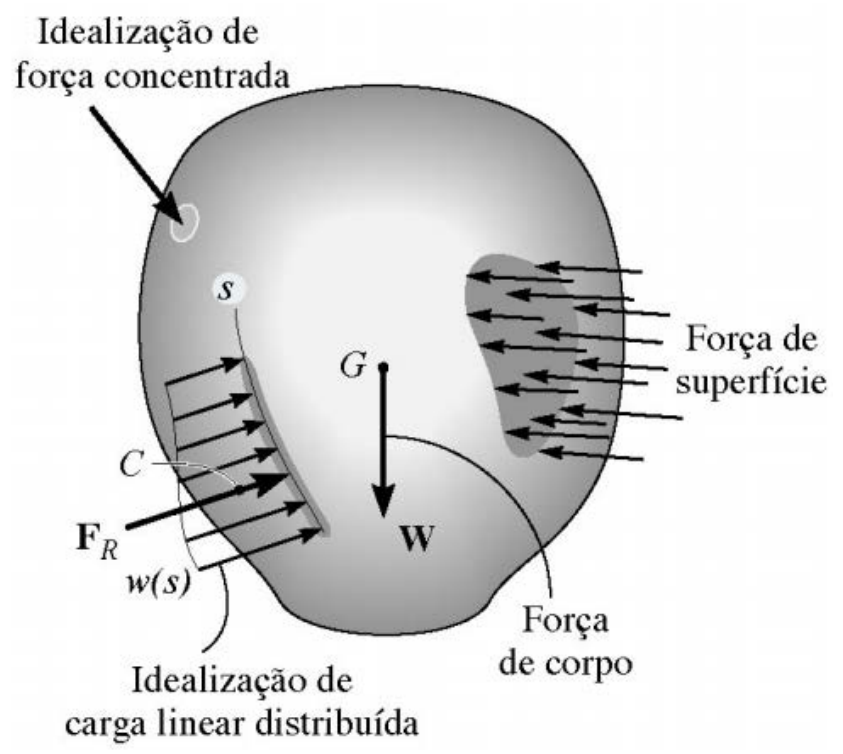

Figura 6 - Corpo Deformável (HIBBELER, 2004)

Forças Externas - Um corpo pode ser submetido a diversos tipos de cargas externas; entretanto, elas podem ser classificadas como força de superfície ou como força de corpo de acordo com a Figura 6.

- Forças de Superfície - As forças de superfície ocorrem devido ao contato direto de um corpo com a superfície de outro. Essas forças são distribuídas pela área de contato entre os corpos. Caso essa área seja pequena quando comparada com o total da área da superfície do corpo, diz-se que a força de superfície é exercida em forma de força concentrada, aplicada em um ponto do corpo. O contato da roda de uma motocicleta com o solo é um caso de força concentrada onde o solo exerce uma força sobre as rodas quando se estuda as cargas exercidas na motocicleta. - Outro caso de força de superfície ocorre quando aplicado ao longo de uma área estreita, gerando uma carga que poder ser imaginada como uma carga linear distribuída, $w(s)$. Essa por sua vez é 
medida como tendo uma intensidade de força/comprimento ao longo da área e é representada graficamente por uma série de setas ao longo da reta $s$ como visto na Figura 6 . A Força resultante de $w(s), F_{R}$, equivale à área sob a curva de distribuição da carga e sua resultante atua no centroide $\mathrm{C}$ ou centro geométrico dessa área.

- Força de Corpo - É a força quem um corpo exerce sobre outro sem que ocorra contato físico direto entre eles. O efeito da Gravidade é um exemplo de forças de corpo assim como o efeito causado por campos magnéticos. No caso da gravidade essa força de corpo é chamada de força peso.

Reações de apoio - As forças de superfície que se desenvolvem nos apoios ou pontos de contato entre corpos são chamadas de reações. O Engaste é um tipo de reação com o acoplamento de acordo com a Figura 7 e suas reações podem ocorrer na translação em dada direção com ocasionando uma força nessa direção (sentido oposto), ou em uma rotação aplicando um conjugado sobre o elemento.

Figura 7 - Engaste 
Equações de Equilíbrio - O equilíbrio de um corpo é composto por dois equilíbrios. O Primeiro deles é o equilíbrio de forças onde o corpo não sofre translação e nem tenha movimento acelerado, seja em trajetórias retilíneas ou curvilíneas. O Segundo é o equilíbrio de momentos onde a rotação do corpo é nula. Essas condições de equilíbrio podem ser expressas pelas seguintes equações:

$$
\begin{gathered}
\sum F=0 \\
\sum M_{O}=0
\end{gathered}
$$

Onde $\sum F$ representa a soma de todas as forças que atuam sobre o corpo, e $\sum M_{O}$ representa a soma dos momentos de todas as forças em relação a um ponto qualquer $O$ tanto sobre o corpo quanto fora dele.

As cargas que incidem sobre um corpo podem ser definidas de acordo com (HIBBELER) em quatro tipos diferentes de cargas resultantes, como:

Força Normal, N, atuando perpendicularmente à área sendo criada sempre que as forças externas tenderem a empurrar ou puxar as duas partes do corpo;

Força de Cisalhamento, V, localizada no plano da área é criada quando as cargas externas tendem a provocar o deslizamento das duas partes do corpo, uma sobre a outra;

Momento de Torção ou Torque, T, criado quando as cargas externas tendem a torcer uma parte do corpo em relação à outra;

Momento Fletor, $\mathbf{M}$, provocado quando as cargas externas tendem a fletir 0 corpo em relação ao eixo localizado no plano da área.

As forças e momentos que atuam sobre os corpos, representam os efeitos resultantes da distribuição da força que atuam nestes. Determinar a distribuição das cargas internas é de grande importância na mecânica dos materiais. Para resolver este problema é necessário estabelecer os conceitos de tensão e consequente dessa tensão o conceito de deformação. 


\section{Tensão Mecânica}

Para estabelecer o conceito de tensão mecânica de acordo com (GERE), utilizaremos uma haste como mostrada na Figura 8.

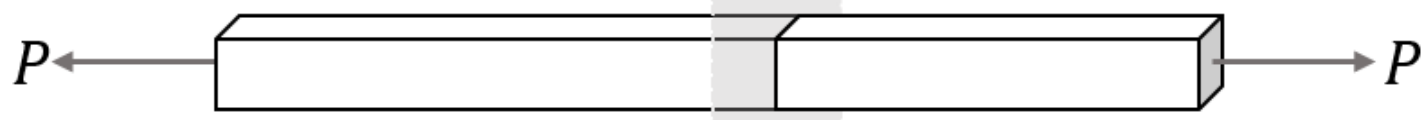

Figura 8 - Seção transversal da Haste

Se desprezarmos o peso da haste e a secionarmos como indicado, então, para o equilíbrio do segmento do lado esquerdo (Figura 9), a resultante da força interna que atua na seção transversal deverá ser igual em intensidade, oposta em direção e colinear à força externa que atua na extremidade direita da haste.

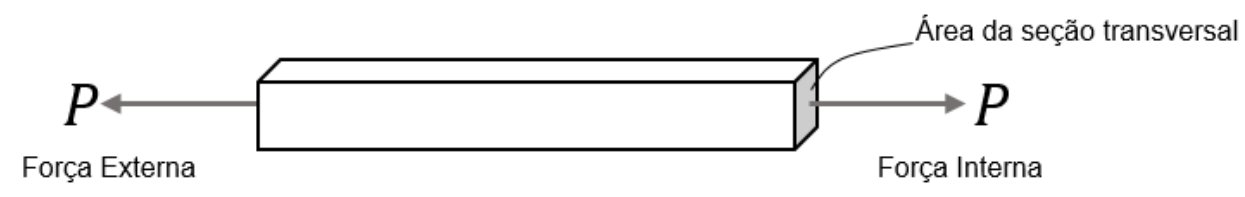

Figura 9 - Área da seção transversal da Haste

Antes de revisarmos a distribuição média de tensão que atua na área da seção transversal da haste, é necessário estabeler duas hipóteses relacionadas à descrição do material e à aplicação específica de carga.

Primeiramente, faz-se necessário que a haste permaneça reta tanto antes, como depois da aplicação da carga. Além disso, a seção transversal deve permanecer 
plana durante a deformação, isto é, durante o tempo em que a haste muda seu volume e sua forma. Segundo, a fim de que a haste possa sofrer deformação uniforme, é necessário que $P$ seja aplicada ao longo do eixo centroide da seção transversal e o material seja homogêneo e isotrópico. Um material homogêneo possui as mesmas propriedades físicas e mecânicas em todo o seu volume, e um material isotrópico possui essas mesmas propriedades em todas as direções.

Uma curiosidade interessante é que o aço, por exemplo, contém milhares de cristais orientados aletoriamente em cada milímetro cúbico de seu volume, mas, como a maioria dos problemas que envolvem esse material tem um tamanho físico muito maior do que um simples cristal, a hipótese referente à isotropia desse material é bastante realista. Ressalte-se, porém, que o aço pode tornarse anisotrópico por laminação a frio, isto é, se for laminado ou forjado em temperaturas subcríticas. Os materiais anisotrópicos possuem propriedades diferentes em direções diferentes, mas, apesar disso também se deformarão uniformemente quando submetidos a uma carga axial (HIBBELER, 2004).

\section{Distribuição da Tensão Normal Média}

Considere-se uma haste infinita e em seguida isolamos um segmento dela como um corpo livre (Figura 10a). Ao analisarmos esse diagrama de corpo livre, o peso da haste é desconsiderado e assumimos que as únicas forças são as forças axiais $\mathrm{P}$ nas extremidades. Agora considerando as duas vistas da haste: $\mathrm{A}$ primeira mostrando a haste antes da aplicação das cargas (Figura 10b) e a segunda mostrando-a depois das cargas serem aplicadas (Figura 10c). 


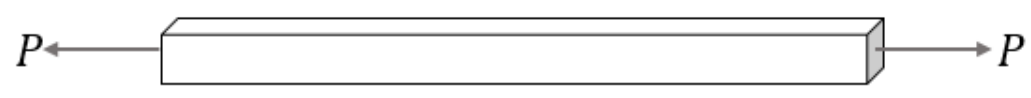

(a)

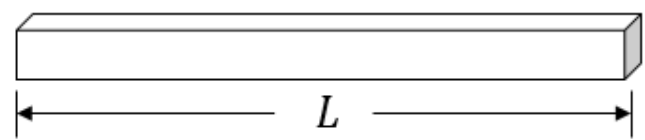

(b)

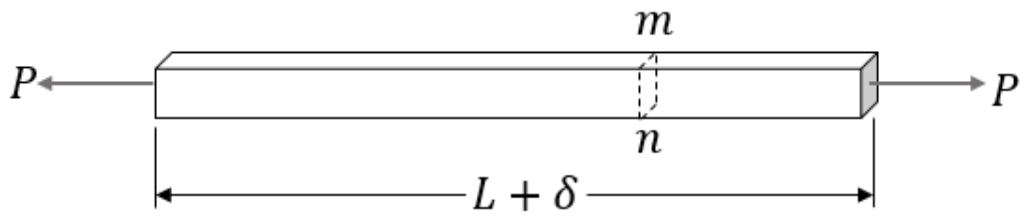

(c)

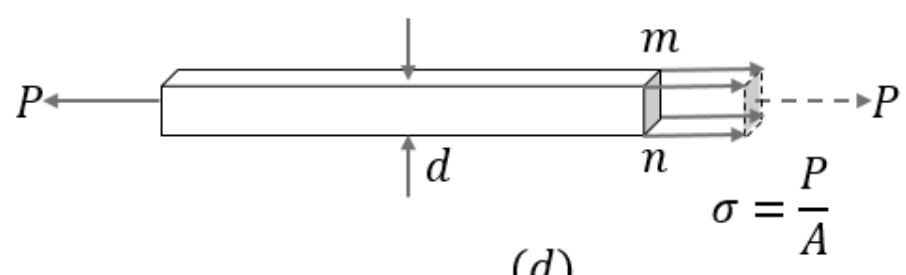

$(d)$

Figura 10 - (a) Haste em Tração, (b) segmento da haste antes do carregamento, (c) segmento da haste após o carregamento e (d) tensões normais na haste

Sendo $L$ o comprimento original da haste, o comprimento final, após a aplicação da carga, é $L+\delta$, onde a letra grega delta $(\delta)$ representa o aumento no comprimento devido às cargas.

As tensões internas são vistas facilmente se fizermos um corte imaginário através da haste de na seção mn (Figura 10c). Como essa seção é tomada perpendicularmente ao eixo longitudinal da haste, é chamada de seção transversal. Agora isolamos a porção da haste à esquerda da seção transversal mn como um corpo livre (Figura 10d). Na extremidade direita desse corpo livre (seção $\mathrm{mn}$ ) mostramos a ação da porção removida da haste (isto é, a parte da direita da seção $m n$ ) sob a parte remanescente. Essa ação consiste de uma força distribuída contínua agindo sobre toda a seção transversal. Visto que a haste está submetida a uma deformação uniforme constante, então a deformação é o 
resultado de uma tensão constante. $O$ resultado é que a cada $\Delta A$ da seção transversal está sujeita a uma força $\Delta F=\sigma \Delta A$ e o somatório das forças que atuam sobre toda a área da seção transversal deve ser equivalente à força interna resultante $\boldsymbol{P}$ na seção. Se $\Delta A \rightarrow d A$ e, portanto, $\Delta F \rightarrow d F$, então, admitindo que $\sigma$ seja constante, temos:

$$
\begin{gathered}
\int d F=\int_{-\frac{A}{2}}^{\frac{A}{2}} \sigma d A \\
P=\sigma A \\
\sigma=\frac{P}{A}
\end{gathered}
$$

Onde:

$\sigma=$ tensão normal média em qualquer ponto da área da seção transversal $P=$ resultante da força normal interna, aplicada no centroide da área da seção transversal. $P$ é determinada pelo método das seções e pelas equações de equilíbrio

$A=$ área da seção transversal da haste

A intensidade da força (isto é, a força por unidade de área) é chamada de tensão e denotada pela letra grega sigma $(\sigma)$. Dessa forma, a força axial $P$ agindo na seção transversal é a resultante das tensões distribuídas continuamente. (A força resultante é mostrada com uma linha tracejada na Figura 10d)

A equação acima nos dá a intensidade de tensão uniforme em uma haste prismática, carregada axialmente e de seção transversal de forma arbitrária. Quando a haste é esticada pelas forças $P$, as tensões são chamadas de tensões de tração. Quando a haste é comprimida por uma força $P$, obtemos a tensão de compressão. Sendo assim, diz-se que as tensões que agem na direção perpendicular à superfície de corte, são chamadas de tensões normais. Além das tensões normais, existem aquelas que agem tangencialmente à superfície 
do material e são chamadas de tensões de cisalhamento e representadas pela letra Tau $(\tau)$.

Geralmente, se tratando de convenção de sinais para tensões normais, é comum definir as tensões de tração como positivas e as tensões de compressão como negativas.

Sendo a tensão normal $\sigma$ obtida dividindo a força axial pela área da seção transversal $m n$, a unidade dessa tensão será força por unidade de área. No sistema internacional (SI), a força é expressa em newtons (N) e a área em metros quadrados $\left(\mathrm{m}^{2}\right)$. Consequentemente, a tensão tem unidades de newtons por metro quadrado $\left(\mathrm{N} / \mathrm{m}^{2}\right)$, a qual foi denominada pascal $(\mathrm{Pa})$. Em termos de grandezas, não é muito usual trabalhar com pascal, pois se trata de uma unidade muito pequena. Sendo assim, se faz necessário trabalhar com números de ordens maiores, geralmente o megapascal (MPa) que também pode ser escrita como $\left(\mathrm{N} / \mathrm{mm}^{2}\right)$. (GERE, 2003)

\section{Deformação}

Quando uma força é aplicada sob um corpo, este, tende a mudar sua forma e tamanho. Tais mudanças são denominadas deformação e podem ser perfeitamente visíveis ou praticamente dependendo do caso. Um exemplo bem simples é a borracha, que sofre uma deformação muito grande quando esticada. Por outro lado quando um edifício é ocupado por pessoas se movimentando, ocorrem apenas pequenas deformações de membros estruturais. Um corpo também pode sofrer deformação quando sua temperatura muda. Um exemplo típico é a expansão ou a contração de um telhado provocadas pelas condições atmosféricas. (HIBBELER, 2004)

Tecnicamente falando, como já foi observado, uma haste irá mudar de comprimento quando carregada axialmente, tornando-se mais comprida quando em tração e mais curta quando em compressão. O alongamento $\delta$ (delta) dessa haste (Figura 10c) é o resultado cumulativo do estiramento de todos os elementos do material através do volume da haste. Considerando que o material é o mesmo em todo lugar da haste, se metade da barra (comprimento $L / 2$ ), ela terá um alongamento igual $\delta / 2$ e, se considerarmos um sexto da barra, ela terá 
um alongamento $\delta / 6$. Sendo assim, concluímos que o alongamento de um segmento é igual ao seu comprimento dividido pelo comprimento total $L$ e multiplicado pelo alongamento total $\delta$. Por isso, uma unidade de comprimento da haste terá um alongamento igual a $1 / L$ vezes $\delta$. Essa quantia é chamada de alongamento por unidade de comprimento, ou deformação, e é denotada pela letra grega épsilon $(\epsilon)$. Concluindo, tem-se que a deformação é dada pela equação

$$
\epsilon=\frac{\delta}{L}
$$

Analogamente à tensão, se a barra está em tração, a deformação é chamada de deformação de tração, significando que houve um alongamento do material. Estando a barra em compressão logo a deformação é de compressão e a barra encurta. A deformação de tração usualmente é tomada como positiva e a deformação de compressão é tomada como negativa. A deformação $\epsilon$ é chamada de deformação normal porque está associada a tensões normais.

Observe que a deformação é uma grandeza adimensional, pois é a relação entre dois comprimentos. Na prática, as unidades originais de $\delta$ e $L$ são geralmente incluídas na própria deformação, e então a deformação é registrada em formas como $\mathrm{mm} / \mathrm{m}$ e $\mu \mathrm{m} / \mathrm{m}$. A deformação as vezes é expressa também como uma porcentagem, especialmente quando as deformações são grandes.

Uma vez determinados os conceitos de tensão e deformação, as propriedades mecânicas de um material devem ser conhecidas para que se possa relacionar a deformação medida nesse material com a tensão associada a ela.

\section{Diagramas de Tensão-Deformação}

Um projeto mecânico sempre deve ser feito criteriosamente de acordo com a finalidade. Caso seja um projeto de uma máquina ferramenta, por exemplo, ela deverá ser robusta, precisa e sofrer o mínimo possível com as interferências externas. Caso o projeto seja de um edifício com mais de cem andares, este edifício deve estar preparado para suportar a carga planejada, com alto coeficiente de segurança, absorver as forças externas sem comprometer seus limites mecânicos. E para que tudo funcione corretamente, faz-se necessário 
que entendam-se o comportamento mecânico dos materiais que estão sendo usados. Quando se projeta sensores baseados em esforços mecânicos, também é essencial escolher e conhecer o material utilizado para otimizar ao máximo a relação entre o valor medido e o valor aferido, com o mínimo de erro possível.

A Figura 11 representa a inter-relação de variáveis na solução de problemas de mecânica dos materiais. As forças de corpo e de superfície, geram uma tensão no material (calculada através das equações de equilíbrio). Essa tensão mecânica, baseado nas leis constitutivas (de acordo com o material utilizado), deforma o material que por sua vez, sofre deslocamento e mudança de forma de acordo com a Geometria (Compatibilidade).(CHEN,SALEEB, 1994)

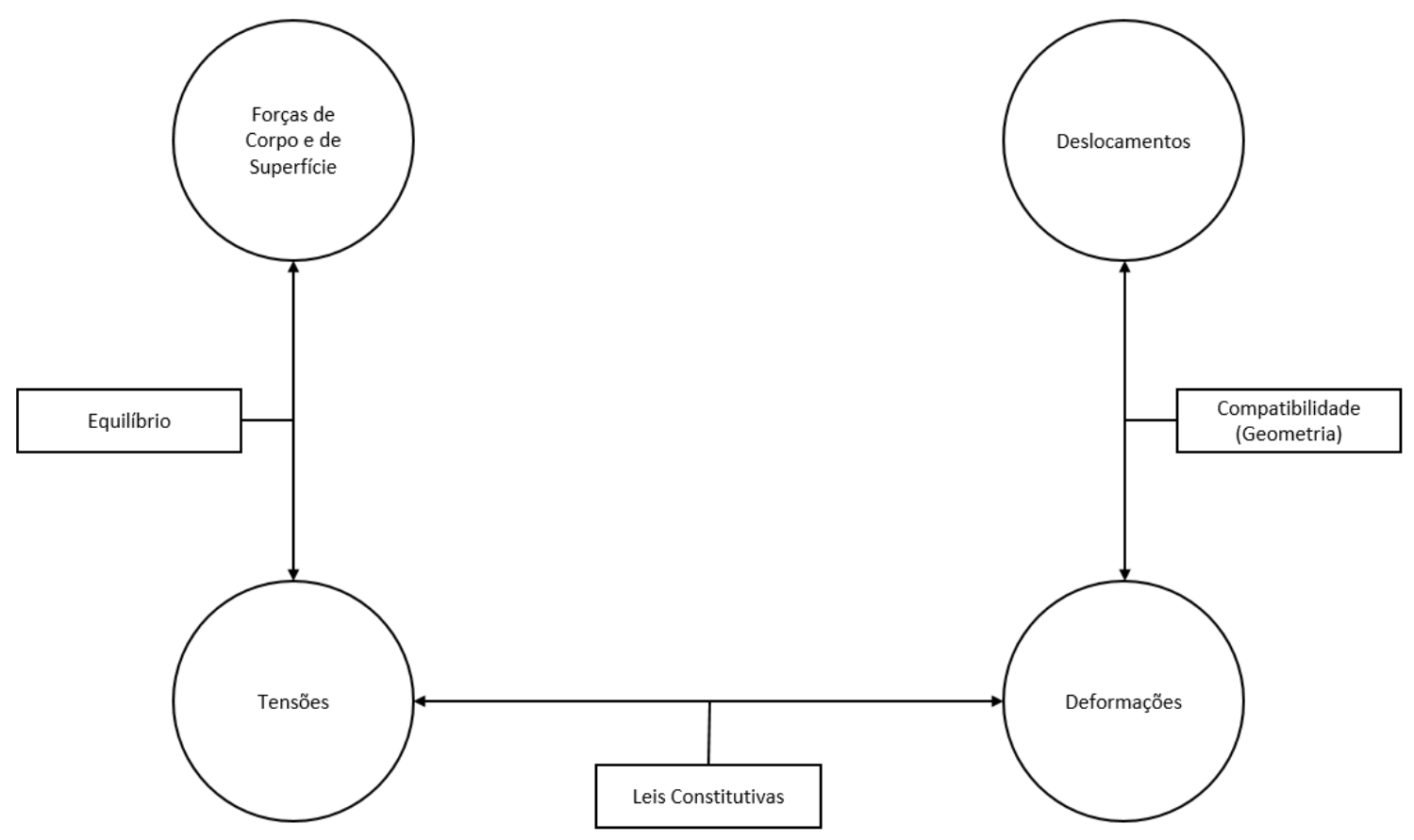

Figura 11 - Inter-relações de variáveis na solução de problemas de mecânica dos materiais (CHEN,SALEEB, 1994)

A lei constitutiva ou equação constitutiva citada acima é a descrição matemática do comportamento mecânico de um material. Não se podem fazer quaisquer análises mecânicas sem o conhecimento das leis constitutivas dos materiais analisados. A melhor maneira de determinar como os materiais se comportam quando submetidos a cargas é executar experimentos em laboratório. O procedimento mais comum é colocar pequenos corpos de prova 
dentro de máquinas de teste, aplicar cargas e então medir as deformações resultantes.

Para que os resultados dos testes sejam comparáveis às dimensões dos corpos de prova, os métodos de aplicação de carga foram padronizados. Uma das maiores organizações de padronização é a American Society for Testing and Materials (ASTM), uma sociedade técnica americana que publica especificações e padrões para materiais e testes. A título de curiosidade, o corpo de prova padrão da ASTM tem um diâmetro de 12.827 mm e um comprimento padrão de 50.8 mm entre as marcas de medição, achuradas utilizando visão computacional para a medição da deformação usando câmeras filmadoras. Essa análise da deformação pode ser realizada também utilizando de strain gauges avaliando pontualmente as deformações ou até com extensômetro com dois braços que medem o alongamento durante o carregamento.

Com os resultados dos testes, os valores de tensão e deformação no corpo de prova podem ser calculados. Depois, é possível construir um gráfico com esses resultados. Este gráfico é conhecido como diagrama tensão-deformação. A Figura 12 mostra um exemplo de diagramas de tensão-deformação convencional e real de um aço.

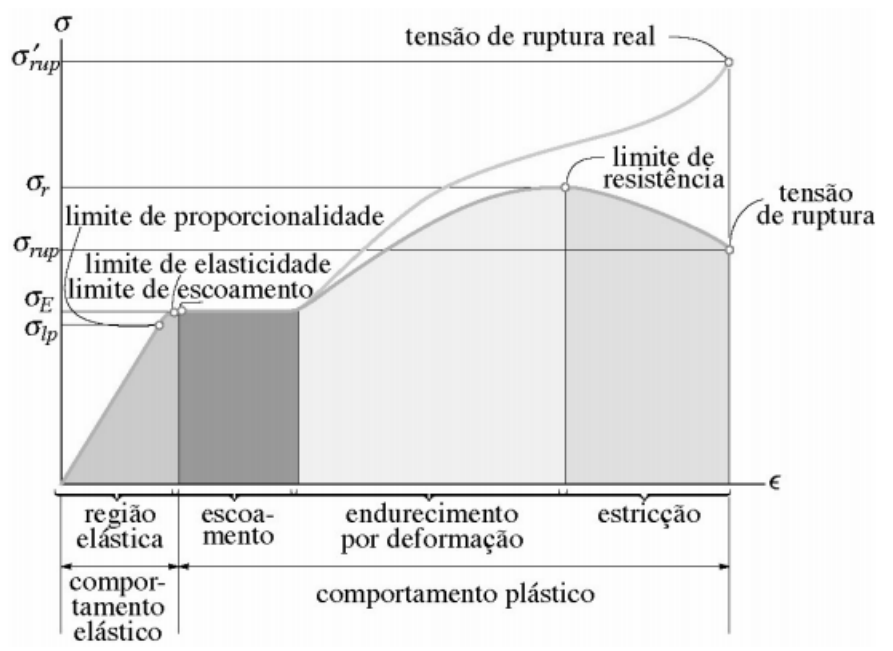

Figura 12 - Diagramas tensão-deformação convencional e real para material dúctil (aço estrutural) (sem escala) (HIBBELER, 2004) 
A equação constitutiva da elasticidade está representada na região elástica do diagrama, com início da origem até o limite de proporcionalidade $\sigma_{l p}$. Para o desenvolvimento deste trabalho é de suma importância que os esforços mecânicos trabalhem dentro dessa região para que a relação entre tensão e deformação seja linear e não ocorra escoamento ${ }^{2}$ do material.

Na maioria dos metais, não ocorre escoamento constante além da faixa de elasticidade como mostrado na Figura 12. O Alumínio é um exemplo, pois não possui um ponto de escoamento bem definido. Entretanto ele tem uma região linear inicial com um limite de proporcionalidade reconhecível.

A inclinação da linha da origem até $\sigma_{l p}$ é chamada de módulo de elasticidade ou módulo de Young e é representada pela letra E. Uma vez que a deformação é adimensional, as unidades de $E$ são as mesmas que as unidades de tensão, geralmente GPa.

A relação linear entre tensão e deformação para uma haste em tração ou compressão simples é expressa pela equação

$$
\sigma=E . \epsilon
$$

Onde $\sigma$ é a tensão axial, $\epsilon$ é a deformação axial e $E$ é o módulo de Young. Esta relação constitutiva também é conhecida como Lei de Hooke simplificada.

Ao definir o módulo de Young, considera-se apenas a deformação longitudinal (axial), no entanto, qualquer material elástico ao ser deformado axialmente, também sofre deformação transversal, proporcionalmente. A razão entre a deformação transversal e a deformação longitudinal na direção do esforço, é chamado de coeficiente de Poisson, $v$ :

$$
v=-\frac{\text { Deformação transversal }}{\text { Deformação longitudinal }}=-\frac{\epsilon^{\prime}}{\epsilon}
$$

\footnotetext{
2 Escoamento - Um pequeno aumento da tensão acima do limite de elasticidade resulta em
} colapso do material e faz com que ele se deforme permanentemente.(HIBBELER, 2004) 


\subsection{Flexão}

Com os conceitos de tensão e deformação de um material revisados, assim como as propriedades mecânicas do mesmo, para o desenvolvimento do sensor de monitoramento da PIC dissertado neste trabalho, é importante a conceituação e revisão das forças de cisalhamento e momentos fletores, para projetar a viga em balanço, do inglês, cantilever, com concentrações de tensões, onde os extensômetros serão colados.

Quando um cantilever sofre a ação de forças ou momentos, são criadas tensões e consequentemente deformações em seu interior. Para determinar essas tensões e deformações, primeiro é necessário encontrar as forças e os momentos internos que atuam nas seções transversais da viga.(GERE, 2003)

De acordo com as leis de equilíbrio de forças da estática vistos no início do capítulo 2.2, as tensões agindo na seção transversal de uma viga em balanço podem ser reduzidas a uma força de cisalhamento $V$ e um momento fletor $M$ como mostrado na Figura 13b. Como o carregamento $P$ é transversal ao eixo da viga, a força axial na seção transversal é nula. Tanto a força de cisalhamento quanto o momento fletor atuam no plano da viga.

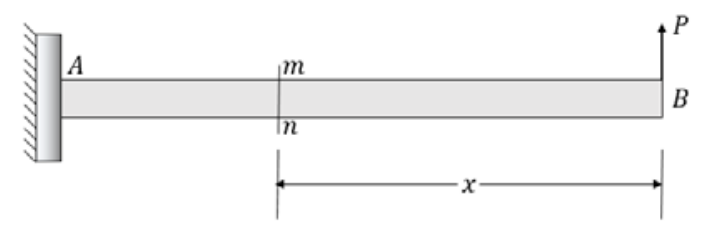

(a)

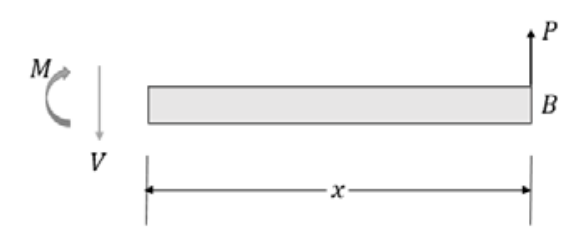

(b)

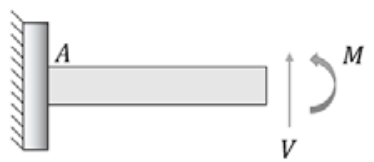

(c)

Figura 13 - Força de cisalhamento $V$ e momento fletor $M$ em uma viga

As resultantes de tensões em uma viga em balanço estaticamente determinada podem ser calculadas a partir das equações de equilíbrio. No caso da viga em balanço da Figura 13a, utiliza-se o diagrama de corpo livre da Figura 13b. 
Lembrando que pela convenção de sinais, de acordo com (GERE, 2003), "em vigas, uma força de cisalhamento positiva tende a girar o material no sentido horário (Figura 13b e c) e uma força de cisalhamento negativa tende a girar o material no sentido anti-horário. Além disso, um momento fletor positivo comprime a parte superior da viga (Figura 13b e c) e um momento fletor negativo comprime a parte inferior".

No sentido de ilustrar a intensidade, a força cisalhante e o momento fletor, os seus respectivos diagramas foram desenhados e estão ilustrados abaixo:

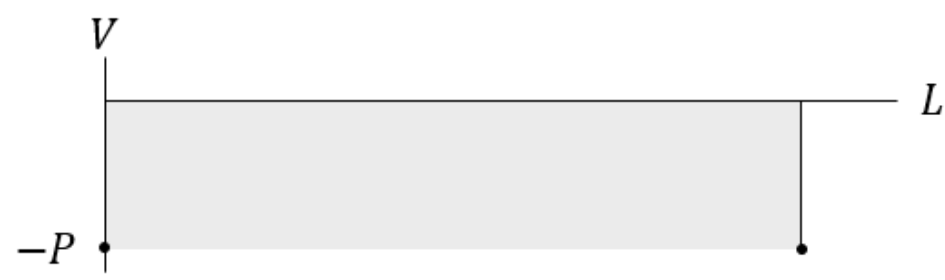

Figura 14 - Diagrama de Força Cisalhante

De acordo com o diagrama acima, e considerando que a força $P$ da Figura 13b tem um sinal positivo na equação de equilíbrio, porque aponta pra cima, a força de cisalhamento $V$ (que é uma força de cisalhamento positiva) tem um sinal negativo pois está direcionada para baixo.

A Figura 15 representa a distribuição de momento fletor para o exemplo da Figura 13. O Valor máximo do momento fletor é no ponto A da Figura 13 , onde seu valor é a Força peso vezes o comprimento $(L)$ da viga.

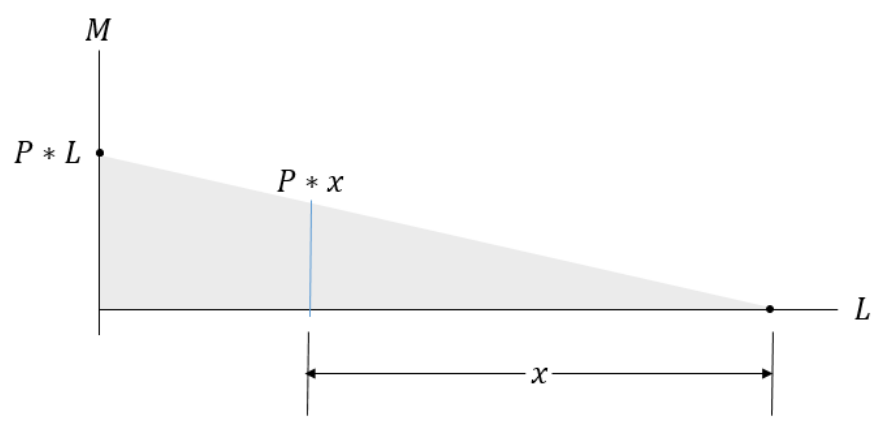

Figura 15 - Diagrama de Momento Fletor

Considerando o Momento na seção de corte $m n$, temos: 


$$
\begin{aligned}
& \sum F_{\text {vert }}=0 \quad P+V=0 \text { ou } \quad V=-P \\
& \sum M=0 \quad M-P x=0 \text { ou } \quad M=P x
\end{aligned}
$$

Onde $x$ é a distância da extremidade livre da viga (onde a força $\mathrm{P}$ está sendo exercida) até a seção transversal $m n$ onde $V$ e $M$ serão determinados.

As fórmulas de flexão e de cisalhamento discutidas anteriormente, são válidas para vigas sem descontinuidades (como entalhes, furos ou outras mudanças abruptas nas dimensões).

Essas descontinuidades resultam na modificação da distribuição de tensões, criando pontos de altas tensões, conhecidas como concentrações de tensão. Essas concentrações de tensão são extremamente importantes para o desenvolvimento de sensores baseados em esforços mecânicos pois elas funcionam um amplificador de tensões e deformações nessas descontinuidades. De acordo com o princípio de Sain-Venant (Adhemar Barré de SV - 1797-1886) as concentrações de tensão modificam as tensões apenas nas proximidades das mesmas.

Para os casos de tensão e flexão, o fator chamado de $K$ para concentrações de tensão é definido como:

$$
K=\frac{\sigma_{\max }}{\sigma_{\text {nom }}}
$$

Os casos de concentração de tensões mais comuns são vigas com um furo em sua linha neutra e vigas com entalhes, sendo a última delas, foco da nossa abordagem.

A Figura 16 mostra um exemplo de concentração de tensões com entalhes em uma chapa em flexão. Esses entalhes estão dispostos nas bordas (direita e esquerda) da chapa, perpendiculares à flexão. 


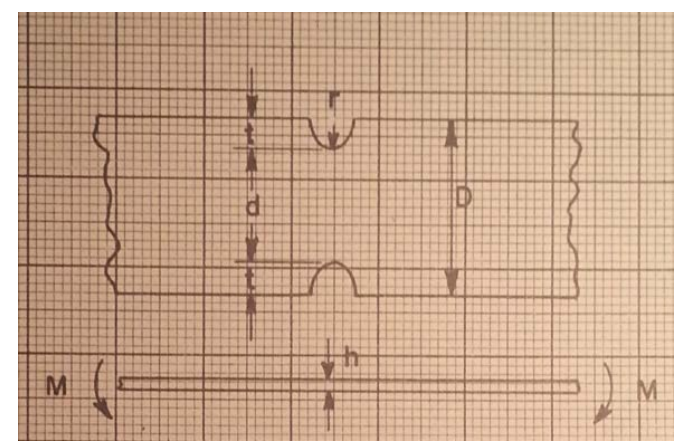

Figura 16 - Concentração de tensão em uma chapa em flexão (PETERSON, 1974)

De acordo com (PETERSON, 1974), a tensão nominal dessa concentração é dada pela fórmula abaixo:

$$
\sigma_{n o m}=\frac{6 M}{h^{2} d}
$$

Onde M é o momento fletor, h é a espessura e d é a largura entre os entalhes.

Perceba que não foram introduzidos os valores de $r$ e $d$ para a obtenção da $\sigma_{n o m}$. Porém para a solução do valor de concentração $K$, a relação entre $D$ e $d$ e a relação entre $r$ e $d$ são necessárias para encontrar graficamente o valor de $K$ de acordo com a figura abaixo: 




Figura 17 - Fator de Concentração de Tensão para chapa fina com entalhes perpendiculares à flexão. (Baseado nas análises matemáticas de SHIOYA, G. H. LEE, NEUBER) (PETERSON, 1974)

Uma vez determinado o valor de $K$ ( $K_{t}$ na Figura 17), para saber a tensão máxima $\sigma_{\max }$, basta seguir a fórmula abaixo:

$$
K=\frac{\sigma_{\max }}{\sigma_{\text {nom }}}
$$

Uma vez determinado a concentração de tensões em uma chapa em flexão, é importante determinar a deflexão $v_{A}$ que ocorre na chapa de acordo com uma determinada força aplicada. Para isso de acordo com HIBBELER (2004) uma viga em a deflexão de uma viga em balanço é mostrada na Figura 18. 


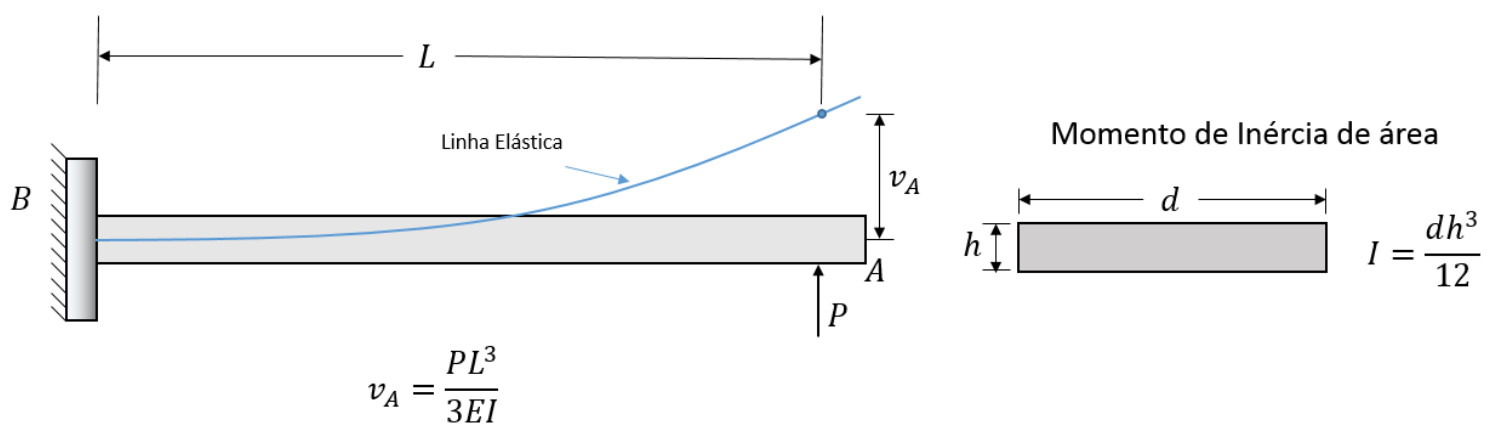

Figura 18 - Deflexão da viga em balanço

Substituindo o momento de inercia da seção retangular na equação do deslocamento, tem-se:

$$
v_{A}=\frac{12 P L^{3}}{3 E d h^{3}}=\frac{4 P L^{3}}{E d h^{3}}
$$

Essas equações serão importantes para análise da melhoria do sensor no capítulo 3.1 . 


\subsection{Extensometria}

Em 1856, Lord Kelvin apresentou uma publicação perante o Royal Society em Londres, observando que a resistência elétrica de fios de cobre e ferro aumentavam quando submetidos a esforços de tração. Esta observação levou à desenvolvimento do "strain gauge" ou "strain gage" no MIT (Massachusetts Institute of Technology) em 1939 por Arthur Claude Ruge. Existem várias razões pelas quais mais de 80 anos se passaram antes da utilização da ideia de William Thomson (1824-1905, Lord Kelvin depois de 1892) para aplicação técnica do fenômeno ocorrido. Uma delas é de que a mudança da resistência em um fio tensionado é muito pequena. Para essas medições Thomson utilizou um galvanômetro altamente sensível, o que inviabilizava o uso em aplicações técnicas ou industriais (HOFFMANN, 1989).

Entretanto o conceito do strain gauge é muito simples. Em essência, um fio ou folha eletricamente condutora (isto é, o strain gauge) está ligado à estrutura de interesse e a resistência do fio ou folha é medida antes e depois do carregamento da estrutura. Uma vez que o strain gauge esteja firmemente ligado na estrutura (por deposição, colagem, etc.), qualquer deformação induzida na estrutura pela carga, também é induzida no strain gauge. Isso provoca uma mudança na resistência do extensômetro (tradução para strain gauge) servindo assim como um medida indireta da tensão induzida na estrutura (HANNAH,REED, 1992).

Nos primeiros extensômetros utilizados no início deste século o elemento resistente era constituído por um depósito de carbono coloidal sobre um suporte isolante. Notou-se rapidamente que fatores secundários, temperatura e umidade exerciam uma influência considerável sobre as indicações do gauge. (HOFFMANN, 1989)

Estes problemas foram os que levaram à concepção de gages constituídos por fio, onde, em sua forma mais simples, é composto por um fio muito fino (10 a 30 $\mu m$ de diâmetro) em liga $\mathrm{Ni}-\mathrm{Cr}$ ou $\mathrm{Cu}-\mathrm{Ni}$. O fio, depois de dobrado, é colocado sobre um suporte isolante à base de papel. A Figura 19 mostra uma imagem da representação de um strain gauge de fio. 


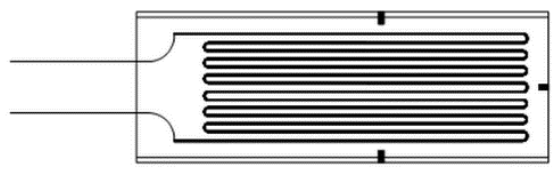

Figura 19 - Strain gauge de fio (ANDOLFATO, 2004)

Já a figura mostra uma visão transversal da representação ampliada de um strain gauge de fio.

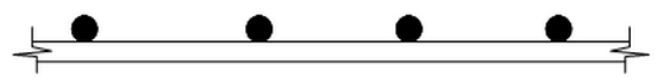

Figura 20 - Visão transversal do strain gauge de fio (ANDOLFATO, 2004)

No final da $2^{\mathrm{a}}$ Guerra Mundial, registraram-se progressos consideráveis nas técnicas da extensometria elétrica e os gauges à base de fio foram substituídos por gauges tipo "lâmina" ou "folha", sobre suportes em resina epóxi (20 a $80 \mu \mathrm{m}$ de espessura), trazendo várias vantagens. A Figura 21 mostra a representação do strain gauge de folha.

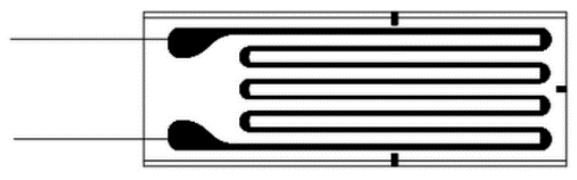

Figura 21 - Strain gauge de lâmina (ANDOLFATO, 2004)

O strain gauge de lâmina tem seu processo de produção feito a partir de fotogravura, conseguindo maior precisão (na ordem de mícrons) reduzindo a dispersão de características geométricas num mesmo lote, permitindo até a obtenção de geometrias variadas com grandes reduções de dimensões. Seu 
suporte que antes era de papel, agora passa a usar o epóxi, uma estrutura mais sólida e podendo até ser mais fina, transmitindo mais fielmente as deformações para o elemento sensível (lâmina). Por ser extremamente fina, o efeito transversal é muito menor que os gauge à fio como visto na ampliação da visão transversal do extensômetro na Figura 22.

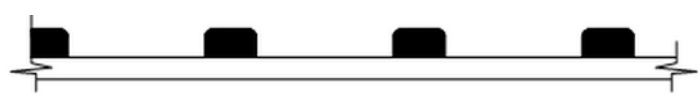

Figura 22 - Visão transversal do strain gauge de lâmina (ANDOLFATO, 2004)

Os strain gauges de lâmina são os mais utilizados atualmente.

\section{Princípio de Funcionamento dos Strain Gauges Metálicos}

A medição de deformações utilizando extensômetros, assume que a deformação do objeto sob investigação é transferida sem perdas para o strain gauge. Isto requer um vínculo estreito entre o strain gauge e o objeto como por exemplo um bom processo de colagem ou deposição do extensômetro sob o objeto. Na maioria dos casos apenas a superfície do objeto está acessível para medições, apesar de ser possível medir tanto na superfície quando em algum orifício do objeto.

A resistência elétrica de um fio é descrita pela fórmula

$$
R=\frac{\rho . l}{S}
$$

Onde, $\rho$ é a resistividade do metal do gauge, $l$ e $S$ são, respectivamente, o comprimento e a área da seção transversal das lâminas do gauge.

O termo "strain" (deformação) definido em 2.2 é normalmente usado para descrever o alongamento de uma seção. A deformação pode ser causada por efeito de um força ou por efeito da temperatura. Essa deformação altera o comprimento $l$ do strain gauge, alterando também sua resistência. A 
resistividade também é alterada quando o strain gauge sofre deformação, porém essa mudança é tão pequena quando comparado às mudanças na geometria do strain gauge que geralmente para fórmulas simples acaba sendo desprezada.

As unidades utilizadas em extensometria são as mesmas utilizadas em deformações como visto na seção 2.2. Geralmente utiliza-se a pseudo-unidade $\mu \varepsilon$ ou $\mu D$ para representar as microdeformações.

Para a correta escolha do strain gauge algumas perguntas devem ser respondidas para avaliar o melhor para cada problema. A seleção depende dos modelos disponíveis pelos fabricantes de acordo com a aplicação e as condições as quais o strain gauge é exposto durante a medição, pois não existe um extensômetro que atenda a todos os casos. Para os casos menos comuns, strain gauges podem ser fabricados de acordo com a necessidade, porém a realidade do preço é outra. Porém a maioria dos problemas podem ser solucionados sem a necessidade de recorrer a uma fabricação especial, mas essa escolha pode não ser tão simples e deve ser feita criteriosamente. De acordo com (HOFFMANN), foi demonstrado que a metade de todos os problemas, podem ser resolvidos com uma coleção de duas dezenas de tipos de extensômetros.

Um sistema de seleção apresentado por (HOFFMANN) exige que o usuário analise o seu problema de medição. Para usar o sistema, dois requisitos devem ser cumpridos:

- Primeira exigência: a tarefa de medição deve ter um objetivo claro e os detalhes do processo e suas condições de contorno devem ser conhecido.

- Segunda exigência: As características strain gauge devem ser conhecidos.

A Tabela 2 se destina a fornecer ajuda no cumprimento da primeira exigência. Aqui, os fatores mais importantes que afetam a seleção de um tipo de strain gauge são listados como títulos em cinco grupos. A tabela pode ser utilizada 
como uma lista de verificação de modo a que o utilizador não negligenciar um ponto importante.

Tabela 2 - Lista de verificação da aplicação para escolha adequada do extensômetro. (HOFFMANN, 1989) Tradução livre.

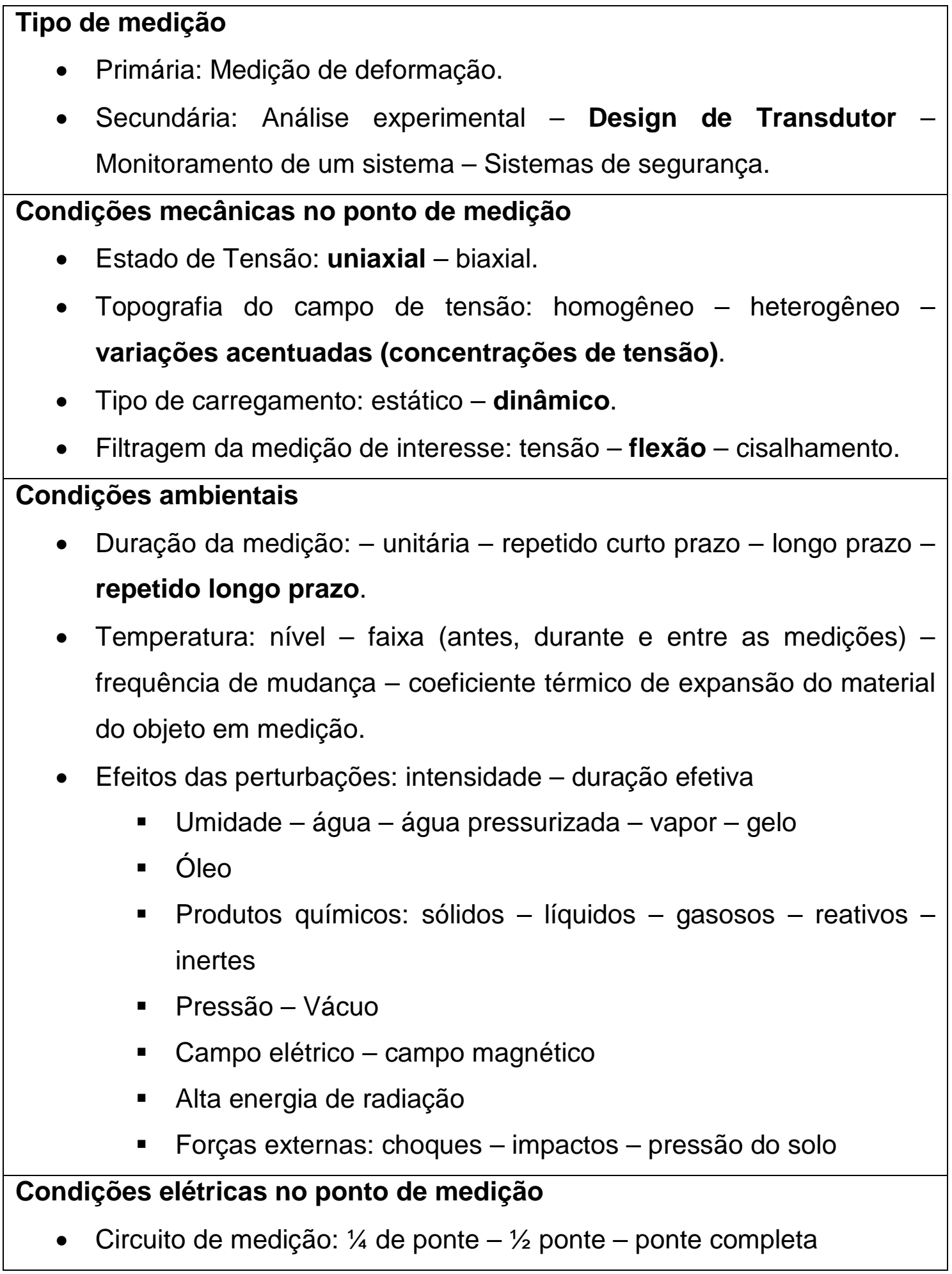


- Alimentação do strain gauge: corrente contínua - corrente alternada (frequência portadora) - potenciômetro - Etc.

- Cabos: comprimento - resistência - isolação - capacitância resistência aos efeitos do ambiente (mecânico, térmico e químico) elementos de conexão (plugues e conexões)

\section{Condições de aplicação}

- Material: usinabilidade - propriedades de colagem e soldagem

- Tratamento da superfície de aplicação: jateamento de areia - ataque químico

- Roteamento do cabo

- Condições espaciais: strain gauge - cabo - agente de cobertura

A princípio todo extensômetro pode ser usado para solucionar problemas de analise experimental e para a construção de transdutores, porém existem certas diferenças entre os tipos de strain gauges comercializados e as empresas diferenciam as séries levando a finalidade em consideração para facilitar a vida do usuário.

São vários os tipos de strain gauge e eles estão dispostos em várias formas e tamanhos.
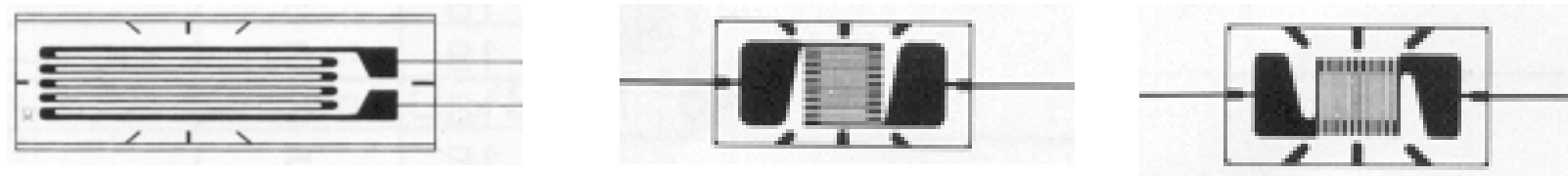

Figura 23 - Extensômetros uniaxiais (KYOWA, 2013)
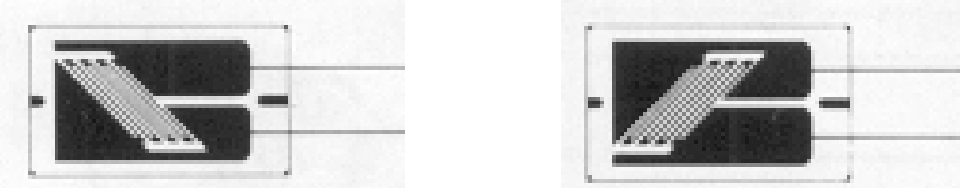

Figura 24 - Extensômetros uniaxiais com grade à 45º (KYOWA, 2013)
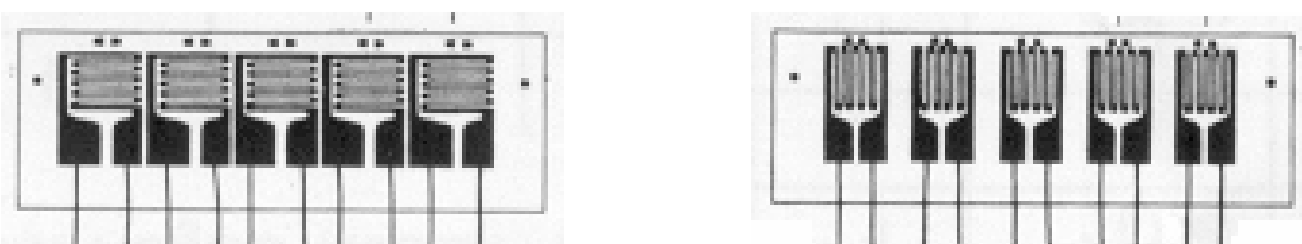

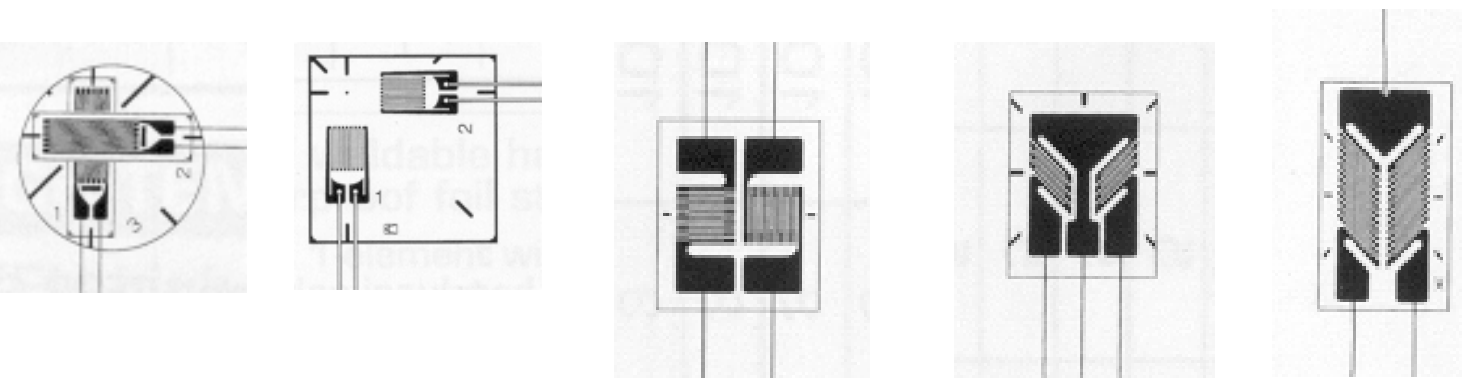

Figura 26 - Extensômetros biaxiais (rosetas de 2 elementos) (KYOWA, 2013)
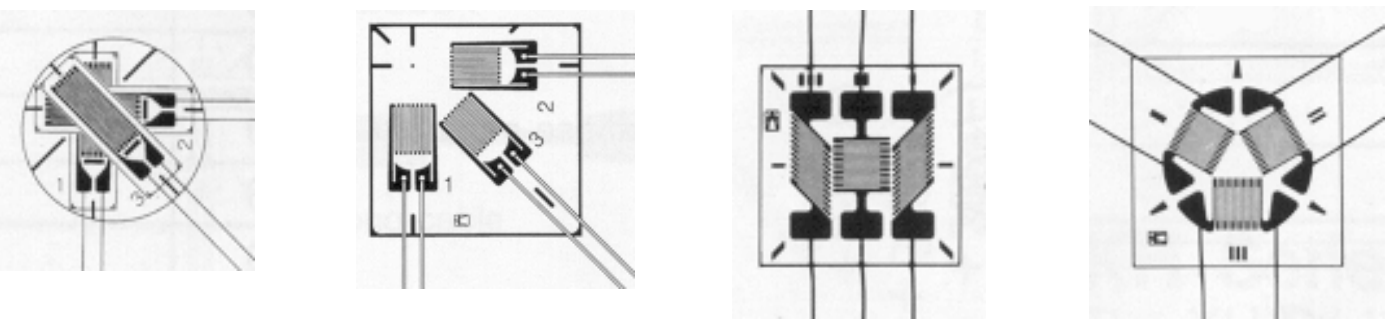

Figura 27 - Extensômetros triaxiais (rosetas de 3 elementos) (KYOWA, 2013)
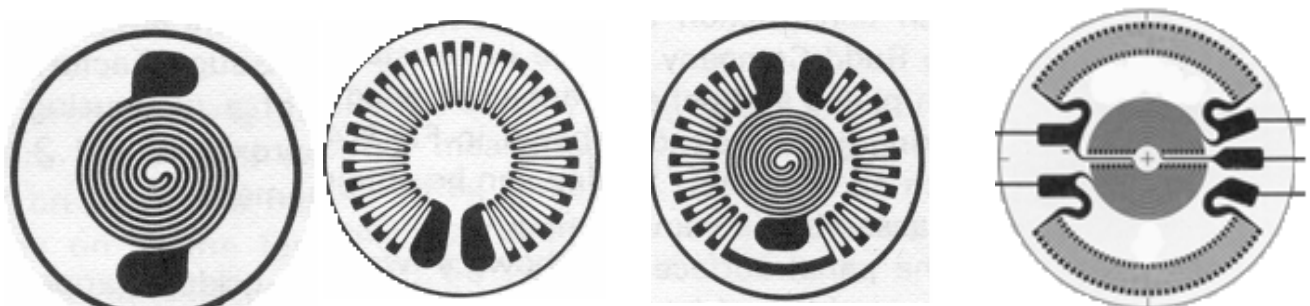

Figura 28 - Extensômetros de diafragma (tangencial e radial) (KYOWA, 2013)

Os extensômetros são produzidos em várias faixas de resistência. O valor de $120 \Omega$ é o mais popular para análise de tensão, porém para desenvolvimento de transdutores o valor de $350 \Omega$ é mais utilizado e a escolha do valor depende muito do tipo de sistema onde o extensômetro está conectado, pois existem sistemas amplificadores que necessitam de um valor de impedância mínima da ponte, ou se o cabo tiver uma resistência alta, valores maiores são aconselhados para evitar o desbalanceamento. 
A faixa de temperatura é um item que merece destaque na escolha do strain gauge, pois a mudança térmica influencia no princípio de medição e existem extensômetros projetados para diversas faixas de temperatura variando principalmente o tipo de material utilizado na produção do mesmo. Todos os objetos alteram suas dimensões quando sua temperatura é alterada. Calor produz expansão e resfriamento causa contração.

O coeficiente de expansão longitudinal $\alpha$, também chamado de coeficiente de expansão térmica linear, indica a variação relativa de comprimento em $10^{-6} \mathrm{~m} / \mathrm{m}$ per $K$ :

$$
\alpha=\frac{l_{2}-l_{1}}{l_{1}} * \frac{1}{\Delta \vartheta}=\frac{\Delta l}{l_{0} * \Delta \vartheta} \text { em }\left[\frac{\frac{m}{m}}{K}\right]=\left[\frac{1}{K}\right]
$$

Onde:

$l_{1}=l_{0}=$ Comprimento inicial antes da mudança de temperatura;

$l_{2}=$ Comprimento final depois da mudança de temperatura;

$\Delta l=$ Mudança de comprimento durante a mudança de temperatura;

$\Delta \vartheta=$ Mudança de temperatura, positiva para aquecimento, negativo para resfriamento.

A razão $\mathrm{m} / \mathrm{m}$ também é cancelada aqui então a unidade é dimensionada apenas com $1 / \mathrm{K}$

Abaixo segue a Tabela 3 com alguns valores comerciais de $\alpha$ para strain gauges:

Tabela 3 - Coeficientes térmicos comerciais para strain gauges (HBM)

Tipo de Material

\begin{tabular}{l|c}
\hline Aço ferrítico & $\alpha=10.8 * 10^{-6} / K$ \\
\hline Alumínio & $\alpha=23 * 10^{-6} / K$ \\
\hline Aço austenítico & $\alpha=16 * 10^{-6} / K$ \\
\hline Quartzo & $\alpha=0.5 * 10^{-6} / K$ \\
\hline Titânio/Ferro fundido cinzento & $\alpha=9 * 10^{-6} / K$ \\
\hline
\end{tabular}




\begin{tabular}{l|c}
\hline Material plástico & $\alpha=65 * 10^{-6} / K$ \\
\hline Molibdênio & $\alpha=5.4 * 10^{-6} / K$ \\
\hline
\end{tabular}

Apesar desta compensação, um erro residual permanece, o qual é impresso na cartela do strain gauge.

De acordo com (HANNAH,REED, 1992), os materiais elásticos reagem com uma deformação espontânea, positiva ou negativa, quando submetido a uma carga súbita. No caso de uma carga constante a ser aplicada, o material continuará a ser deformado na direção da carga. Esse fenômeno é comumente chamado de efeito de creep e é um problema constante em fabricação de células de carga de precisão. Como os transdutores são carregados dentro da deformação elástica, o processo aqui descrito é reversível e chamado especificamente de "elastic after-effect". Esse efeito mostrado na Figura 29 provoca um erro dependente do tempo com um sinal positivo (na direção da deformação).

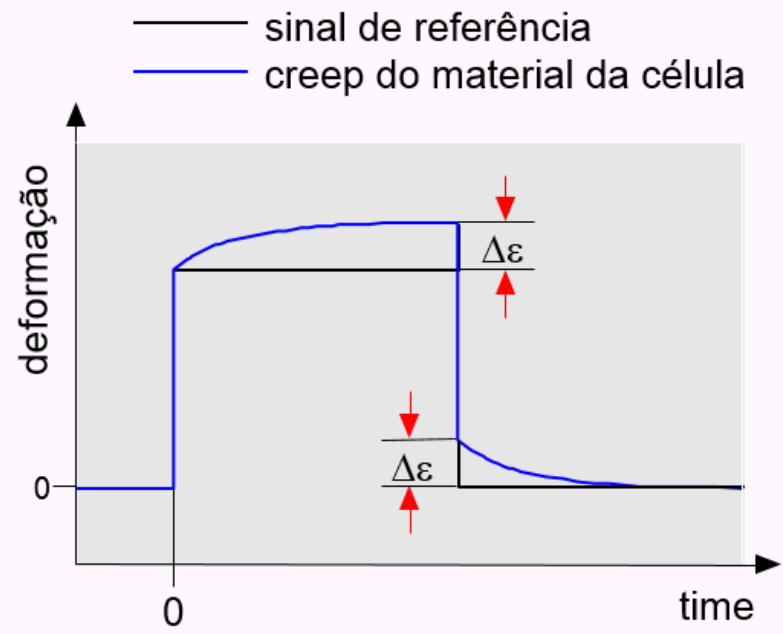

Figura 29 - Evolução do creep do material da célula de carga (DELIJAICOV, 2012).

Entretanto, quando um extensômetro é submetido a uma carga estática, ele apresenta uma outra mudança lenta na resistência ao longo do tempo apesar da deformação ser constante. Esta mudança no sinal de medição ocorre no sentido do alívio da tensão, ou seja, provoca um erro dependente do tempo com um sinal negativo (contra a direção da deformação) e pode ser explicada da seguinte forma: a grelha de medição (grid) ao ser deformada 
age semelhante a uma mola tensionada que gera uma tensão de cisalhamento entre a grade de medição e o suporte plástico (principalmente nas curvas das voltas do grid). Devido à influência dessas tensões, o material plástico onde o strain gauge é depositado e o adesivo usado para a fixação relaxam. A Figura 30 mostra a evolução do creep do material do strain gage.

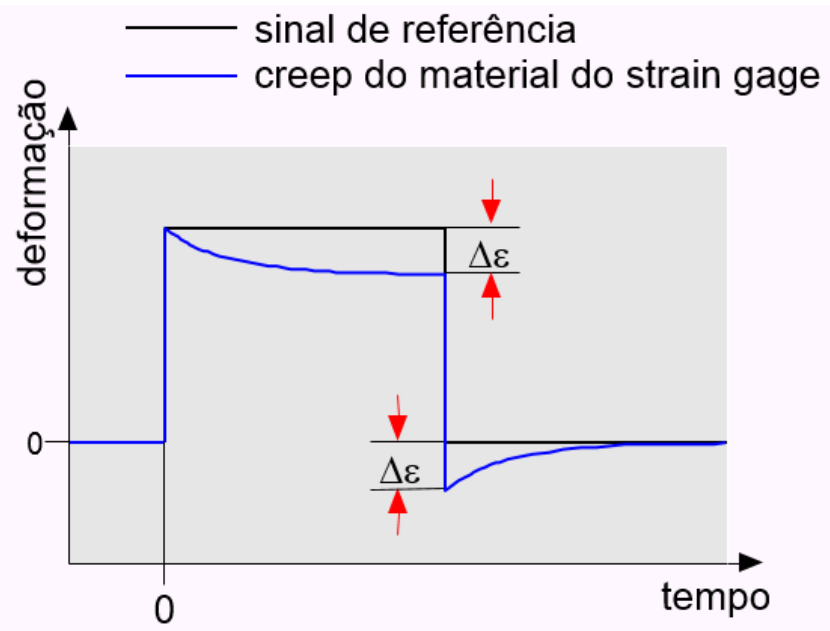

Figura 30 - Evolução do creep do material do strain gauge (DELIJAICOV, 2012).

Porém esse erro varia de acordo com a geometria das curvas do grid. Se usarmos isso de modo a compensar o erro positivo do creep do material da célula de carga com o erro negativo do material do strain gauge é possível minimizar o erro como mostrado na Figura 31. Para fabricantes de transdutores, o erro de creep deve ser de no máximo $0.005 \%$ da faixa de medição em um período de 30 minutos.

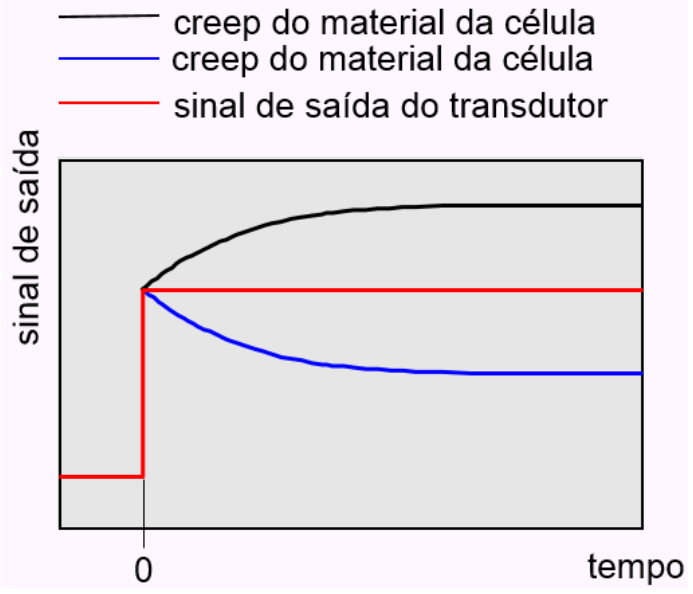

Figura 31 - Compensação dos crepes (DELIJAICOV, 2012). 
Os fabricantes de extensômetros disponibilizam códigos de creep em seus catálogos comerciais para atender as mais diversas aplicações. A Figura 32 mostra a relação entre as dimensões $u$ e $s$ disponíveis para atender à compensação de creep da marca HBM.

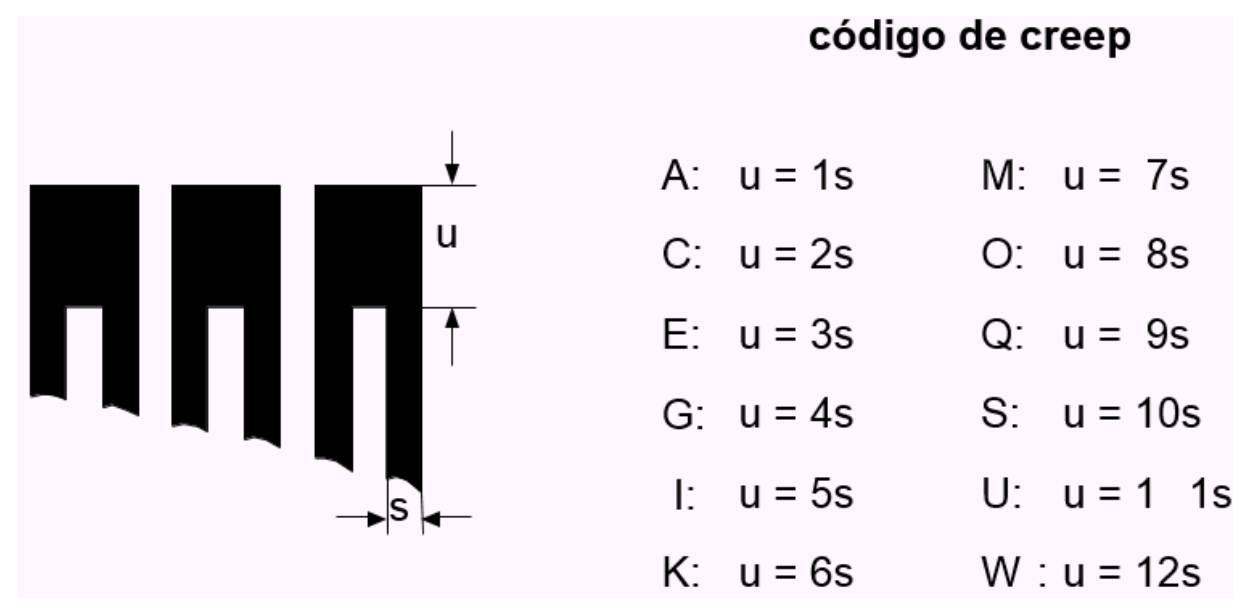

Figura 32 - Código de creep (HBM)

Para a escolha do valor ideal é necessário realizar experimentos práticos calculando o valor do erro atendendo ao indicado acima.

Por último, porém não menos importante, é preciso falar sobre a sensibilidade de strain gauges, ou simplesmente, fator gauge (gage fator). É a relação física entre a deformação e a mudança de resistência em um condutor metálico. Essa relação é linear para alguns tipos de ligas metálicas em certas faixas de temperatura. O gage factor é expresso pela razão da mudança relativa de resistência com a deformação e é representado pelo símbolo $k$.

$$
k=\frac{\Delta R / R_{0}}{\Delta l / l_{0}}=\frac{\Delta R / R_{0}}{\epsilon}
$$

De forma trivial, pode ser visto que $k$ é uma grandeza adimensional, porém para expressar ordem de grandeza ela pode ser expressa por:

$$
\left[\frac{\mathrm{m} \Omega / \Omega}{\mathrm{mm} / \mathrm{m}}\right]
$$

Na fabricação de extensômetros não é possível ajustar o valor do gage fator, pois ele depende apenas da liga da qual é fabricada. A Tabela 4 mostra alguns 
dos valores comerciais mais comuns, assim como suas ligas e nomes comerciais.

Tabela 4 - Sensibilidade do SG de acordo com a liga metálica utilizada.

Nome do Material Composição da liga Valor aproximado do gage factor

\begin{tabular}{l|l|l}
\hline Constantan & $57 \mathrm{Cu}, 43 \mathrm{Ni}$ & 2.05 \\
\hline Karma & $73 \mathrm{Ni}, 20 \mathrm{Cr}$ & 2.1 \\
\hline Nichrome V & $80 \mathrm{Ni}, 20 \mathrm{Cr}$ & 2.2 \\
\hline Platinum-tugsten & $92 \mathrm{Pt}, 8 \mathrm{~W}$ & 4.0 \\
\hline
\end{tabular}

Geralmente os valores comercializados estão próximos de 2. A dificuldade de encontrar valores superiores não é coincidência e tem relação direta com a linearidade e histerese. Em um material sob investigação onde um extensômetro é colado, para uma perfeita relação linear entre $\Delta R / R_{0}$ do extensômetro e a deformação aplicada no ponto onde foi colado, é necessário que o gage factor seja constante para o intervalo de deformação medido. De acordo com (HANNAH,REED, 1992), qualquer material com a sensibilidade maior ou menor que 2 mostra não linearidade e/ou histerese nessa relação quando seu limite elástico é aproximado. 


\subsection{Ponte de Wheatstone}

Em 1843, o cientista inglês Sir Charles Wheatstone (1802 - 1875) desenvolveu um circuito que possibilita a medição com precisão de resistências elétricas. Este circuito ficou conhecido como ponte de Wheatstone. (HOFFMANN, 1989)

A ponte de Wheatstone pode ser usada de duas maneiras para medir resistências elétricas:

- Determinar o valor absoluto de uma resistência em comparação com resistências conhecidas.

- Para determinação da mudança relativa da resistência.

Este último método é o usado nas técnicas de extensometria e ele possibilita que as mudanças relativas de resistência do strain gauge, que geralmente são da ordem de $10^{-4}$ a $10^{-2} \Omega / \Omega$, sejam medidos com grande precisão. A ponte de Wheatstone é extraordinariamente versátil e será mostrada a seguir, dando enfoque nas técnicas de extensometria.

A Figura 33 mostra a representação clássica da ponte de Wheatstone.

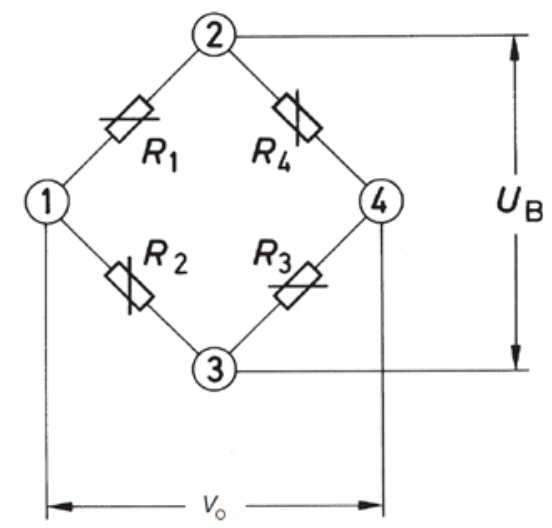

Figura 33 - Representação clássica da Ponte de Wheatstone

O princípio de funcionamento da ponte de Wheatstone é muito simples. De acordo com a Figura 33, uma fonte de tensão $U_{B}$ é aplicada entre os pontos $2 \mathrm{e}$ 3 , pontos estes que ligam duas meia-pontes $R_{1}, R_{2}$ e $R_{4}, R_{3}$. Ao colocar um medidor de tensão $\left(V_{0}\right)$ entre os pontos 1 e 4 , analisando o circuito, a tensão correspondente será dada pela seguinte fórmula: 


$$
V_{0}=U_{B}\left(\frac{R_{1}}{R_{1}+R_{2}}-\frac{R_{4}}{R_{3}+R_{4}}\right)
$$

Se a ponte estiver balanceada, isto é

$$
\frac{R_{1}}{R_{2}}=\frac{R_{3}}{R_{4}}
$$

a tensão de saída da ponte $V_{0}$ é zero.

Se um sistema em ponte completa sofrer deformações, as resistências dos strain gauges terão uma alteração de $\Delta R$, assim como mostra a equação a seguir:

$$
V_{0}=U_{B}\left(\frac{R_{1}+\Delta R_{1}}{R_{1}+\Delta R_{1}+R_{2}+\Delta R_{2}}-\frac{R_{4}+\Delta R_{4}}{R_{3}+\Delta R_{3}+R_{4}+\Delta R_{4}}\right)
$$

Para a medição de deformações, as resistências $R_{1}$ e $R_{2}$ devem ter o mesmo valor inicial. O mesmo deve se aplicar para as resistências $R_{3}$ e $R_{4}$.

Portanto, igualando as resistências, tem-se:

$$
\begin{gathered}
V_{0}=U_{B}\left(\frac{R_{1}+\Delta R_{1}}{R_{1}+\Delta R_{1}+R_{1}+\Delta R_{2}}-\frac{R_{3}+\Delta R_{4}}{R_{3}+\Delta R_{3}+R_{3}+\Delta R_{4}}\right)= \\
U_{B}\left(\frac{R_{1}+\Delta R_{1}}{2 R_{1}+\Delta R_{1}+\Delta R_{2}}-\frac{R_{3}+\Delta R_{4}}{2 R_{3}+\Delta R_{3}+\Delta R_{4}}\right)= \\
U_{B}\left(\frac{\left(R_{1}+\Delta R_{1}\right) *\left(2 R_{3}+\Delta R_{3}+\Delta R_{4}\right)-\left(R_{3}+\Delta R_{4}\right) *\left(2 R_{1}+\Delta R_{1}+\Delta R_{2}\right)}{\left(2 R_{1}+\Delta R_{1}+\Delta R_{2}\right) *\left(2 R_{3}+\Delta R_{3}+\Delta R_{4}\right)}\right)
\end{gathered}
$$

Expandindo a equação acima teremos alguns termos onde $\Delta R_{x}{ }^{*} \Delta R_{y}$, porém estes termos são muito pequenos quando comparados ao termos maiores e serão desconsiderados.

$$
V_{0}=U_{B}\left(\frac{R_{1} \Delta R_{3}+R_{1} \Delta R_{4}+2 \Delta R_{1} R_{3}-R_{3} \Delta R_{1}-R_{3} \Delta R_{2}-2 \Delta R_{4} R_{1}}{4 R_{1} R_{3}+2 R_{1} \Delta R_{3}+2 R_{1} \Delta R_{4}+2 R_{3} \Delta R_{1}+2 R_{3} \Delta R_{2}}\right)
$$

Analisando criteriosamente o denominador, percebe-se que a ordem de grandeza do primeiro termo é muito maior que os outros termos. 
Imaginemos uma ponte completa de $350 \Omega$ com um strain gauge com $15 \mu \mathrm{m}$ de deformação. Para o primeiro termo, tem-se:

$$
4 R_{1} R_{3}=490000 \Omega^{2}
$$

Para o segundo termo, por exemplo, tem-se:

$$
2 R_{1} \Delta R_{3}=7,35 \Omega^{2}
$$

Sendo assim, iremos considerar apenas o primeiro termo no denominador.

O resultado é:

$$
V_{0}=U_{B}\left(\frac{R_{1} \Delta R_{3}+R_{1} \Delta R_{4}+2 \Delta R_{1} R_{3}-R_{3} \Delta R_{1}-R_{3} \Delta R_{2}-2 \Delta R_{4} R_{1}}{4 R_{1} R_{3}}\right)
$$

Simplificando e separando os termos comuns,

$$
\frac{V_{0}}{U_{B}}=\frac{\Delta R_{3}}{4 R_{3}}+\frac{\Delta R_{1}}{4 R_{1}}-\frac{\Delta R_{2}}{4 R_{1}}-\frac{\Delta R_{4}}{4 R_{3}}
$$

Retornando os valores de $R_{2}$ e $R_{4}$, tem-se:

$$
\frac{V_{0}}{U_{B}}=\frac{1}{4}\left(\frac{\Delta R_{1}}{4 R_{1}}-\frac{\Delta R_{2}}{R_{2}}+\frac{\Delta R_{3}}{R_{3}}-\frac{\Delta R_{4}}{R_{4}}\right)
$$

Agora, considerando o princípio da extensometria elétrica onde:

$$
\frac{\Delta R}{R}=k * \varepsilon
$$

Sendo $k$ o fator de multiplicação do strain gauge (gage factor citado no capítulo anterior) e $\varepsilon$ a deformação, tem-se por fim:

$$
\frac{V_{0}}{U_{B}}=\frac{k}{4}\left(\varepsilon_{1}-\varepsilon_{2}+\varepsilon_{3}-\varepsilon_{4}\right)
$$

Onde $\varepsilon_{n}$ é a deformação em cada um dos strain gauges da ponte da Figura 33. A equação acima assume que todas as resistências na ponte mudam de valor quando o sistema sofre uma deformação, porém isso nem sempre acontece e varia de acordo com a forma do circuito da ponte de Wheatstone aplicada. 
Basicamente existem quatro formas de circuito de ponte de Wheatstone usados na extensometria. São eles:

(a)

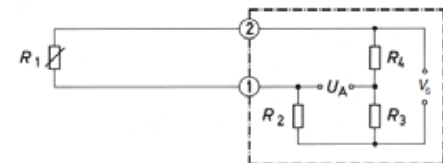

(b)

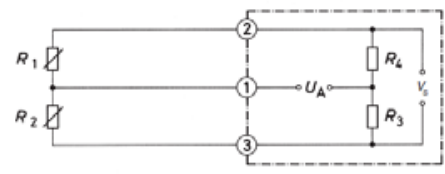

(c)

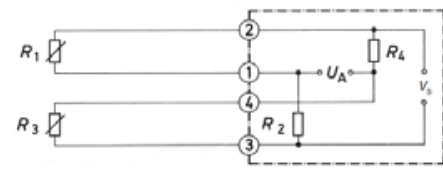

(d)

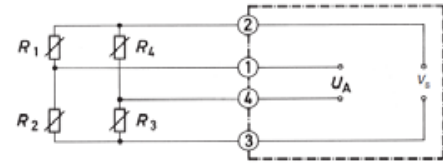

Figura 34 - Tipos de pontes extensiométricas - (a) 1/4 de ponte - (b) 1/2 ponte - (c) ponte diagonal - (d) ponte completa

Para desenvolvimento de transdutores, é essencial que o engenheiro saiba usar os benefícios da ponte de wheatstone para evitar diversos problemas. Esses benefícios estão dispostos no capítulo 2.7 .

Os sensores a base de ponte são largamente utilizados, inclusive os principais sensores não invasivos como o CODMAN ${ }^{\circ}$ e o CAMINO ${ }^{\circledR}$ são à base de pontes de Wheatstone. 


\subsection{Materiais utilizados na montagem de strain gauges}

Para se obter bons resultados de deformação com extensômetros elétricos, é indispensável uma boa colagem com técnicas e materiais desenvolvidos na área pelos diversos fabricantes.

A escolha do adesivo é de extrema importância e basicamente temos três tipos distintos de acordo com os catálogos de fabricantes:

Adesivos a base de cianoacrilato: A Cura (tempo que o adesivo leva para ter uma aderência firme entre o strain gauge e a base) leva apenas alguns minutos. A temperatura para a colagem pode ser a ambiente e ele é muito fácil de manusear.

Adesivos a base de nitro-celulose: Uso à temperaturas próximas da ambiente, secagem relativamente rápida, porém precisa de alta pressão entre o gauge e a peça devido a evaporação do solvente.

Adesivos a base de poliéster, acrílico e epóxi: usados normalmente com um catalizador, são aplicados com alta pressão entre o gauge e a peça, os tempos de cura variam de acordo com o tipo de produto, podendo ser lento (com duração de 12 horas) ou praticamente instantâneo (acrílicos).

O primeiro tipo citado, adesivo a base de cianoacrilato, é largamente utilizado, devido a facilidade de uso. E apesar de existirem produtos à base de cianoacrilato no mercado como o Super Bonder ${ }^{\circledR}$, as empresas de extensometria disponibilizam o cianoacrilato em seu catálogo de acessórios.

Antes do processo de colagem, faz-se necessário preparar e limpar a área de interesse a ser medida. A umidade da região onde será colado, precisa ser pequena, porém experiências de colagem mostram, que colagem em locais muito secos também não são tão efetivas. A experiência do técnico é muito importante nesse momento. Alguns materiais são utilizados para fazer a limpeza do local onde o extensômetro é aplicado. São eles:

- Lixas de diversas granulações

- Acetona ou éter

- Gaze 
No processo de limpeza dos metais, faz-se necessário retirar as oxidações superficiais. As lixas são boas para este serviço. Recomenda-se iniciar 0 processo com lixas de granulação maior (entre 600 e 400) e finalizar com lixas com granulação menor (entre 120 e 80). O esforço aplicado no processo de abrasão, não deve ser grande o suficiente a ponto de aplicar grandes tensões superficiais, o que atrapalharia a medição. As direções de aplicação também são importantes para evitar as tensões superficiais. Quanto mais uniforme seja o processo de abrasão, menor tendem a ser as tensões aplicadas.(HBM, 2006)

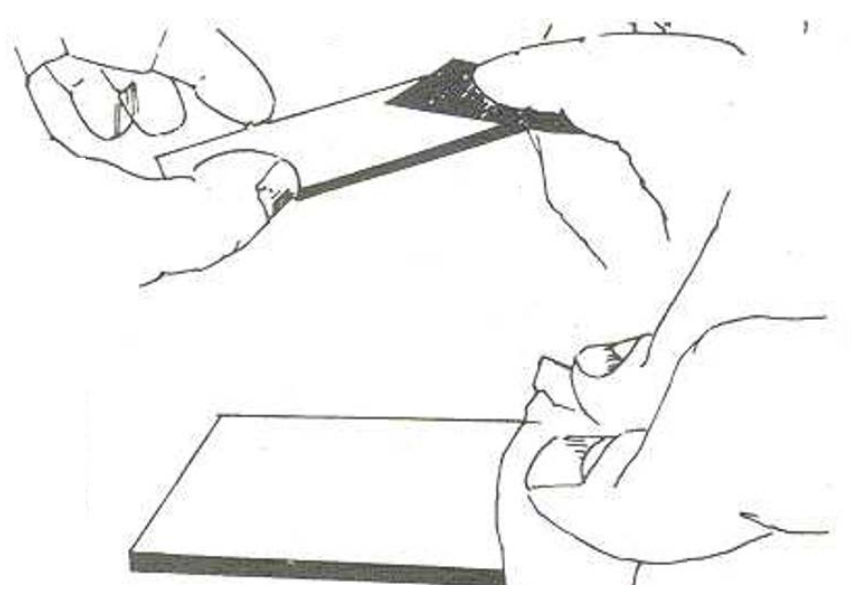

Figura 35 - Processo de lixação de uma superfície

O processo de lixação deve ser acompanhado de uma limpeza frequente com gaze e acetona ou éter, porém o éter implica em uma concentração de umidade maior. Após a lixação, deve ser retirada toda a impureza (partículas dispersas pelo processo abrasivo) do material utilizando gaze (ou cotonete) e acetona. Um cuidado ao utilizar cotonetes deve ser tomado para evitar que os fios de algodão se prendam à superfície onde será colado o strain gauge.

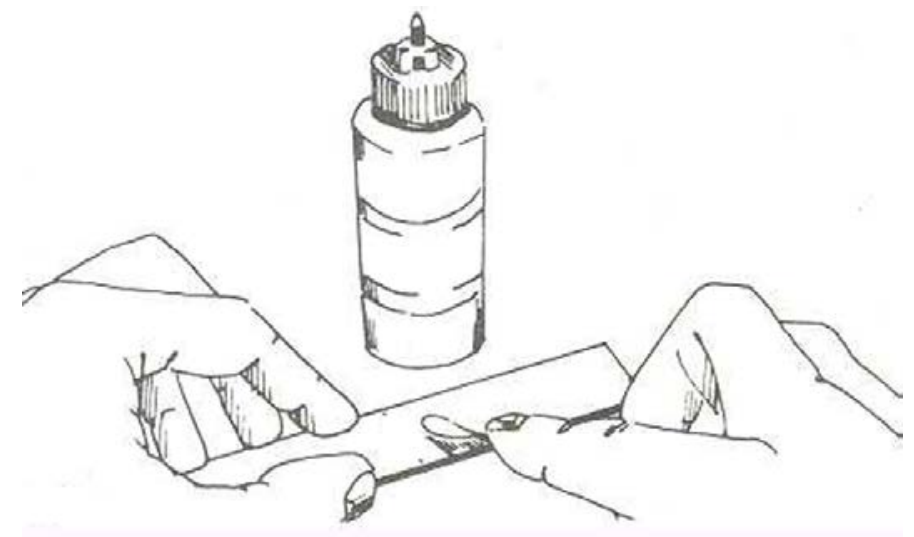


Outros agentes de limpeza(solventes) são recomendados por fabricantes. A principal ação desse solventes é reduzir a oleosidade da região onde é aplicado. Acetona, éter e Isopropanol são agentes bastante utilizados na limpeza.

No processo de colagem, a direção na qual o extensômetro será colado é extremamente importante, sendo assim, para evitar erros neste processo, fitas adesivas transparentes e canetas esferográficas são importantes para ajustar o posicionamento.

Para obter uma boa simetria no circuito da ponte, os strain gauges escolhidos para a montagem devem estar os mais próximos possíveis entre sí. A utilização de um ohmimetro é essencial para medir o erro de cada strain gauge com erros menores que 0.25\% (HOFFMANN, 1989). Ohmímetros com precisão abaixo de $0.1 \Omega$ é suficiente para encontrar e selecionar extensômetros que estejam na mesma faixa de erro.

Após a colagem dos extensômetros, para proteger o circuito contra agentes externos, revestimentos de proteção são aconselhados. Os mais comuns são vernizes à base de poliuretano, borracha nitrílica, silicone, dentre outros. As vantagens destes, são as proteções contra umidade e água, podendo ser usados até imersos durante longos períodos dependendo da temperatura. A desvantagem é que os revestimentos acima geralmente não são resistentes a certos tipos de óleos e solventes. Para cada tipo de aplicação existem revestimentos indicados podendo até usar uma combinação entre eles.(HOFFMANN, 1989) 


\subsection{Técnicas de redução de erros de medição em pontes}

Cada medição, independentemente do tipo, está sujeita a erros. Cabe ao responsável por executar a medição, manter o erro dentro dos limites aceitáveis usando meios razoáveis para isso. O quanto o erro pode influenciar na medição depende de alguns fatores, como o método de medição, o cuidado e a atenção do usuário, conhecimento das possíveis causas de erro e as informações para solucionar ou minimizar estes erros.

A temperatura é um grande vilão na extensometria, pois o extensômetro é feito de uma grade metálica e esse metal sofre influências da temperatura, mudando assim sua resistência, afetando diretamente o valor lido na ponte de wheatstone.

É muito importante o usuário saber exatamente o tipo de sinal que deseja medir. O extensômetro por definição mede a deformação média da região a qual ele está fixado. Fazendo o uso da ponte de wheatstone, pode-se definir exatamente as variáveis que se desejam ler através da deformação de um strain gauge. A técnica de configuração da ponte permite, dependendo do caso, que a ponte sofra influência apenas de algum ou alguns tipos de ações, como flexão, força normal, temperatura e torção.

As figuras a seguir mostram a dependência da posição geométrica dos extensômetros, o tipo de circuito de ponte utilizado e a sensibilidade (gage factor) para a Temperatura $(\mathrm{T})$, Força normal $(\mathrm{F})$, Momento Fletor $(\mathrm{Mb})$ e Torque $(\mathrm{Md})$.

Cada figura representa um tipo de configuração diferente, exibindo a equação e a tabela de sensibilidade. As equações são usadas para calcular a deformação efetiva na saída do sinal (Ua/Ub).
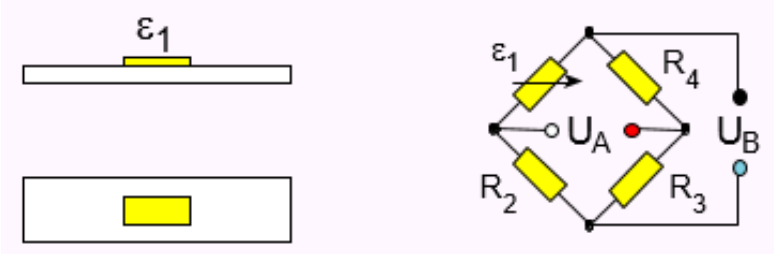

$\varepsilon=\varepsilon_{\mathrm{n}}+\varepsilon_{\mathrm{b}}=\frac{4}{\mathrm{k}} \cdot \frac{\mathrm{U}_{\mathrm{A}}}{\mathrm{U}_{\mathrm{B}}}-\varepsilon_{\vartheta}$
\begin{tabular}{|c|c|c|c|}
\hline $\mathrm{T}$ & $\mathrm{F}$ & $\mathrm{Mb}$ & $\mathrm{Md}$ \\
\hline 1 & 1 & 1 & 0 \\
\hline
\end{tabular}

Figura $36-1 / 4$ de ponte simples

Sendo: 
$k=$ gage factor dos strain gauges;

$\varepsilon=$ deformação total;

$\varepsilon_{n}=$ deformação devido à força normal;

$\varepsilon_{b}=$ deformação devido ao momento fletor;

$\varepsilon_{\vartheta}=$ deformação devido à mudança de temperatura;

$U_{A}=$ tensão de saída da ponte;

$U_{B}=$ tensão de entrada da ponte.

A Figura 36 mostra uma ponte simples. Essa configuração não possui compensação de temperatura e capta as forças normais e momentos fletores na barra.
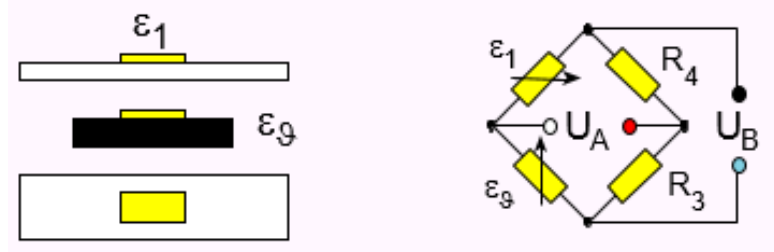

$\varepsilon=\varepsilon_{\mathrm{n}}+\varepsilon_{\mathrm{b}}=\frac{4}{\mathrm{k}} \cdot \frac{\mathrm{U}_{\mathrm{A}}}{\mathrm{U}_{\mathrm{B}}}$
\begin{tabular}{|c|c|c|c|}
\hline $\mathrm{T}$ & $\mathrm{F}$ & $\mathrm{Mb}_{\mathrm{b}}$ & $\mathrm{Md}$ \\
\hline 0 & 1 & 1 & 0 \\
\hline
\end{tabular}

Figura 37 - Meia ponte com Dummy

A Figura 37 utiliza um extensômetro como Dummy. Este Dummy não sofre influência das forças e momentos, apenas da temperatura, pois está fixado e um local próximo. Sendo assim, como os extensômetros foram colocados vizinhos, o efeito da temperatura é anulado entre os extensômetros. Assim essa configuração capta e força normal e o momento fletor, com a compensação de temperatura. 

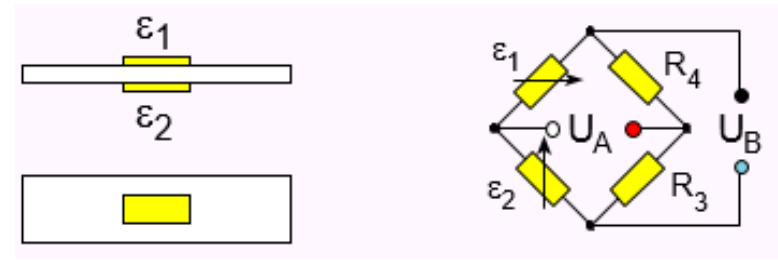

$\varepsilon=\varepsilon_{\mathrm{b}}=\frac{1}{2} \cdot \frac{4}{\mathrm{k}} \cdot \frac{\mathrm{U}_{\mathrm{A}}}{\mathrm{U}_{\mathrm{B}}}$
\begin{tabular}{|c|c|c|c|}
\hline $\mathrm{T}$ & $\mathrm{F}$ & $\mathrm{Mb}$ & $\mathrm{Md}$ \\
\hline 0 & 0 & 2 & 0 \\
\hline
\end{tabular}

Figura 38 - Meia ponte ativa - lados opostos - (+-)

A Figura 38 possui uma configuração interessante. Com meia ponte, sendo um extensômetro colocado na parte de cima e outro na parte de baixo, o resultado é um sistema com compensação de temperatura e da força normal, pois qualquer influência longitudinal é anulada entre os extensômetros que são vizinhos na ponte. Essa configuração é muito utilizada para deformações em barras engastadas.
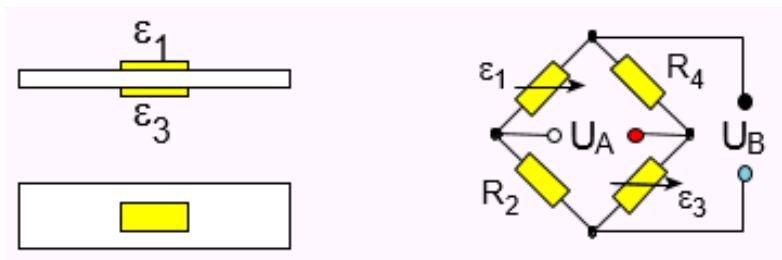

$\varepsilon=\varepsilon_{\mathrm{n}}=\frac{1}{2} \cdot \frac{4}{\mathrm{k}} \cdot \frac{\mathrm{U}_{\mathrm{A}}}{\mathrm{U}_{\mathrm{B}}}-\varepsilon_{\vartheta}$
\begin{tabular}{|c|c|c|c|}
\hline $\mathrm{T}$ & $\mathrm{F}$ & $\mathrm{Mb}$ & $\mathrm{Md}$ \\
\hline 2 & 2 & 0 & 0 \\
\hline
\end{tabular}

Figura 39 - Meia ponte ativa - lados opostos - (++)

A Figura 39 é uma configuração que sofre muita influência da temperatura, pois apesar dos extensômetros estarem em lados opostos na peça, na ponte eles também estão de lado opostos. Isso quer dizer que seus valores se somam. Sendo assim o Momento fletor será nulo e a força normal e a temperatura terão a sensibilidade duplicada quando comparado à Figura 36. 

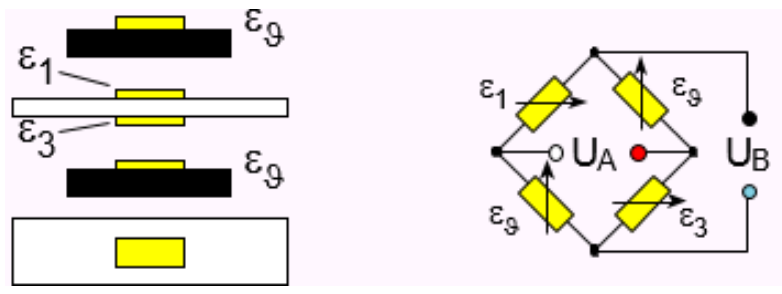

$\varepsilon=\varepsilon_{\mathrm{n}}=\frac{1}{2} \cdot \frac{4}{\mathrm{k}} \cdot \frac{\mathrm{U}_{\mathrm{A}}}{\mathrm{U}_{\mathrm{B}}}$
\begin{tabular}{|c|c|c|c|}
\hline $\mathrm{T}$ & $\mathrm{F}$ & $\mathrm{Mb}$ & $\mathrm{Md}$ \\
\hline 0 & 2 & 0 & 0 \\
\hline
\end{tabular}

Figura 40 - Ponte completa com dois Dummys - Força Normal

Para anular o efeito da temperatura da figura Figura 39, dois Extensômetros Dummys foram adicionados ao sistema. A configuração acima da Figura 40 tem um sensibilidade duplicada da força normal exercida.
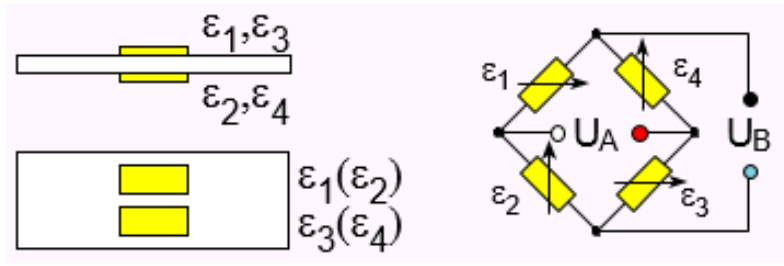

$\varepsilon=\varepsilon_{\mathrm{b}}=\frac{1}{4} \cdot \frac{4}{\mathrm{k}} \cdot \frac{\mathrm{U}_{\mathrm{A}}}{\mathrm{U}_{\mathrm{B}}}$
\begin{tabular}{|c|c|c|c|}
\hline $\mathrm{T}$ & $\mathrm{F}$ & $\mathrm{Mb}$ & $\mathrm{Md}$ \\
\hline 0 & 0 & 4 & 0 \\
\hline
\end{tabular}

Figura 41 - Ponte completa - Momento Fletor

A Figura 41 mostra um exemplo de configuração em ponte completa otimizado para momento fletor. Neste caso a sensibilidade é quadruplicada. É ideal para ler valores baixos de momento fletor, garantindo um sinal quatro vezes mais amplo. 


\subsection{Medição dinâmica da deformação da viga em flexão.}

A Figura 38 e a Figura 41, são configurações específicas para medir momento fletor com a temperatura sendo compensada através de strain gauges ativos. $A$ sensibilidade do sistema em ponte completa (4) é o dobro da sensibilidade no sistema em meia ponte (2), porém apesar do ganho ser interessante, o custo de strain gages dobra e nem sempre é possível inserir dois extensômetros de cada lado do sistema, seja por motivos econômicos ou geométricos da peça.

No início do trabalho, o sensor utilizava o sistema de 1/4 de ponte, que além de ter baixa sensibilidade, sofria com o efeito da temperatura. Para esse trabalho, vai-se usar o modelo em meia ponte que dobra a sensibilidade e tem a função de compensar o efeito da temperatura relacionado a expansão térmica da barra.

Considerando o sistema da Figura 38 tem-se que:

$$
\varepsilon=\varepsilon_{b}=\frac{1}{2} * \frac{4}{k} * \frac{U_{A}}{U_{B}}
$$

Geralmente tendo $k$ igual à 2 ,

$$
\varepsilon=\varepsilon_{b}=\frac{U_{A}}{U_{B}}
$$

Essa equação é a relação entre a deformação e a tensão medida pelo extensômetro na região da grade.

Para a medida da deformação dinâmica da viga em flexão $\varepsilon_{b}$ faz-se necessário obter os valores de $U_{A}$ e $U_{B}$. Em sistemas de aquisição em ponte que fazem uso de amplificadores, os valores lidos pelo usuário em volts, geralmente são os valores amplificados e para determinar o valor da tensão de entrada, é essencial conhecer a função de transferência da amplificação da tensão de entrada lida na ponte. Essa função será mostrada em 3.2.3.1. Após determinados, os valores da deformação podem ser calculados em algoritmos automaticamente e servirão para controlar a qualidade da produção dos sensores. 


\subsection{Medidas biológicas utilizando strain gauges}

Existem várias aplicações para medição de tensões em biomecânica ortopédica e biomateriais (LITTLE,FINLAY, 1992) e (DAVIS,ASM INTERNATIONAL., 2003) onde os strain gauges são implantados diretamente no osso ou através de pinos. Estas incluem testes e desenvolvimento de próteses e dispositivos implantáveis (Finlay et al., 1992; Hansenkam et al., 1994), determinação de propriedades mecânicas de estruturas biológicas (BOWMAN et al., 1996; DAVIS,ASM INTERNATIONAL., 2003), determinação da deformação de ossos durante atividades fisiológicas (PAGE et al., 1993), determinação de níveis de deformação que conduzem a uma resposta adaptativa e remodelação óssea e validam ou complementam simulações computacionais (LANYON,BAGGOTT, 1976). Embora existam vários técnicas de medição de esforço ósseo, tais como fotoelasticidade, interferometria, e análise de stress por termografia, o mais comum é a medida utilizando extensômetro de resistência elétrica (MILES,TANNER, 1992).

A utilização mais comum dos strain gauges in vitro, foi para se determinar a distribuição de tensões e stress em osso de cadáver, sob várias condições de carga e na avaliação de implantes. No entanto, é extremamente difícil simular com precisão cargas e esforços musculares em conjunto, durante atividades fisiológicas com equipamentos de teste mecânicos. Por esta razão, estudos in vitro de ossos inteiros de animais são muito menos comuns do que em estudos in vitro de ossos humanos inteiros.

Um dos desafios enfrentados na utilização de strain gauge in vivo é a determinação de um ponto zero de deformação, consistente. Visto que os ossos são sempre carregados por músculos em animais vivos, não sendo possível definir uma postura em que a carga no osso seja zero. Medidores podem ser utilizados para medir alterações na deformação em ossos, em relação a um ponto "zero" estabelecido durante uma atividade específica. 


\subsection{O Strain gauge e seu uso em biomecanismos}

Em 1944, Gurdjian e Lissner foram os primeiros a descrever o uso do strain gauge em osso vivo. O strain gauge foi colado com polimetilmetacrilato (PMMA), no crânio de um animal de teste anestesiado, onde foi coletada a medida da deformação do osso in vivo. No início deste estudo, o metacrilato levou 2 horas para sua cura completa, e neste caso o campo teve que ser mantido aberto devido à falta de impermeabilização.

A primeira revisão sobre técnicas de preparação e colagem de strain gauge, foram fornecidas por Roberts (1966). Ele descreveu várias maneiras de impermeabilização e colagem de strain gauge em ossos de animais vivos.

O primeiro a relatar o uso de strain gauges em seres humanos (embora tenha sido anexado a uma prótese e não diretamente ao osso) foi Rydell (1966). Neste estudo, strain gauges foram fixados a uma prótese femoral antes de ter sido implantada. A prótese instrumentada foi utilizada para determinar a força que agia sobre a cabeça femoral.

A prova de que o strain gauge colocado in vivo, poderia medir a fisiologia da deformação óssea, foi obtida quando foram correlacionados os dados obtidos por leituras apresentadas por acelerômetros e potencial elétrico. Um destes estudos mostra uma relação linear entre a carga na superfície do osso e sua deformação durante uma caminhada.

In vitro, strain gauges tem sido utilizados para medir a deformação de ossos desde as proximidades de 1950. Lambert relatou que sensores podem ser instalados diretamente à superfície do osso cortical úmido e descreve métodos de impermeabilização dos transdutores e fios. No estudo de Lambert, a deformação e capacidade de suportar peso da tíbia e perônio foram medidas (LAMBERT, 1971).

Por volta de 1979, grande interesse nas medições das deformações fisiológicas e avanços nos strain gauges e novas tecnologias para adesivos, levaram à proliferação de casos de medida de deformação em ossos. Procedimentos in vitro, foram utilizados para determinar o comportamento 
mecânico de ossos sob diversas condições de carregamento (GIES,CARTER, 1982).

Recentemente em nosso grupo de pesquisa em São Carlos (MASCARENHAS et al., 2012), foi desenvolvido um método de monitoramento minimamente invasivo (VILELA, 2010). O sistema é composto basicamente por um extensômetro, capaz de captar as variações das deformações ósseas decorrentes da variação da pressão intracraniana, um sistema eletrônico de aquisição de dados com módulo analógico digital, onde as informações são digitalizadas e enviadas ao computador para visualização e registro dos dados, como mostrado na Figura 42.

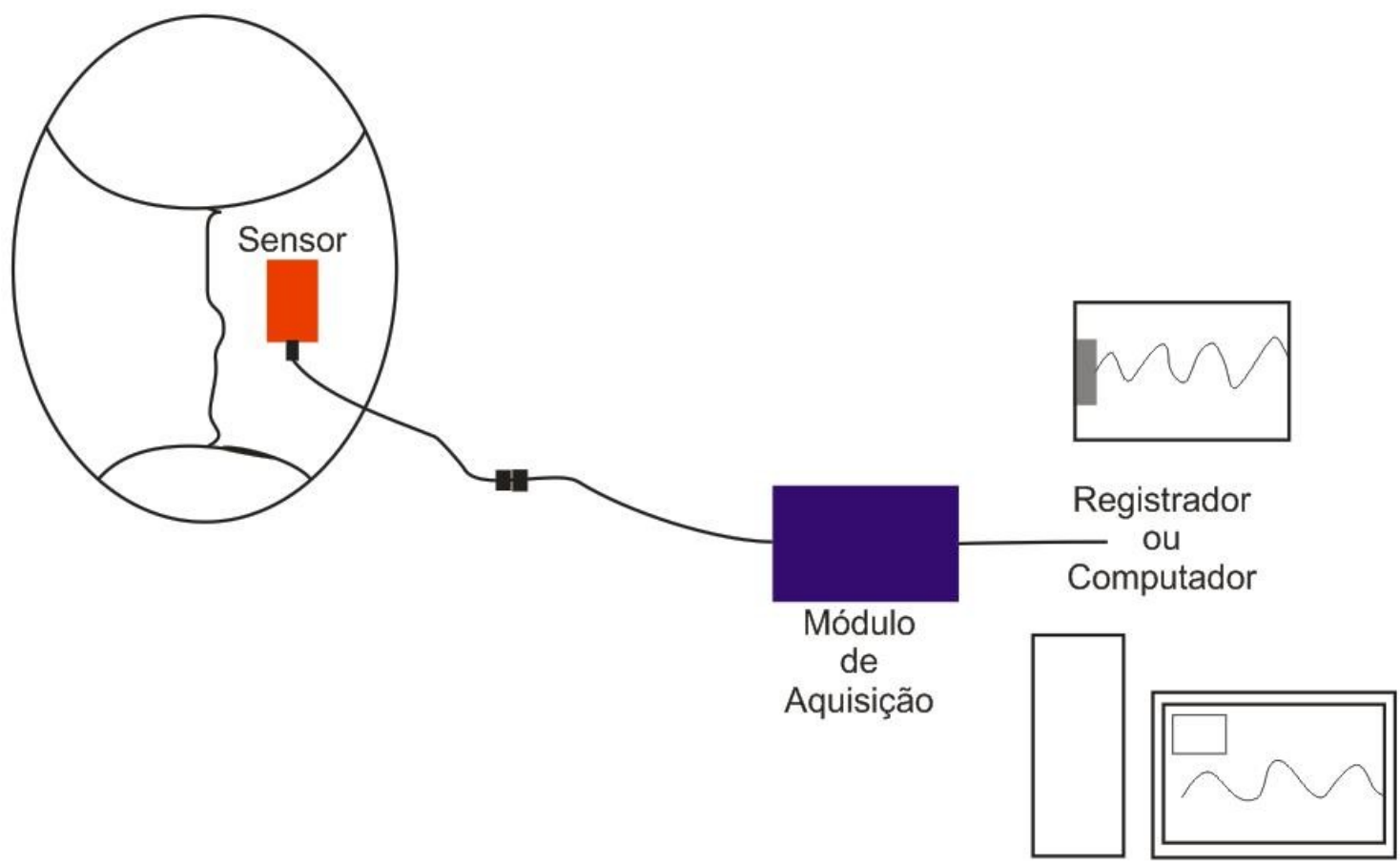

Figura 42 - Sistema Minimamente invasivo de monitoramento da PIC (VILELA, 2010) 


\section{Propostas de Método para monitorar a PIC}

O Sensor utilizado como tema nessa dissertação é um transdutor de expansão craniana à base de extensometria para monitoramento da pressão intracraniana. Para chegar à versão atual, trabalhos anteriores foram desenvolvidos.

O desbravador e inventor da ideia, Professor Sérgio Mascarenhas (OLIVEIRA, 2013), tem uma relação ímpar com sua invenção, pois a ideia surgiu justamente após o tratamento e recuperação de uma doença de difícil diagnóstico: A hidrocefalia de pressão normal (HPN).

A HPN é uma doença causada pela dificuldade do organismo de absorver o líquor cefalorraquidiano produzido em excesso. O Tratamento se faz pela implantação cirúrgica de uma válvula que leva o excesso do líquor da caixa craniana para a cavidade abdominal.

Os sintomas dessa doença se confundem bastante com as do Parkinson. A ressonância magnética por exemplo, pode ajudar a chegar ao real diagnóstico de HPN, no entanto, normalmente dispende-se muito tempo. O Tempo nesse caso é inimigo do paciente.

O método - existente no mercado - mais eficaz para medir e monitorar a PIC é através de um cateter inserido através de uma punção lombar. Um procedimento extremamente invasivo e aplicado somente em casos mais graves e/ou aparentes como mostrado na Tabela 1. Pensando nisso, inicialmente pensou-se em medir a expansão craniana e compara-la com a pressão intracraniana. Utilizou para isso um extensômetro, que colado no osso parietal de um crânio, foi capaz de medir a deformação enquanto um esfignomanômetro inflava uma bexiga dentro do crânio como mostra a Figura 43. 


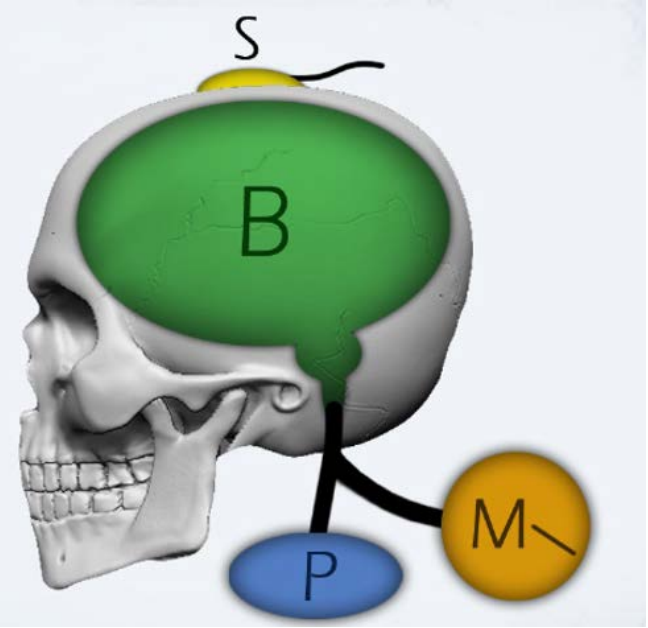

Figura 43 - Sistema para medir a deformação óssea. (MASCARENHAS et al., 2012)

A Figura 44 mostra o resultado gerado a partir desse experimento.

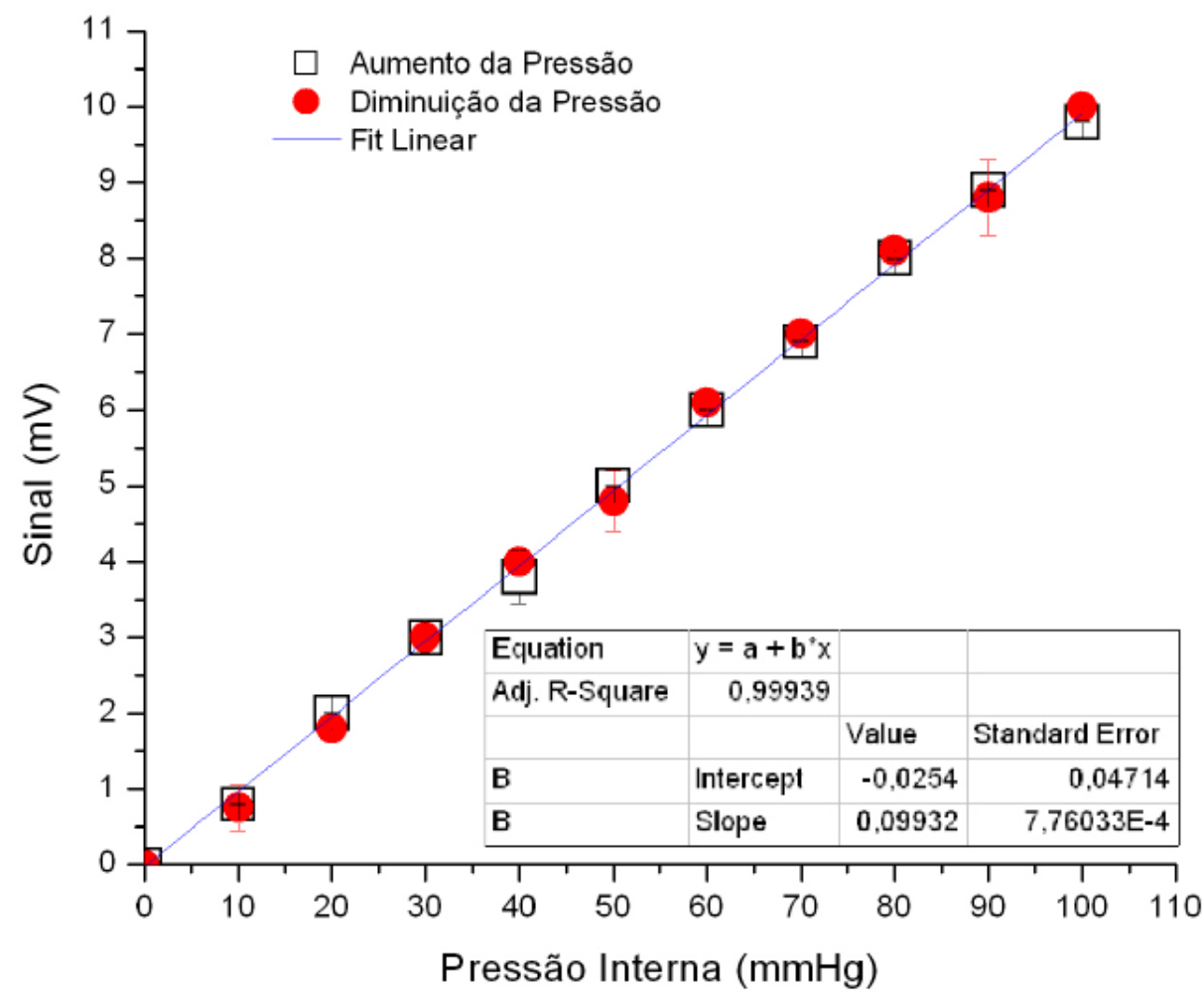

Figura 44 - Gráfico da relação entre expansão craniana $(\mathrm{mV})$ e pressão intracraniana $(\mathrm{mmHg})$ de um crânio específico. (MASCARENHAS et al., 2012) e (VILELA, 2010) 
Esse experimento foi importante para mostrar que o crânio de um humano adulto não é um compartimento inexpansível como pensava Alexander Monro (MONRO, 1783) e George Kellie de Leith. O gráfico da Figura 44 mostra uma boa linearidade entre a pressão interna e a expansão do crânio medida através de extensômetros.

Após esse experimento, o mesmo foi testado "in vivo" em ratos e coelhos (VILELA, 2010), realizando manobras posturais e simulando hidrocefalias com uso de solução salina $0,9 \%$ no canal raquiano nos camundongos e simulando tumores utilizando para isso uma bexiga com água inserida na região subdural do coelho. A Figura 45 mostra o resultado da simulação de hidrocefalia em ratos.

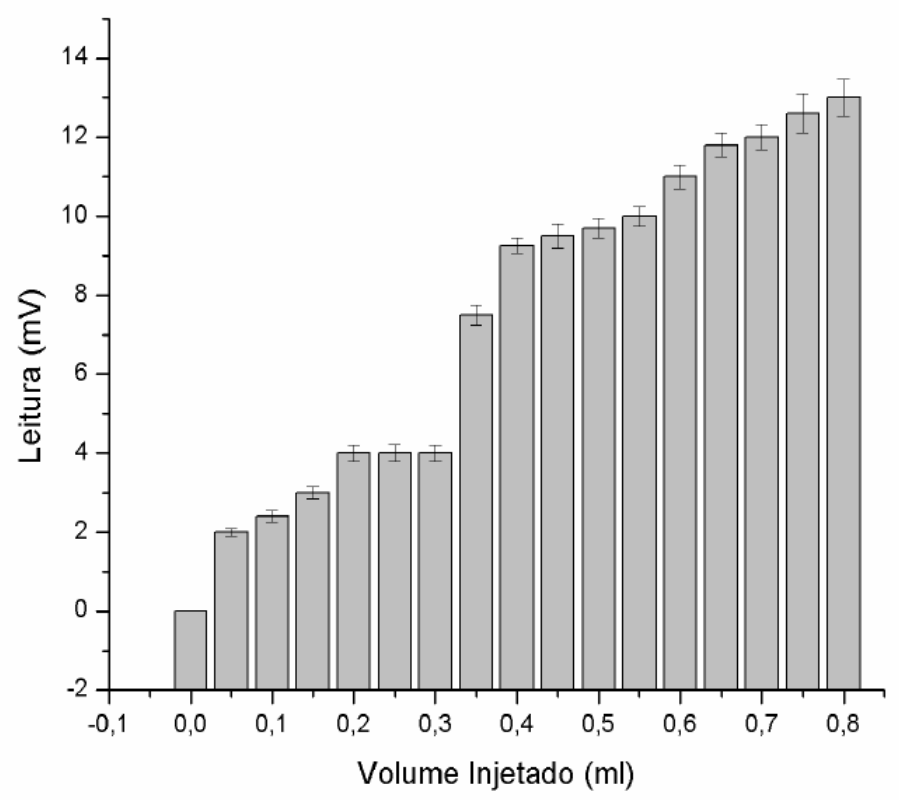

Figura 45 - Simulação de hidrocefalia em ratos Wistar através de injeção de solução salina $0.9 \%$ no canal raquial.(VILELA, 2010)

O primeiro protótipo de um sistema não invasivo desenvolvido pelo grupo liderado pelo Professor Sérgio Mascarenhas, surgiu em 2009. Chamado de Capecete ou Brain Helmet, consiste em um aparato estereotáxico, que objetiva a fixação e estabilidade da cabeça do paciente durante o monitoramento, um sensor de deformação (strain gauge) e um sistema de aquisição e digitalização dos dados, responsável por enviá-los ao computador. A Figura 46 ilustra a simulação de uso. 


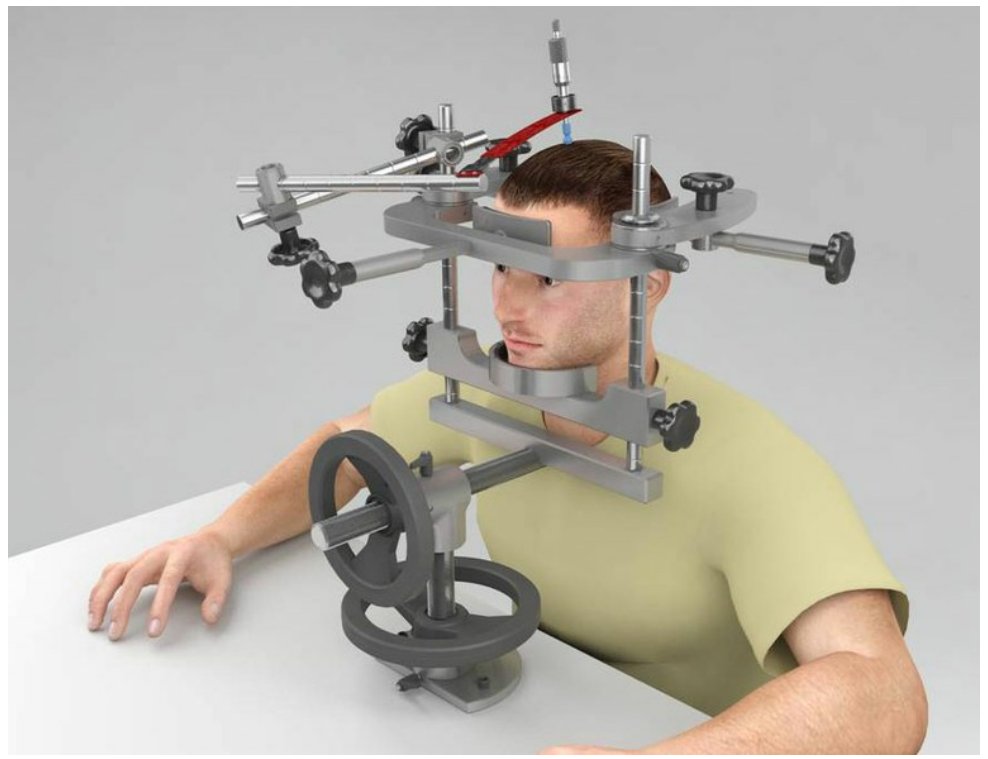

Figura 46 - Brain Helmet - Simulação de uso do primeiro protótipo desenvolvido pelo grupo em 2009 (VILELA, 2010).

O extensômetro está localizado na barra engastada destacada em vermelho posicionada na parte superior do equipamento.

O gráfico da Figura 47 mostra a aquisição do sinal de um voluntário fazendo uso do sistema Brain Helmet.

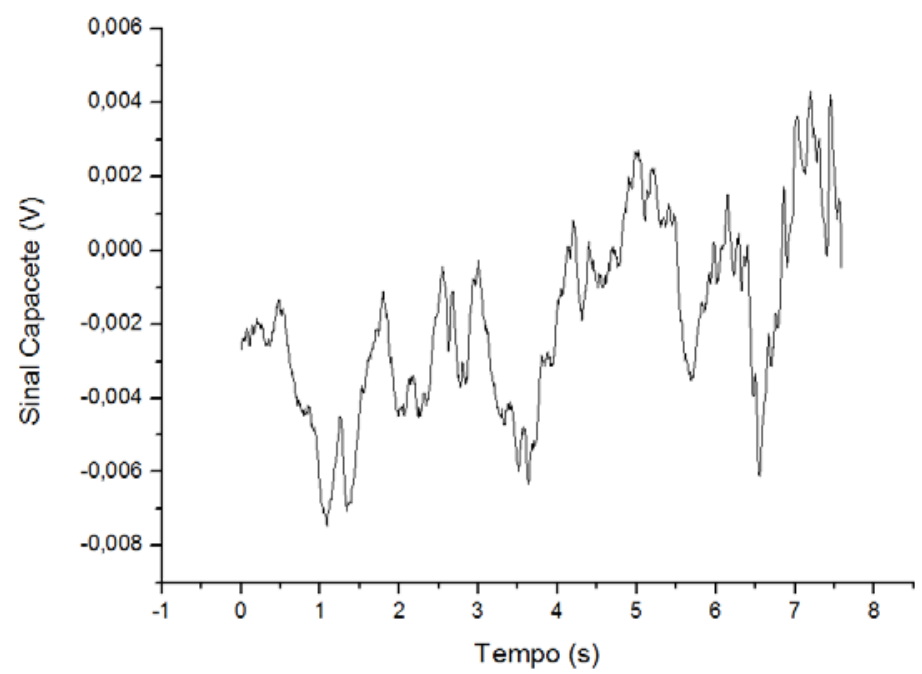

Figura 47 - Amostra do sinal captado pelo sensor Brain Helmet. 
A dificuldade em fazer com que os pacientes fiquem com a cabeça imóvel, trouxe problemas para a evolução do protótipo.

Em meados de 2011, o pesquisador Gustavo Vilela, auxiliado pelo professor Sérgio, inseriu uma mola com extensômetro acoplado no interior de um suporte circular e colocou na cabeça fixado com uma tira elástica. Através da aquisição dos dados obtidos pela deformação da mola, foi possível monitorar a PIC e pela primeira vez foi capaz de captar os batimentos cardíacos com mais clareza. A partir desse conceito, um protótipo em forma de uma caixa retangular utilizando uma tira elástica em torno do crânio foi construído.

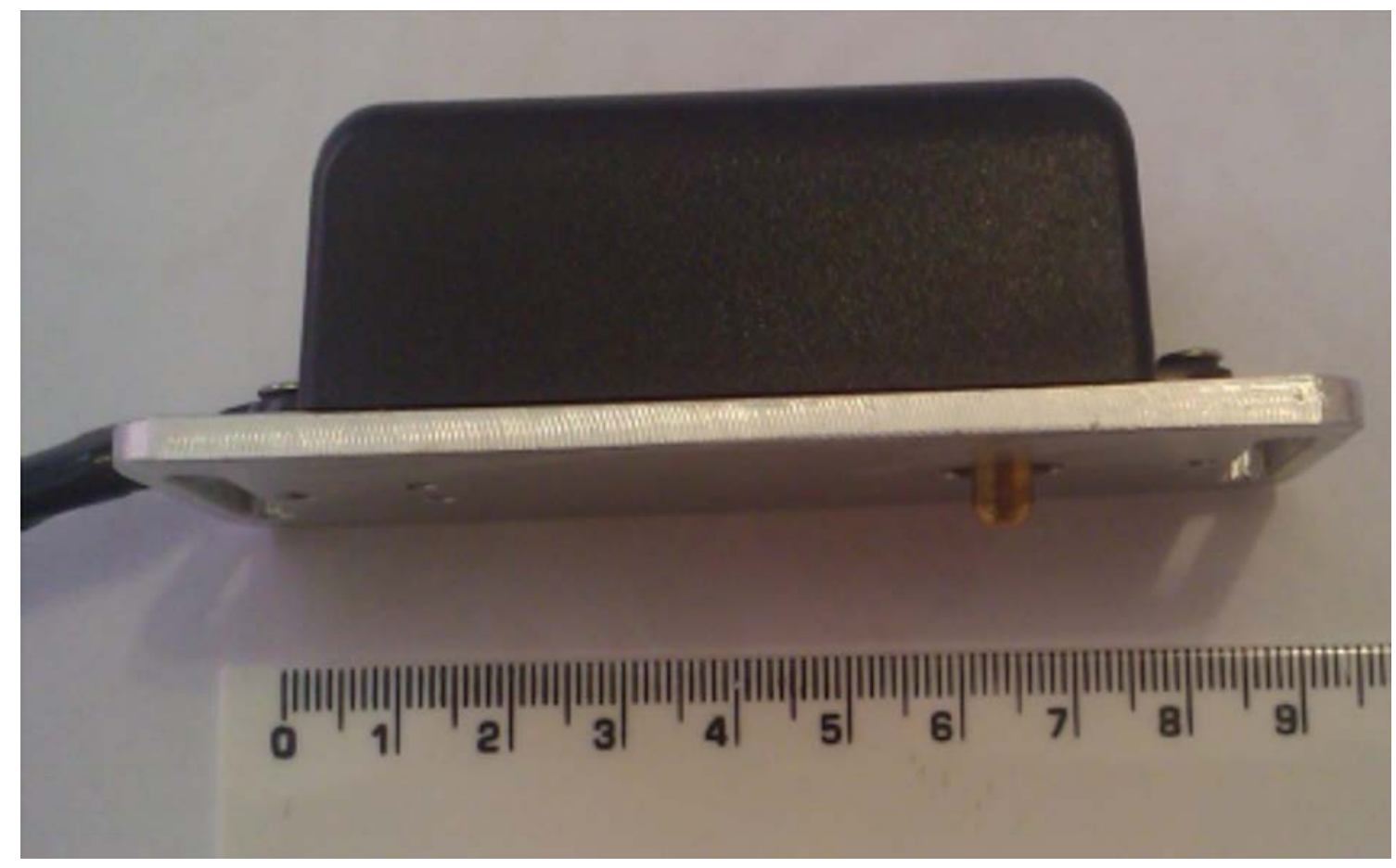

Figura 48 - Primeiro Sensor Brainstrap

Esse primeiro protótipo, fixado somente pela fita elástica em volta da cabeça, batizado de Brainstrap (Figura 48) foi construído sendo uma barra engastada com concentração de tensão, protegida por uma caixa retangular com um furo por onde passa um pino localizado na ponta dessa haste engastada. Esse pino entra em contato com o couro cabeludo na região parietal do crânio, que resulta na flexão da haste, que é sensível a deformações. A Figura 49 mostra o Brainstrap posicionado na cabeça. 


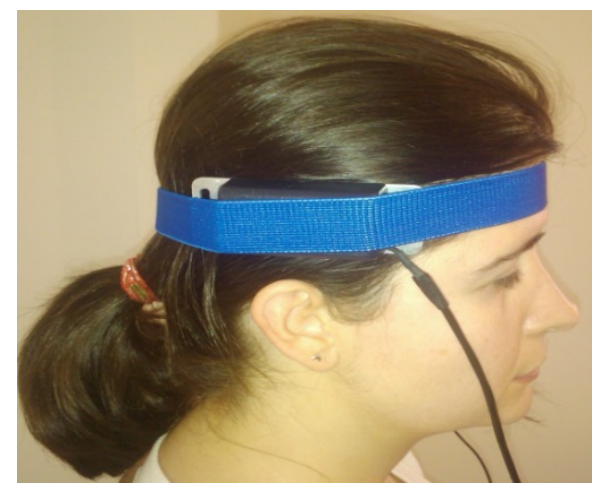

Figura 49 - Posicionamento do sensor Brainstrap na cabeça

A haste do Brainstrap capta (através do strain gauge) as movimentações (vibrações) do crânio com melhor sensibilidade quando comparado ao Brain Helmet. Um dos motivos para essa melhor sensibilidade se deve ao fato do novo protótipo estar fixo somente na cabeça do paciente, sem estar preso a uma mesa. O sensor utilizado nesse trabalho como base para estudo e melhorias, inicia-se do sensor Brainstrap citado acima. A barra sensora inicial, contendo o engaste, extensômetro e a ponta amarela que toca o couro cabeludo, são mostrados na Figura 50.

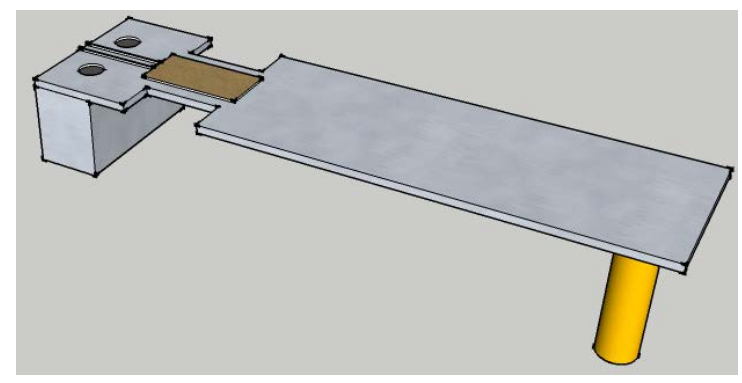

Figura 50 - Esquema simplificado da primeira barra sensora (marrom - extensômetro; amarelo - ponta que toca o couro cabeludo) desenvolvida pelo grupo.

O sensor é posicionado no interior de uma caixa e preso por meio de uma fita elástica na cabeça do paciente. A barra com extensômetro dentro da caixa é mostrada na Figura 51. 


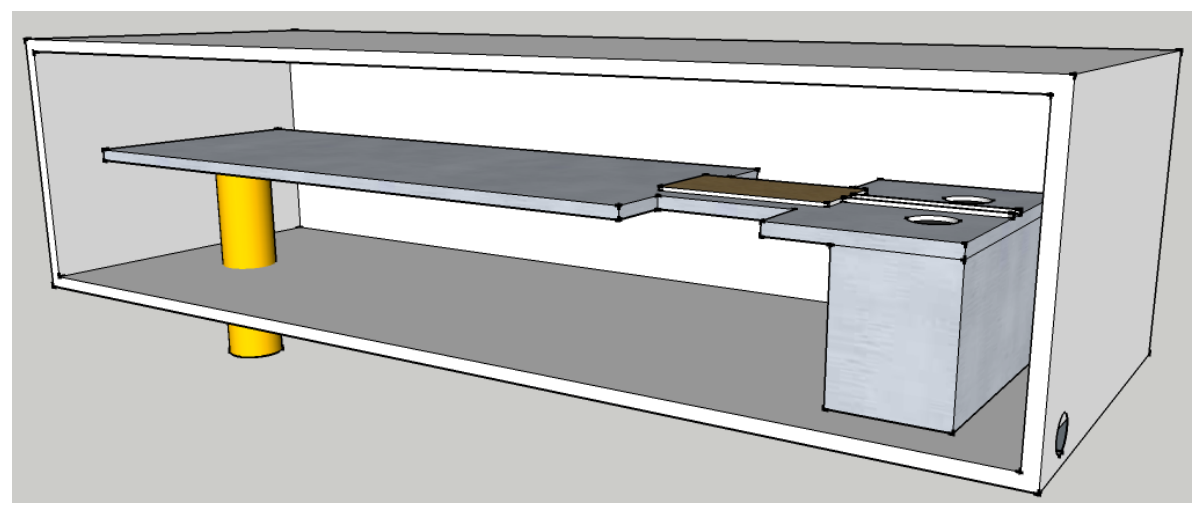

Figura 51 - Sensor montado no interior da caixa que irá receberá faixa elástica para ser posicionada na cabeça do paciente.

Inicialmente o metal utilizado como haste para sofrer deformações era um aço com alto módulo de elasticidade e suas dimensões foram feitas sem um projeto específico da função de transferência entre a deformação da haste e o sinal elétrico captado. A haste era composta por um único strain gauge localizado em uma concentração de tensão não eficiente. O resultado era um protótipo com baixa sensibilidade. Apesar de ter melhorado visivelmente com relação ao Brain Helmet, o sinal ainda era pouco sensível e poderia ser melhorado. O Capítulo 3.1 evidenciará os problemas e apresentará as melhorias propostas.

\subsection{Análise e melhoria do sensor de expansão craniana à base de extensometria}

O método ideal para o monitoramento da PIC é aquele capaz de fornecer dados contínuos do valor da pressão intracraniana do paciente, uma vez que desta forma, além dos valores quantitativos é possível monitorar o aspecto morfológico da curva da PIC.

“Mede o que é mensurável e torna mensurável o que não é." Galileu Galilei

A extensometria foi escolhida para transduzir a expansão craniana como princípio de monitoramento da pressão intracraniana. A escolha do extensômetro se deu pelo trabalho anterior (MASCARENHAS et al., 2012), 
citado no início do capítulo 3, onde a PIC foi monitorada de forma minimamente invasiva com sucesso.

A facilidade e experiência dos pesquisadores em trabalhar com strain gauges adquirida nesse trabalho foi essencial para a escolha inicial, e a ideia tem se mostrado bastante promissora, por isso foi decidido pelo uso de strain gauges ao invés de outros sensores como piezoelétricos, LVDT dentre outros. Entretanto, desenvolver um sistema à base de extensometria que transduza um pequeno sinal para monitoramento médico é muito desafiador. Problemas de ruído, efeitos indesejados da temperatura, baixa sensibilidade, interferência eletromagnética e outros problemas são características comuns em desenvolvimentos de novos sensores, porém a área de extensometria é muito utilizada em sistemas de precisão e é uma tecnologia muito aplicada inclusive em sensores de pressão invasivos e a maioria de seus problemas possui solução existente.

Após a revisão da literatura sobre mecânica dos materiais e extensômetros, viuse que o sensor poderia ter uma melhora na sensibilidade sem alterar drasticamente o design da ferramenta. Os seguintes problemas foram percebidos no sensor Brainstrap antigo:

- A configuração de ponte utilizada era do tipo $1 / 4$ de ponte, o que além de sofrer um maior efeito da temperatura possuía baixa sensibilidade.

- O entalhe onde o strain gauge é colado era retangular, o que resultava em uma da concentração de tensão mais acentuada nas bordas do entalhe (PETERSON, 1974).

- O Metal utilizado era um aço 1020 galvanizado que possui um alto módulo de elasticidade (próximo a 200GPa)(MATWEB, 2013).

- Os outros $3 / 4$ de ponte estavam localizados dentro do equipamento, o que poderia descompensar a ponte com a resistência do cabo. Além disso o cabo não era blindado e estava vulnerável à interferências de diversos tipos.

As melhorias do sensor vieram pelas seguintes mudanças: 
A configuração da ponte passou a ser do tipo $1 / 2$ ponte ativa, de acordo com a Figura 38, dobrou a sensibilidade quando comparado ao sistema inicial de $1 / 4 \mathrm{de}$ ponte, semelhante ao da Figura 36.

O Material da barra engastada que sofre flexão foi substituído. Para aumentar a sensibilidade era necessário buscar um material que tivesse um módulo de elasticidade inferior sem perder o limite de escoamento. Testes de uso foram realizados com alumínio 1100, porém o limite de escoamento (Yield Stress) desse material é muito baixo (25MPa), o que fazia com que a barra se deformasse plasticamente com pequenas deformações. Recentemente foram obtidas amostras de um alumínio aeronáutico (Al2024-T3 - 0,016") que possui tensão de escoamento bem superior ao Al1100 (270MPa x 25MPa) ${ }^{3}$.

Com relação à geometria da barra engastada, algumas melhorias podem ser realizadas, porém, antes é necessário utilizar os conceitos de tensão e flexão do capítulo 2.3 para chegar-se a uma equação ideal da relação entre a deformação medida pelos extensômetros e a deflexão da ponta da barra.

Considerando um modelo ideal onde a base da barra sensora esteja engastada no crânio, a deflexão que ocorre na barra é devida a uma força de reação transmitida pelo pino de contato com o crânio. Essa força de reação é imposta pela variação de pressão intracraniana que por sua vez tende a deformar o crânio aumentando ou diminuindo seu volume, podendo ser aproximado, a título de ilustração, a um vaso de pressão esférico. A própria caixa craniana auxilia a manutenção da pressão interna exercendo reação a essa pressão, porém como todo material elástico, o crânio tende a expandir e essa expansão é vista pelo sensor engastado em um ponto do crânio como uma força de reação através da flexão da barra. Julgando que a força de reação exercida no pino do sensor desenvolvido seja inferior à força exercida pela pressão interna do crânio, a deflexão do sensor será comandada pelo deslocamento do crânio no ponto de contato com o pino em relação ao engaste.

\footnotetext{
${ }^{3}$ De acordo com a base de dados de propriedades dos materiais, MatWeb.com, para os materiais "Aluminum 1100" e "Aluminum 2024-T3" (MATWEB, 2013).
} 
Com essa idealização, a geometria da barra sensora será analisada para alcançar uma maior amplificação da deformação medida pelos extensômetros de acordo com a força aplicada no sensor. Além disso será calculada a deflexão máxima permitida para evitar deformações plásticas na barra sensora.

Portanto relembrando as equações da tensão nominal da chapa (Figura 17),

$$
\sigma_{n o m}=\frac{6 M}{h^{2} d}
$$

e da deflexão da chapa (Figura 18),

$$
v_{A}=\frac{4 P L^{3}}{E d h^{3}}
$$

Sendo $M=P x$ e tendo como termo comum da igualdade a força $P$ de reação exercida, tem-se:

$$
\sigma_{\text {nom }}=\frac{6 P x}{h^{2} d}
$$

Onde,

$v_{A}=$ deflexão da barra sensora;

$E$ = módulo de young;

$h=$ espessura da chapa;

$x$ = distância entre o ponto de tensão desejado e a base do pino do sensor; $L=$ distância do engaste até a base do pino.

As equação acima auxiliam no design da geometria da barra sensora, pois mesmo que essa equação seja uma aproximação ideal sem considerar a concentração de tensões, ela mostra a relação direta ou inversa de cada uma das variáveis em relação à tensão nominal do ponto desejado e em relação ao limite de escoamento do material para garantir o regime elástico. Além disso, como mostrado no capítulo 2.3, a concentração de tensão pode amplificar 
(dependendo do design do entalhe) em até 3 vezes a tensão nominal daquele ponto.

Melhorias na geometria

A princípio, o momento fletor $\mathrm{M}$ foi mantido constante, ou seja, o comprimento da barra e a distância $x$ entre o ponto de aplicação da força e o local onde o extensômetro foi colado permaneceu constante $(40 \mathrm{~mm})$. O valor foi mantido depois de alguns testes iniciais que mostraram que o sensor perdeu sensibilidade quando o comprimento da barra foi alterado. Faz-se necessário uma modelagem mais robusta do sensor em diferentes formatos de crânio comparando a distância $x$ com a diferença de deformação e deslocamento do crânio e analisar o efeito de resistência que a fita elástica exerce mantendo o sensor pressionado.

A primeira alteração adotada na geometria foi a diminuição da espessura "h" da barra de $0.6 \mathrm{~mm}$ para $0.4 \mathrm{~mm}$, que ao ser aplicado na teoria pela fórmula da tensão nominal gera uma amplificação cerca de $125 \%$ da tensão para a mesma força exercida. A largura "d" da barra teve seu valor regrado pela largura do extensômetro, que nesse caso é de 5 milímetros. Vale ressaltar que o valor da largura utilizado é a largura entre os entalhes, como mostrado na Figura 17.

A deflexão máxima da barra sensora no limite da região elástica é relacionada com o limite de escoamento $(270 \mathrm{MPa})$ do material. Entretanto a fómula de deflexão não pode ser utilizada para obter valores reais ou próximos da deflexão máxima pois a concentração de tensão não está contemplada na equação e o gráfico da Figura 17 não mostra a concentração de tensão para o entalhe semicircular. Por isso é necessário simular o comportamento da barra sensora em Elementos Finitos para aproximar do valor da deflexão máxima. As simulações estão contempladas nos Resultados.

O strain gauge foi selecionado de acordo com os critérios de seleção da Tabela 2. Foi selecionado um modelo uniaxial linear de $350 \Omega$ com coeficiente de expansão térmica própria para alumínio $\left(\alpha=23 * 10^{-6} / K\right.$, de acordo com a Tabela 3). Seu gage factor é de aproximadamente 2 , valor mais comum encontrado para strain gauges. 


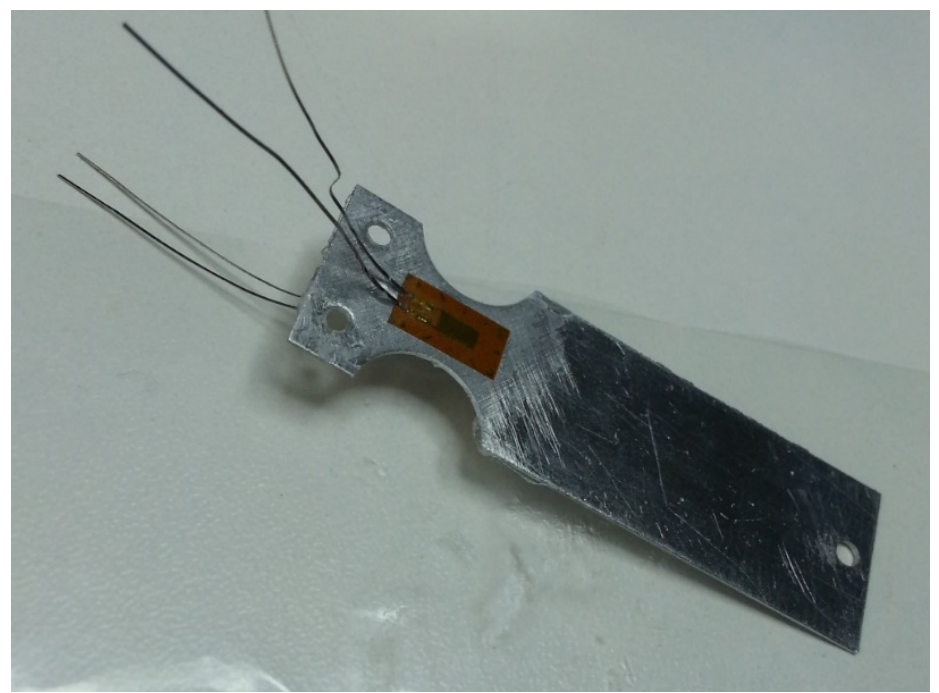

Figura 52 - Nova barra sensora

A Figura 52 mostra a imagem da nova barra sensora com os extensômetros já colados.

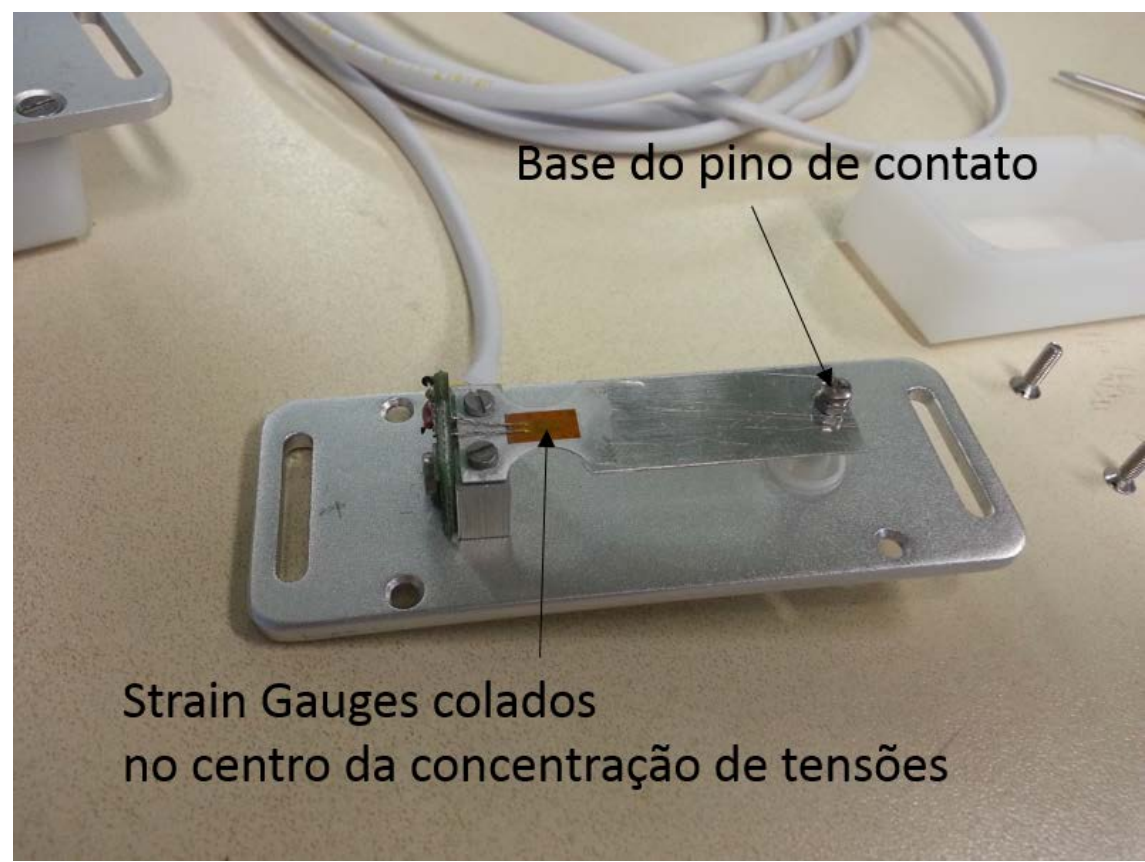

Figura 53 - Visão interna do sensor

A Figura 53 exibe a visão interna da caixa do sensor. Nela é possível ver a base do pino de contato e a concentração de tensão onde os extensômetros são colados. Já na Figura 54 é possível ver a base inferior do sensor com as frestas para a fixação da fita, a tampa de proteção do sensor e o cabo blindado. 


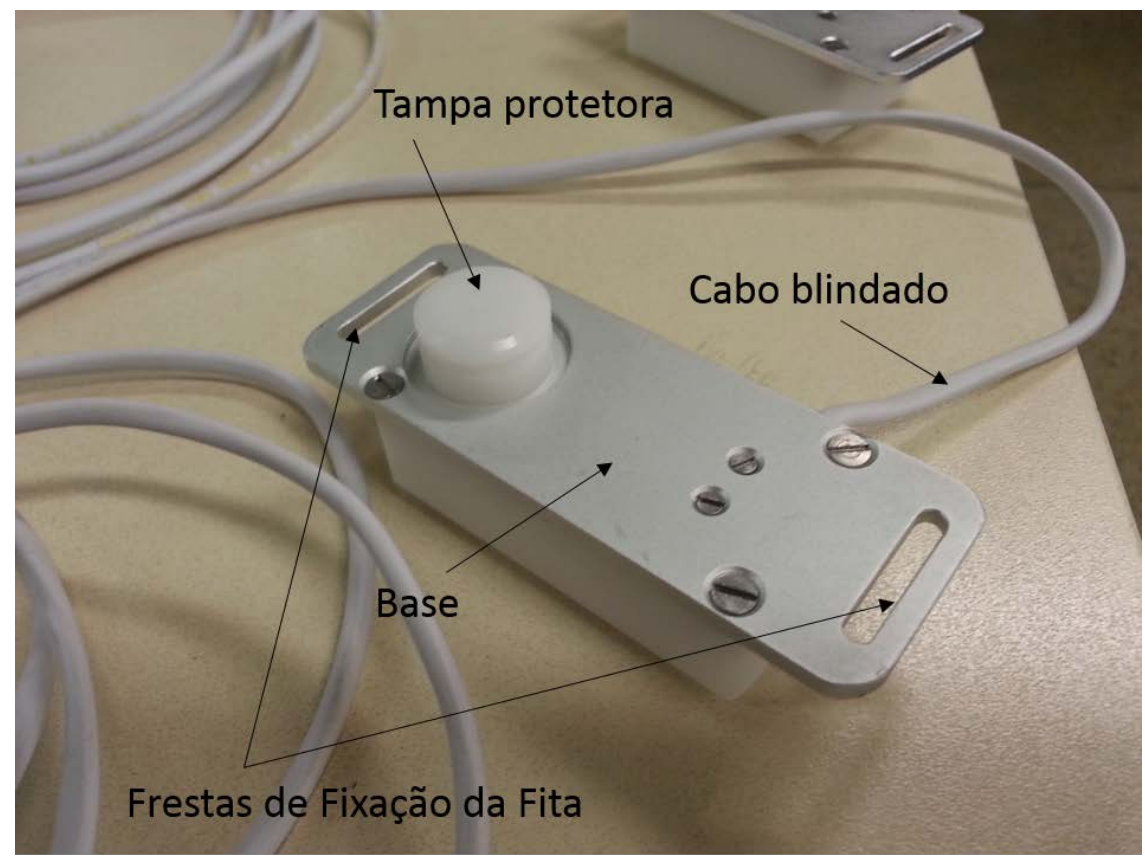

Figura 54 - Base inferior do sensor 


\subsection{Sistema de aquisição e condicionamento dos sinais}

\subsubsection{Sistema antigo}

O Sistema de aquisição e condicionamento de sinais é o equipamento responsável por receber os sinais dos sensores, e exibi-los ao usuário. O sistema antigo possuía apenas um canal e era composto de caixa com fonte de tensão comum, placa de circuito impresso com dois amplificadores operacionais em cascata com ganho fixo ajustados por trimpots (potenciômetros em miniatura ajustáveis) internos, offset ajustado por potenciômetro externo e uma placa de aquisição ethernet com software de aquisição limitado.

Esse sistema se mostrou instável, sofrendo interferências e oscilações em aquisições de longa duração, além do ruído intrínseco ao sistema, que devido à baixa sensibilidade do sensor caracterizava uma baixa relação sinal-ruído. Um novo projeto de um equipamento adequado para auxiliar no desenvolvimento do sensor era uma grande necessidade do grupo.

O sistema foi proposto a partir de uma ideia inicial e vem passando por diversas modificações de acordo com o desenvolvimento do sensor, opinião de médicos e cientistas e as fases intrínsecas do desenvolvimento de um produto.

\subsubsection{O Sistema atual}

O Sistema atual de monitoramento não invasivo da pressão intracraniana (codinome MONA versão 1.5) tem por base um equipamento protótipo amplificador de ponte extensiométrica com ganho programável, utilizando fonte de tensão padrão médico, com módulo de aquisição de dados e suporte a armazenamento dos sinais lidos. A Interface Homem Máquina (IHM) precisa ser simples e agradável e é advinda de uma tela com a exibição dos sinais capturados de até dois sensores por equipamento. 


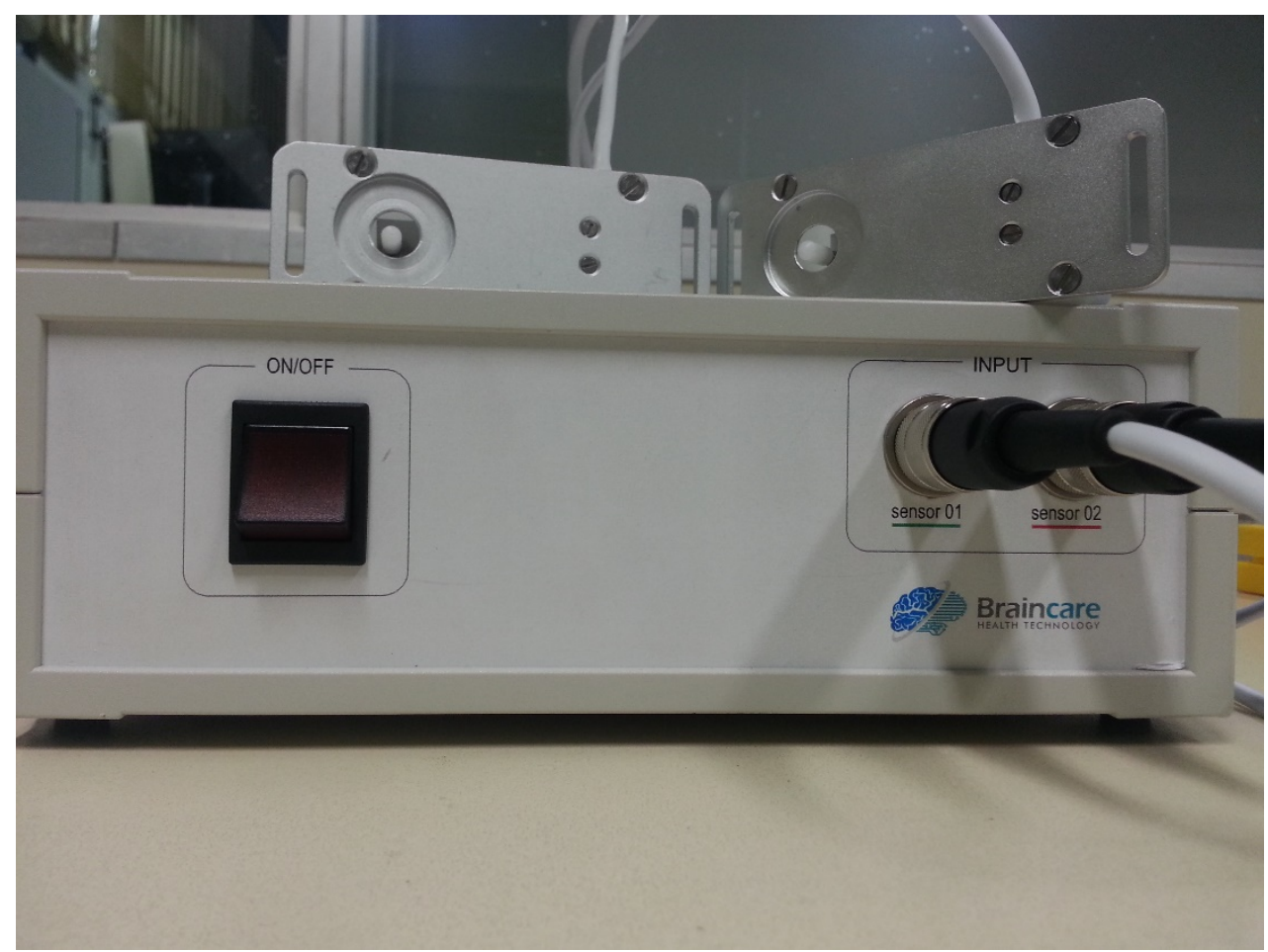

Figura 55 - Sistema atual de monitoramento da PIC - Hardware e Sensores.

Como se trata de um desenvolvimento de produto, o sistema passa por diversas modificações e evoluções afim de validar os componentes eletro-eletrônicos utilizados e buscar a melhor solução de design do sensor a base de strain gauge atendendo aos requisitos médicos e da Anvisa (Agência Nacional de Vigilância Sanitária).

O desenvolvimento de um produto médico necessita atender diversas normas da Anvisa para ser comercializado. Os equipamentos médicos sob regime de Vigilância Sanitária compreendem todos os equipamentos de uso em saúde com finalidade médica, odontológica, laboratorial ou fisioterápica, utilizados direta ou indiretamente para diagnóstico, terapia, reabilitação ou monitorização de seres humanos e, ainda, os com finalidade de embelezamento e estética. Conforme estabelecido no art. 12 da Lei $n^{\circ}$ 6.360, de 23 de setembro de 1976, nenhum produto de interesse à saúde, seja nacional ou importado, poderá ser industrializado, exposto à venda ou entregue ao consumo no mercado 
brasileiro antes de registrado no Ministério da Saúde (OLIVEIRA,PIRES, 2010).

\subsubsection{Descrição do sistema atual}

3.2.3.1Amplificador de ganho programável - PGA309

A amplificação do sinal lido da ponte de wheatstone é feita por um circuito integrado chamado PGA309 da Texas InstrumentS ${ }_{\circledast}$.

O PGA309 é um condicionador (amplificador) de sinal analógico programável e inteligente projetado para aplicações de sensores com ponte resistiva. É um condicionador de sinal completo com excitação da ponte, ajuste de span e offset. Possui a característica de compensar o efeito da temperatura através de curvas de calibração utilizando para isso a medição de temperatura interna ou externamente ao chip.

O PGA309 possui três blocos principais de ganho para um melhor dimensionamento da entrada para o sensor em ponte. O Primeiro bloco, chamado de Front-End contém o maior seleção de ganho para permitir uma relação sinal -ruído mais elevada, aplicando o maior ganho na parte da frente da cadeia de sinal, antes da adição de outras fontes de ruídos. A seleção de ganho do Front-End PGA tem oito configurações de ganho (4, 8, 16, 23.27, 32, 42.67, 64 , e 128). 


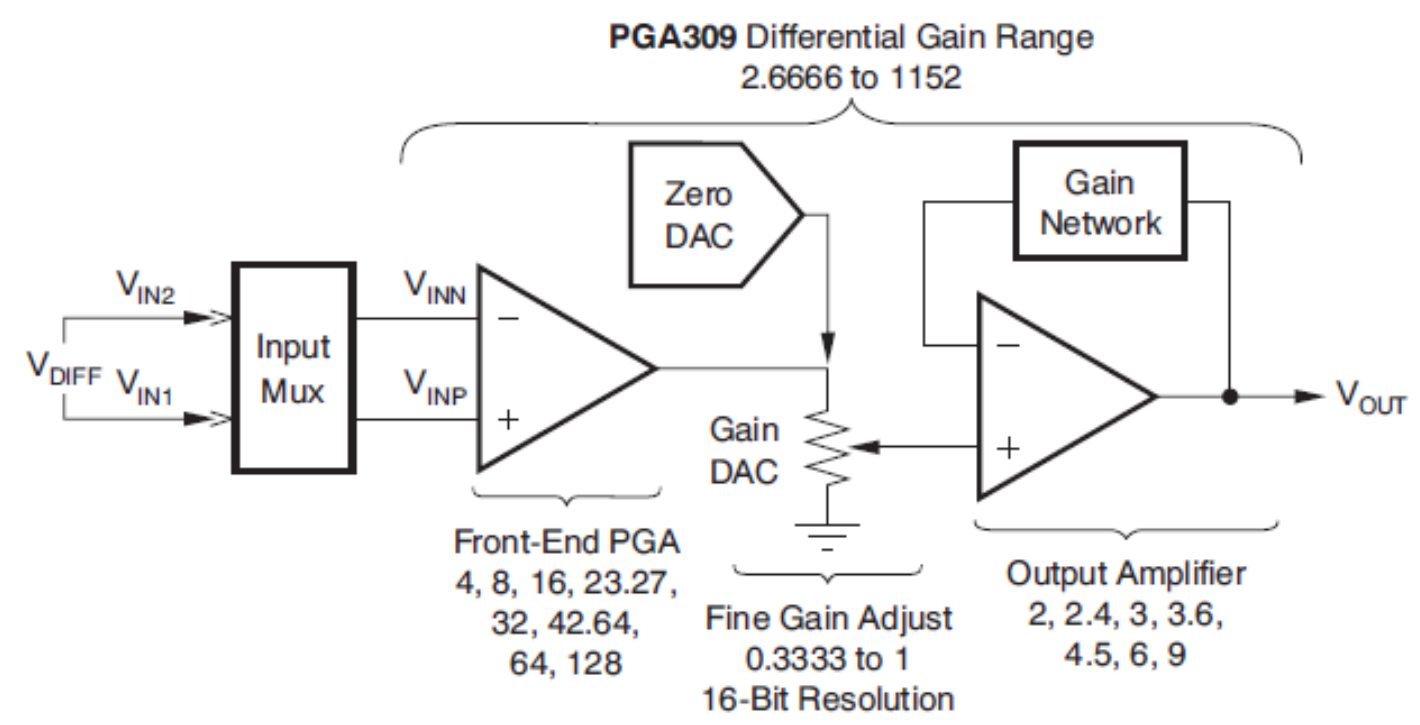

Figura 56 - Bloco de ganhos da PGA309

O Front-End PGA é seguido de um ganho DAC. O Ajuste fino é controlado por um DAC de resolução de 16 bits, sendo ajustado de 0.3333 até 1 . Por último o sinal é amplificado mais uma vez pelo amplificador de saída, que internamente possui uma seleção de sete ganhos possíveis $(2,2.4,3,3.6,4.5,6$ ou 9). O amplificador de saída também possui a opção de desabilitar o ganho interno citado acima e permitir resistores externos fornecidos pelo usuário para selecionar o seu ganho.

Os ganhos dos blocos combinados permite um ganho de $2.666 \mathrm{com} 400 \mathrm{kHz}$ de largura de banda, até 1152 com largura de banda de $60 \mathrm{kHz}$.

Descrição Funcional

$$
V_{\text {OUT }}=\left[\left(\operatorname{mux}_{\text {sign }} * V_{I N}+V_{\text {Coarse offset }}\right) * G I+V_{\text {Zero DAC }}\right] * G D * G O
$$

Onde:

mux $_{\text {sign }}$ : Permite a mudança de polaridade do sinal para sensores sem polaridade predefinida; \pm 1 .

$V_{I N}:$ Sinal de entrada da PGA309;

$V_{\text {Coarse offset }}$ : Ajuste grosso de Offset do DAC; 
GI : Ganho de Front-End;

$V_{\text {Zero DAC }}:$ Ajuste fino da saída de tensão DAC ;

GD : Ganho DAC;

GO : Ganho do Amplificador de saída.

O ajuste grosso de offset ( $V_{\text {Coarse offset }}$ ) é implementado antes do ganho do amplificador de entrada (Fron-End PGA gain) para permitir um range mais dinâmico, pois alguns sensores em ponte possuem um offset inicial muito alto, próximo ao limite de escala. Esse ajuste grosso pode ser positivo ou negativo e é implementado por um DAC de 4 bits + sinal, contendo 14 seleções positivas, 14 seleções negativas e o zero. Para uma tensão de referência de $5 \mathrm{~V}$ o ajuste grosso vai de 0 à $\pm 59,5 \mathrm{mV}$ em passos de $4,25 \mathrm{mV}$.

O ajuste fino é dado pelo Zero DAC $\left(V_{\text {Zero DAC }}\right)$. Ele é unipolar, possui 16 bits de resolução, varia entre $2 \%$ e $98 \%$ da tensão de referência e é amplificado pelo ganho DAC $(G D)$ e pelo Amplificador de saída $(G O)$ resultando no valor mínimo de saída da PGA.

A calibração da função de transferência da amplificação do sinal de entrada pode ser feita via software, aumentando a confiabilidade do sistema.

A PGA309 possui também um sistema de medição da temperatura para compensação térmica e um circuito de linearização para pontes não lineares. Entretanto não foi abordado nesse trabalho a compensação térmica realizada pela PGA309, pois esse recurso ainda não foi implementado na fase atual do projeto.

A Fabricante da PGA309, Texas InstrumentS ${ }_{\circledast}$, comercializa a placa de desenvolvimento da PGA, que possui um software desenvolvido em LabVIEW ${ }_{\circledast}$ com os ajustes todos de fácil acesso para o desenvolvedor. Essa placa está sendo utilizada no projeto atual, afim de validar o uso do amplificador no nosso sistema sem se preocupar inicialmente com o design da eletrônica. 


\subsubsection{Aquisição Analógica}

A aquisição analógica utilizada atualmente para receber o sinal do PGA309 é o modelo USB6008 da NI. Com 12 bits de resolução e permitindo executar a leitura de até 10000 amostras por segundo, essa placa foi escolhida por ser compatível de forma nativa ao software de aquisição e por seu baixo custo no mercado quando comparado a outras soluções OEM USB.

\subsubsection{Software Braincare}

O Software desenvolvido para análise do sinal de monitoramento da pressão intracraniana, começou a ser desenvolvido em 2011. O LabVIEW ${ }_{\circledast}$ foi escolhido como ferramenta de desenvolvimento pela sua robustez e praticidade em desenvolver desde aplicações simples de aquisição analógica, como sistemas mais complexos com FFTs (Fast Fourier Transform), filtros e algoritmos para auxiliar na interpretação do sinal aquisitado.

A tela de leitura do primeiro software desenvolvido para o sensor não invasivo é mostrado na Figura 57. Nele é possível executar a leitura de até dois sensores (sensor não invasivo do lado esquerdo e do lado direito). Os sinais aquisitados são tratados e através de algoritmos baseados em filtros e transformadas rápidas de Fourier (FFTs) é possível ler o comportamento e a frequência cardíaca e respiratória além do monitoramento da PIC em cada um dos sensores. 


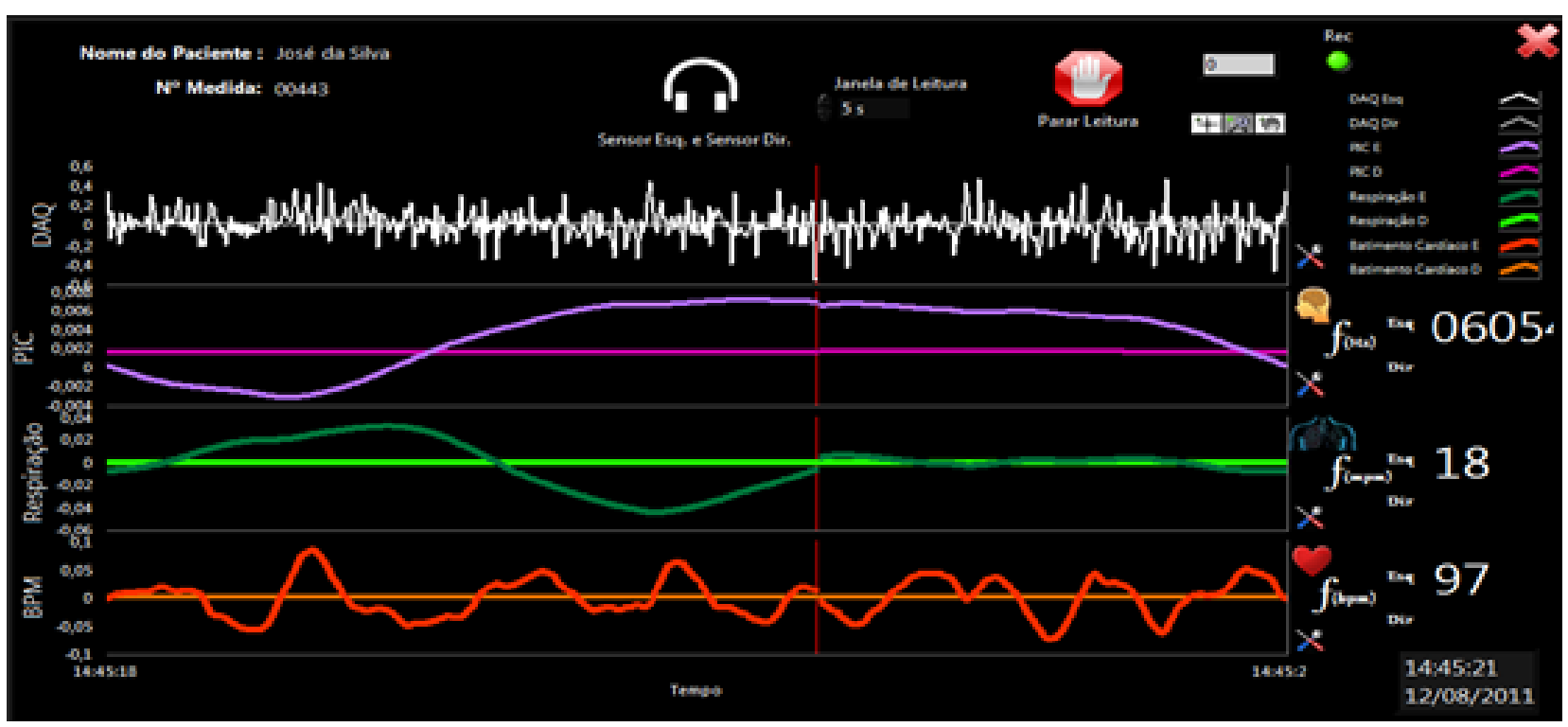

Figura 57 - Software Braincare v1.0 (DAQ - Sinal Bruto; PIC - Sinal da Pressão Intracraniana; Respiração - Avaliação da frequência respiratória; BPM - Frequência cardíaca).

A Figura 58 mostra, a título de ilustração, o algoritmo de filtros do sinal lido pelos sensores não invasivos. Aqui são executados os filtros responsáveis por exibir os sinais da PIC, Respiração e Batimento Cardíaco capturados dos sensores não invasivos. 


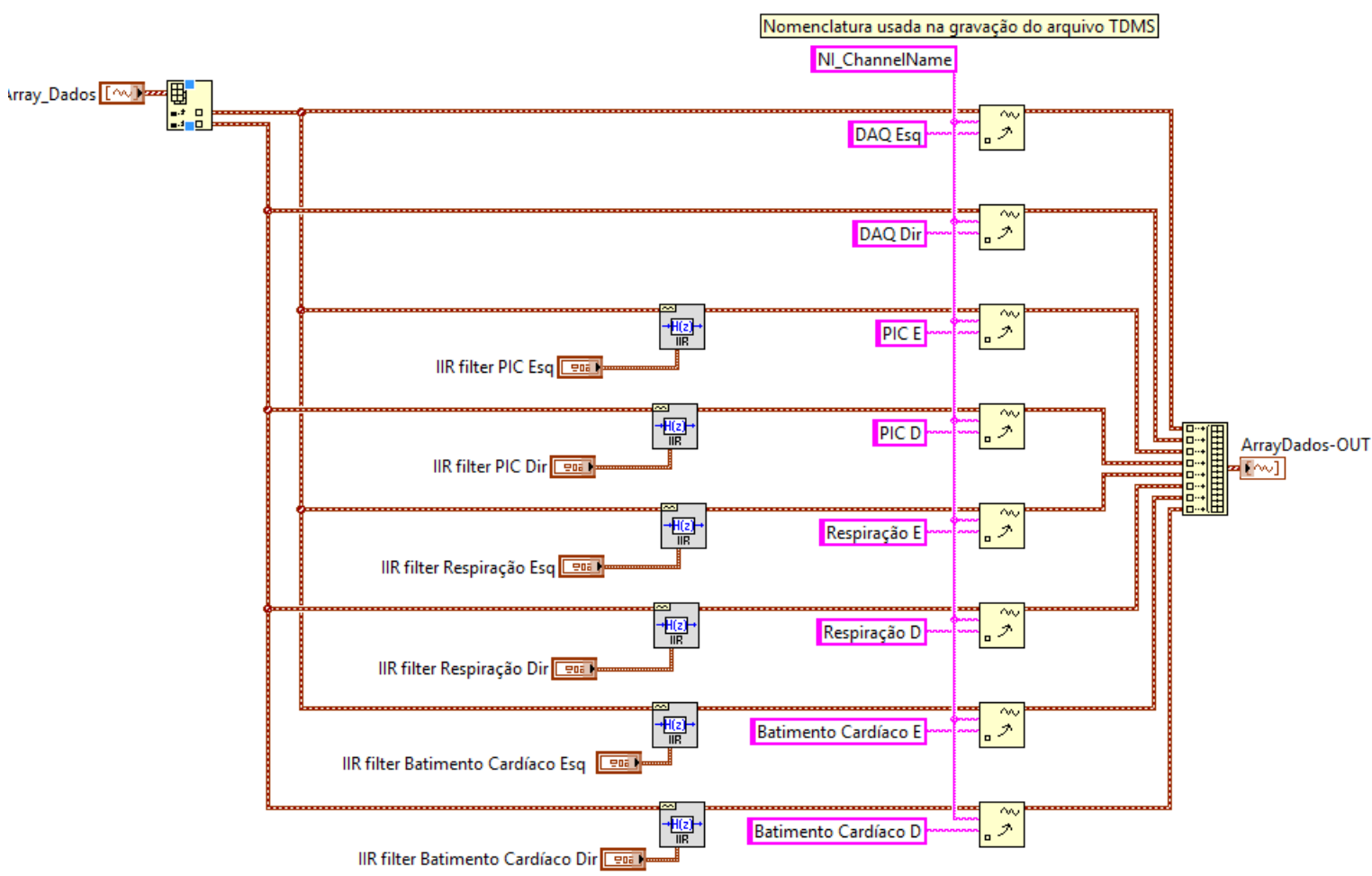

Figura 58 - Diagrama de bloco com os filtros implementados

A Figura 59 mostra apenas a título de ilustração o algoritmo implementado para realizar os FFTs responsáveis por determinar a frequência de cada uma das variáveis fisiológicas.

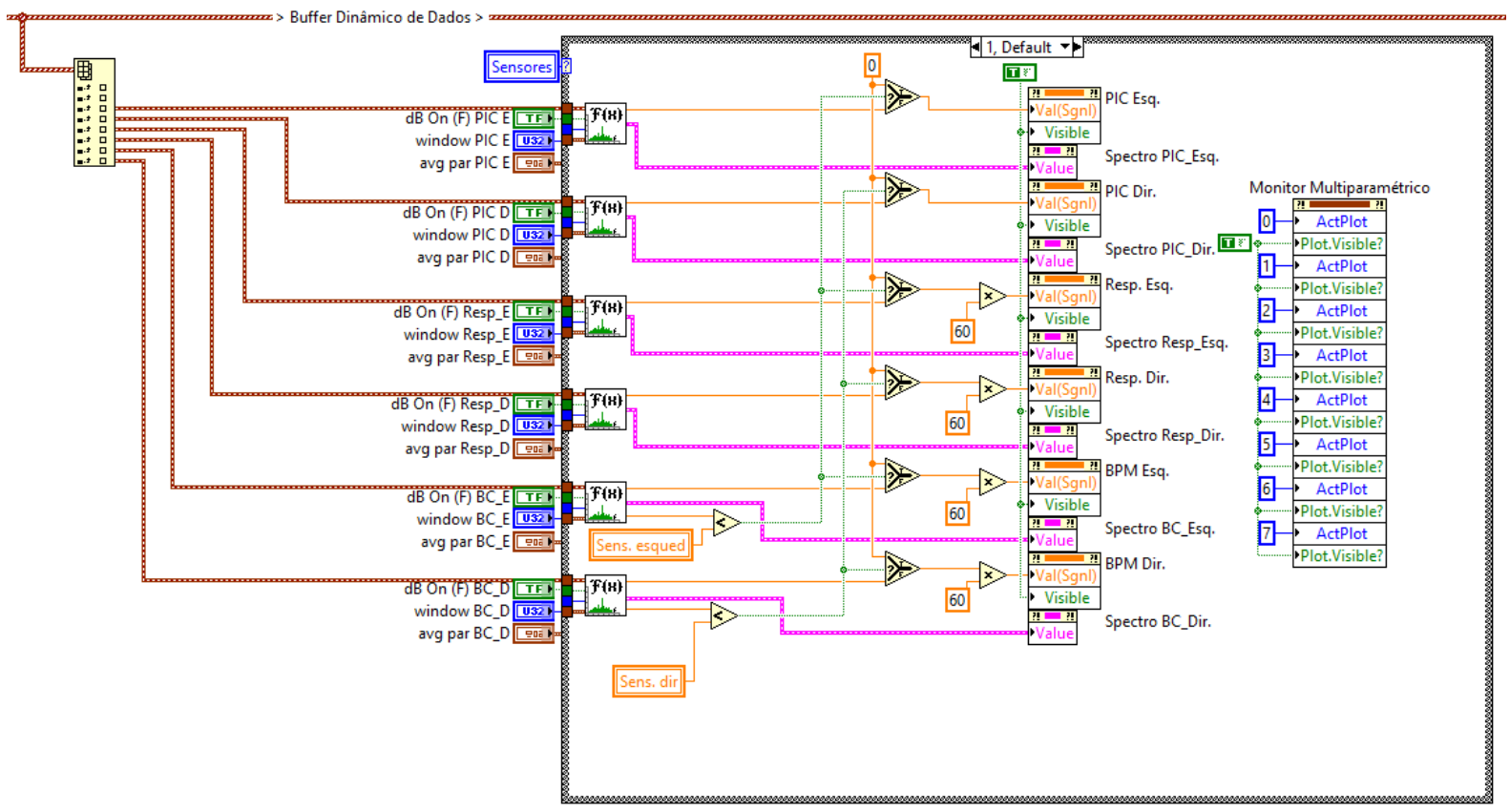

Figura 59 - Diagrama de bloco com os FFTs implementados 
Por ser um software em desenvolvimento, as configurações das características de cada um dos filtros e dos FFTs ficou aberta e disponível como controle para ser ajustado de acordo com a utilização do software pelos desenvolvedores, físicos e médicos com controle de acesso. A Figura 60 ilustra a tela de configuração do sinal da respiração.

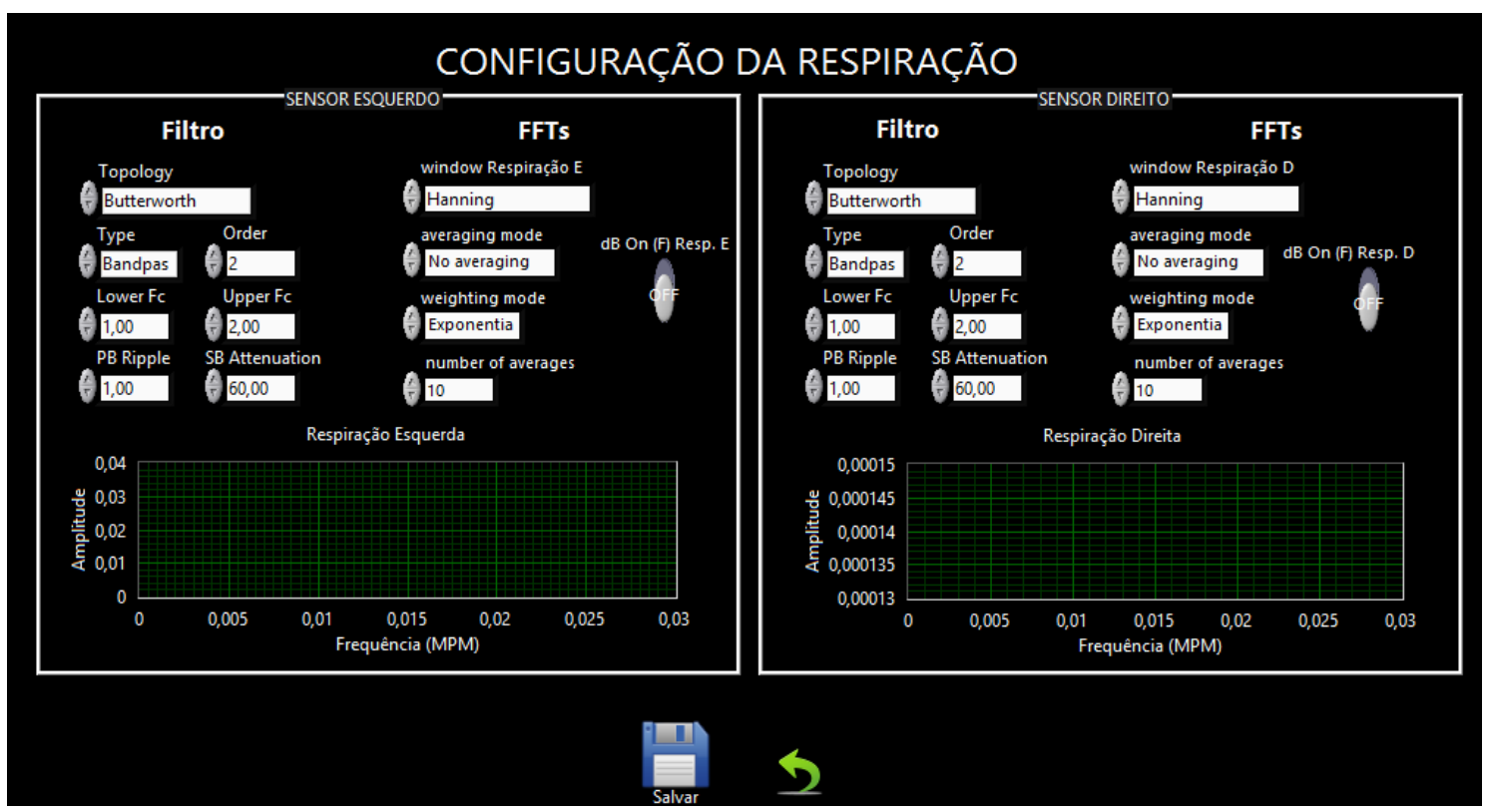

Figura 60 - Configuração dos Filtros e FFTs da respiração (Esquerda e Direita).

Existe uma preocupação grande com relação aos filtros utilizados (sejam digitais ou analógicos), pois se não bem projetado, o filtro pode interferir na amplitude e na fase do sinal, distorcendo sua característica. Por esse motivo, existem pesquisadores do grupo trabalhando no projeto dos filtros. Uma vez determinados os melhores valores, essas configurações ficarão fechadas e intrínsecas ao software.

Os testes realizados em pacientes e voluntários podem ter algumas horas de duração e é importante armazenar todos os dados para efetuar análises posteriores dos sinais medidos. Para armazenar os dados lidos, foi utilizado o formato de arquivo TDMS. Padrão introduzido pela Nationals Instruments, empresa desenvolvedora do software LabVIEW® (INSTRUMENTS", 2012). 
Tabela 5 - Comparativo entre os formatos de arquivo suportados pelo LabVIEW $®$

\begin{tabular}{|l|c|c|c|c|c|}
\hline & ASCII & Binary & XML & Database & TDMS \\
\hline Exchangeable & $\checkmark$ & $\checkmark$ & & $\checkmark$ \\
\hline $\begin{array}{l}\text { Small Disk } \\
\text { Footprint }\end{array}$ & & $\checkmark$ & & & $\checkmark$ \\
\hline Searchable & & & $\checkmark$ & & $\checkmark$ \\
\hline $\begin{array}{l}\text { Inherent } \\
\text { Attributes }\end{array}$ & & $\checkmark$ & $\checkmark$ & & $\checkmark$ \\
\hline $\begin{array}{l}\text { High-Speed } \\
\text { Streaming }\end{array}$ & & $\checkmark$ & $\checkmark$ & $\checkmark^{*}$ & $\checkmark$ \\
\hline $\begin{array}{l}\text { NI Platform } \\
\text { Supported }\end{array}$ & $\checkmark$ & $\checkmark$ & & \\
\hline
\end{tabular}

Esse padrão de arquivo foi desenvolvido para reunir e atender diversos requisitos em um único formato. Ele une a permutabilidade encontrada nos arquivos ASCII e XML, ocupa pouco espaço em disco como os arquivos binários, pesquisável como as bases de dados e transmissão em Alta velocidade como os arquivos binários. Uma comparação entre os formatos suportados pelo LabVIEW ${ }^{\circledR}$ pode ser visto na Tabela 5.

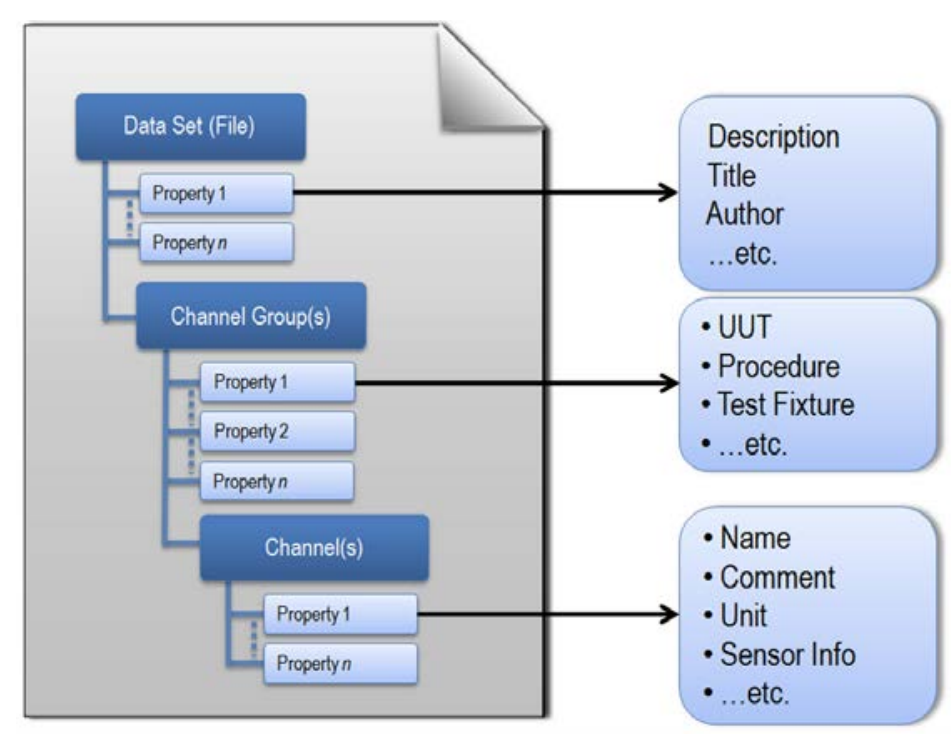

Figura 61 - Organização do Formato TDMS

A característica mais importante sobre o formato interno da estrutura do arquivo TDMS é a sua organização hierárquica inerente. O formato de arquivo TDMS 
está estruturado com três níveis de hierarquia, como mostrado na Figura 61 arquivo, grupo e canal.

O nível do arquivo pode conter um número ilimitado de grupos, e cada grupo pode conter um número ilimitado de canais. Devido a este agrupamento de canais, você pode escolher a forma de organizar os dados para torná-lo mais fácil de entender. Além disso o formato de arquivo pode ser lido usando um software de planilha de dados como o Microsoft Excel ${ }^{\circledR} 4$ dentre outros softwares existentes como Origin ${ }^{\circ}$ e MATLAB ${ }^{\circledR}$.

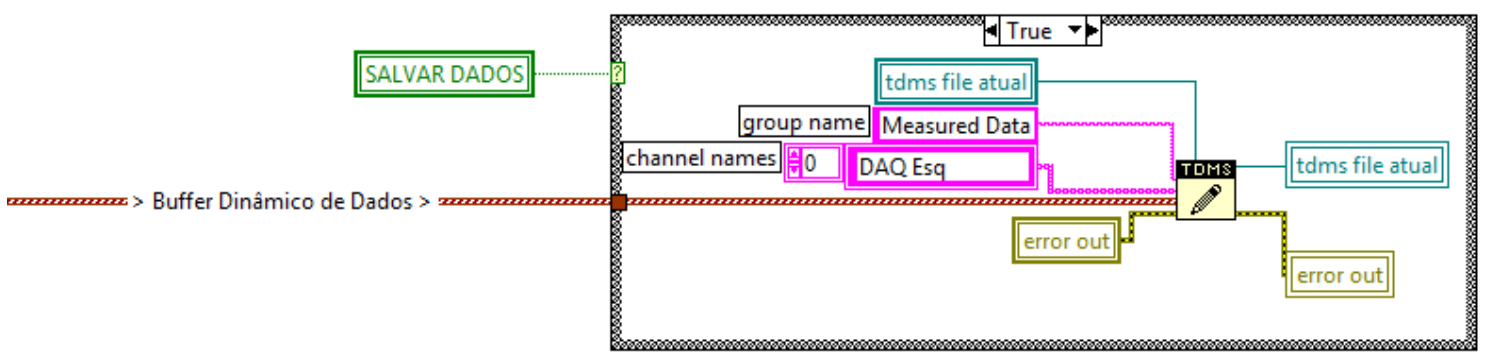

Figura 62 - Armazenamento dos dados dinâmicos via TDMS.

A Figura 62 mostra a título de ilustração o diagrama de blocos dos sinais (Buffer Dinâmico de Dados) sendo armazenados no formato TDMS.

No software atual, versão 1.5, a respiração e o batimento cardíaco não foram implementados para dar ênfase à pressão intracraniana, facilitando assim a visualização do sinal. O design do software foi projetado para ter uma aparência mais agradável e de fácil entendimento como mostrado na Figura 63. Uma vez desenvolvido o sensor e implementado os filtros da forma mais eficiente, a respiração e o batimento cardíaco serão parâmetros monitorados pelo software.

\footnotetext{
${ }^{4}$ Para leitura do arquivo TDMS fazendo uso do software Microsoft Excelø, um Add-in necessita ser instalado. Este complemento pode ser adquirido gratuitamente em: http://zone.ni.com/devzone/cda/epd/p/id/2944
} 


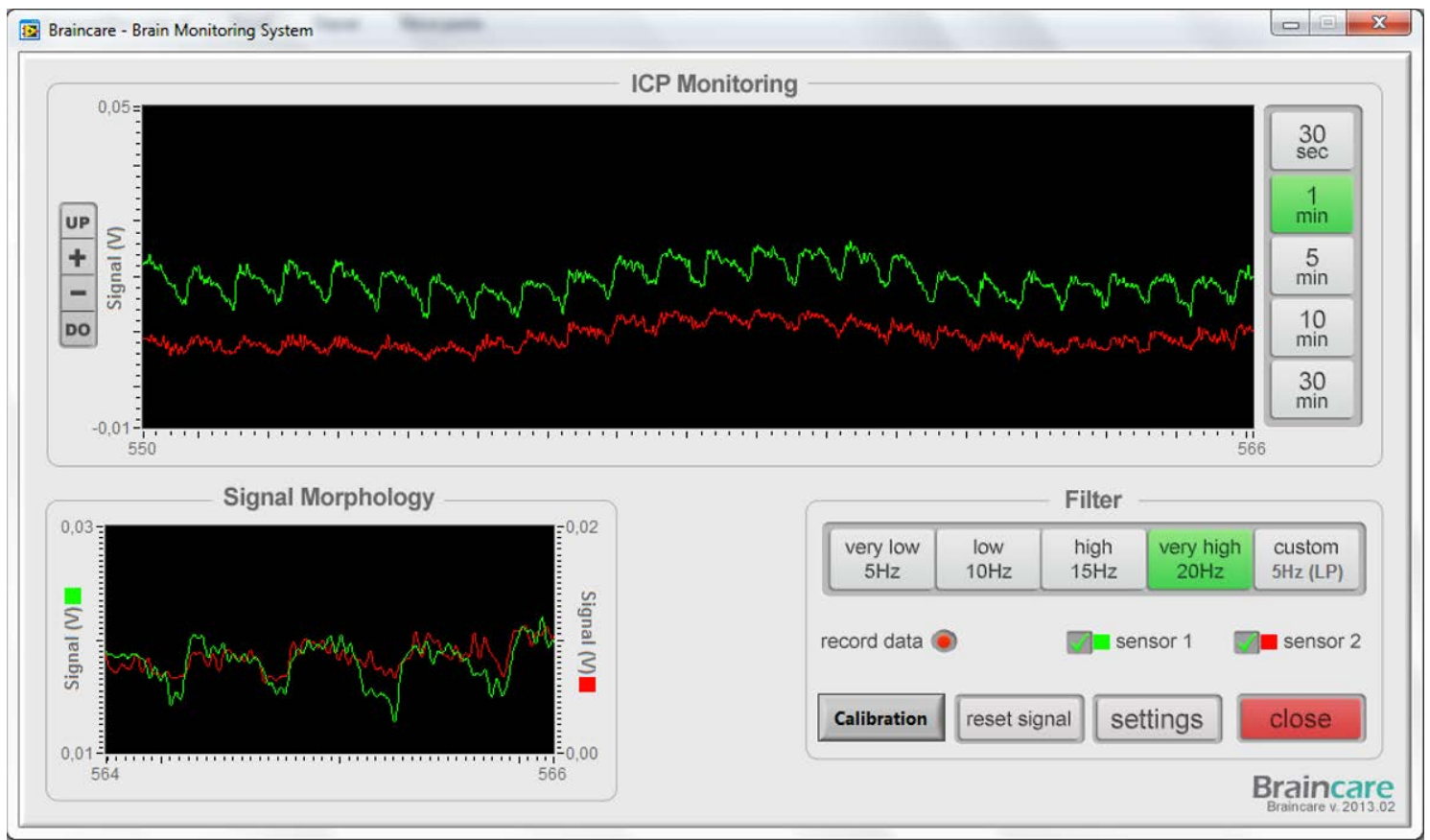

Figura 63 - Tela de monitoramento da nova versão do software.

Alguns filtros foram pré-programados e ainda é possível customizar um filtro de acordo com a necessidade do usuário. A Janela de tempo é facilmente configurada para diversos tempos disponíveis do lado direito do gráfico. Nas configurações, foi adicionado um filtro analógico passivo para anti-aliasing - que filtra as frequências da rede $50 / 60 \mathrm{~Hz}$ - para evitar interferências advindas da rede elétrica que alimenta a fonte do sistema.

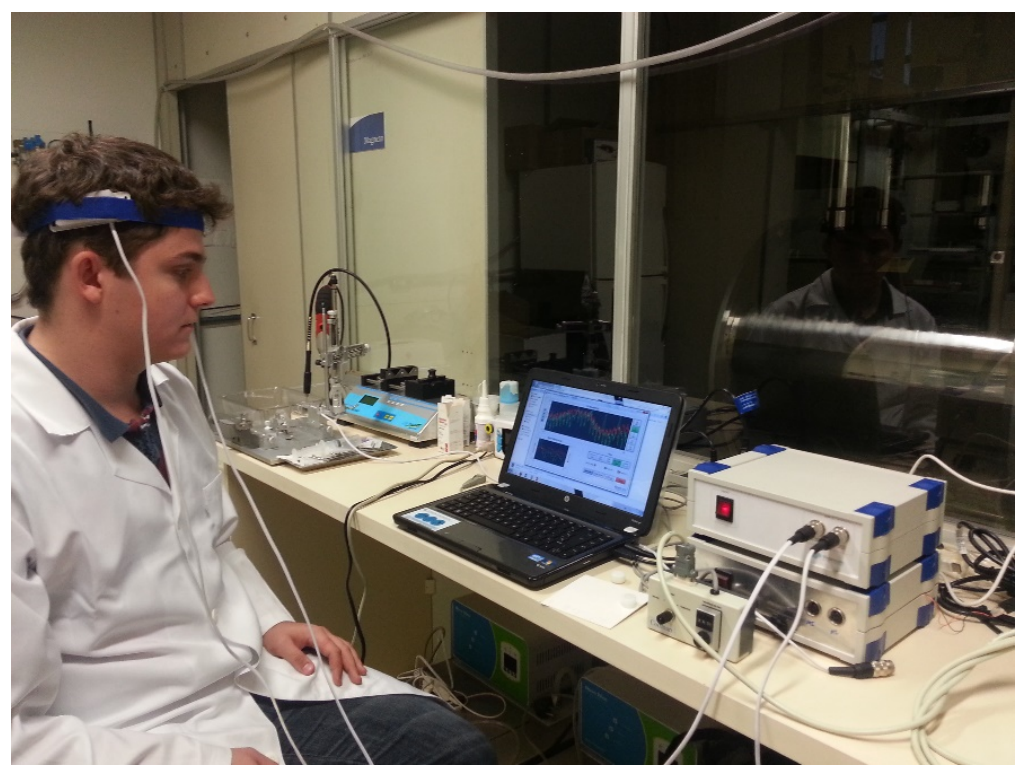

Figura 64 - Teste do Sistema com dois Sensores não invasivos Brainstrap. 
A Figura 64 mostra a utilização do sistema com dois sensores não invasivos posicionados cada um de um lado da cabeça.

Uma visão completa do sistema em desenvolvimento pode ser vista pelo fluxograma da Figura 65.

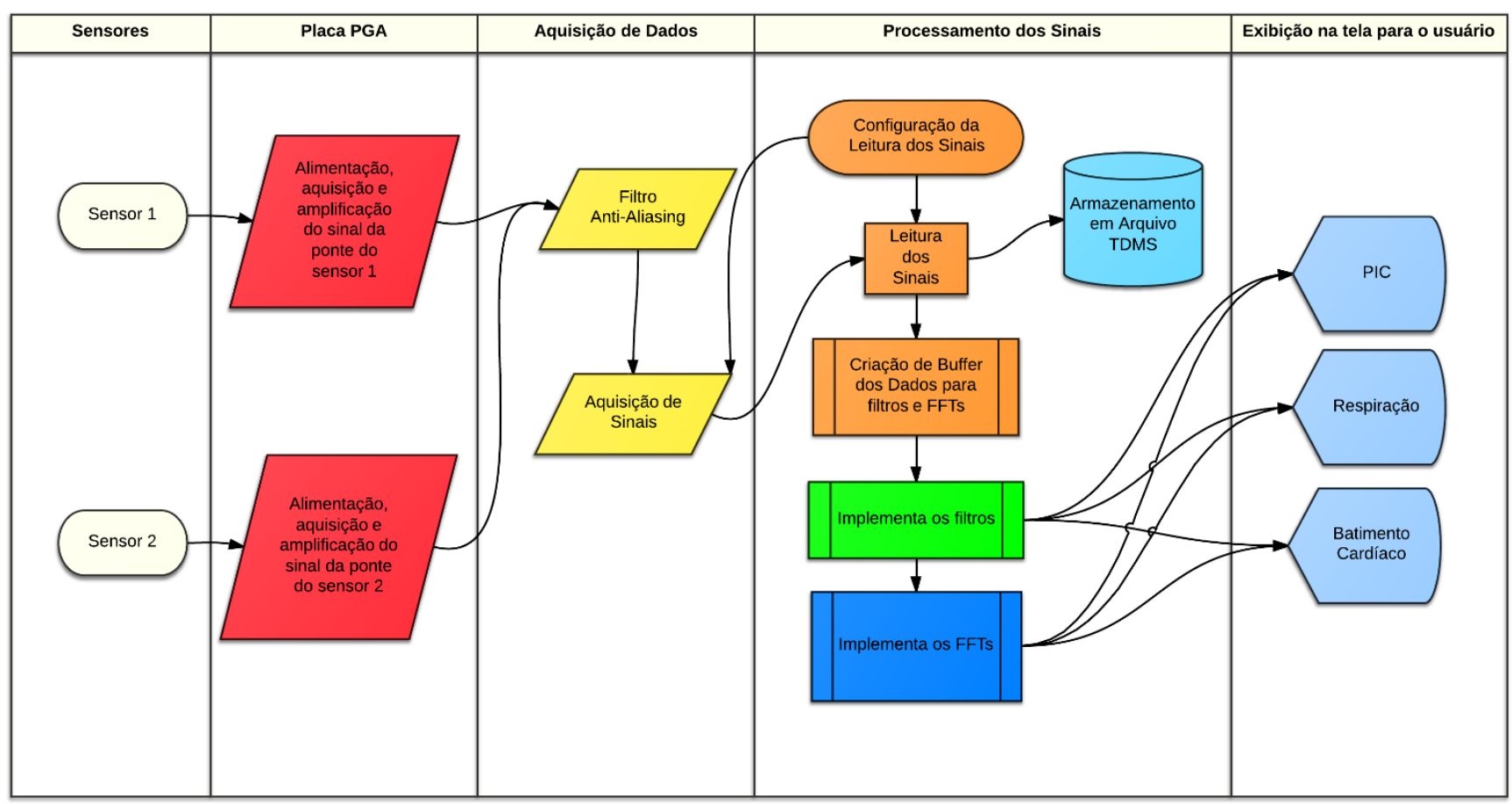

Figura 65 - Fluxograma completo do sistema

\subsection{Preparação do equipamento para comparação do método NI com outros métodos invasivos}

O sensor não invasivo desenvolvido neste trabalho só terá aceitação na comunidade acadêmica após a comprovação de efetividade e da correlação entre o sinal do sensor $\mathrm{NI}$ e o sinal do sensor gold standard. Considerando que atualmente não existe um sistema não invasivo que tenha esse título, essa comparação deve ser realizada com o método gold standard invasivo. $\mathrm{O}$ Codman $\circledast$ é um modelo de equipamento da Johnson\&Johnson® para leitura de sensor invasivo bem difundido e utilizado em diversos hospitais no mundo todo. 
O Hospital das Clínicas da Faculdade de Medicina de Ribeirão Preto possui um único exemplar do equipamento para dar suporte nas cirurgias e exames referentes ao monitoramento da PIC, mostrando a dificuldade em ter acesso a um sistema desse tipo devido alto ao preço do equipamento e dos sensores (descartáveis). Porém através de parcerias com um Hospital de Portugal e com o grupo de estudos de Neurocirurgia de Cambridge - Inglaterra - conseguiramse dois aparelhos portáteis da $\operatorname{Codman}{ }^{\circledR}$ (Figura 66) para realizar testes de comparação com o nosso sensor.

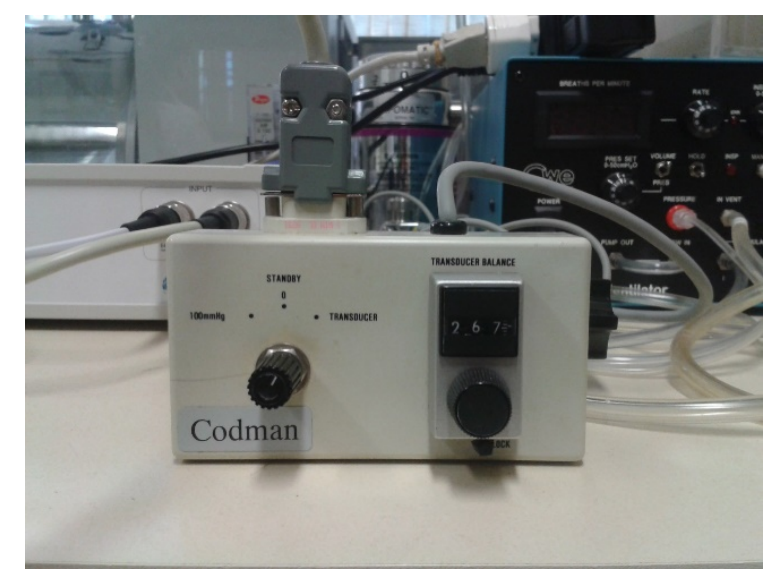

Figura 66 - Codman ICP Express

Para realizar a aquisição de dados do sensor $\mathrm{NI}$ com o Codman ${ }^{\circledR}$ em conjunto foi necessário adequar o nosso equipamento para receber o sinal do sensor e efetuar a calibração do sinal via software utilizando os valores padrões ( 0 e 100mmHg) da figura acima.

Através do diagrama de conexão da Figura 67, foi possível criar um cabo de interface entre um canal do nosso sistema de aquisição e o equipamento Codman®. 


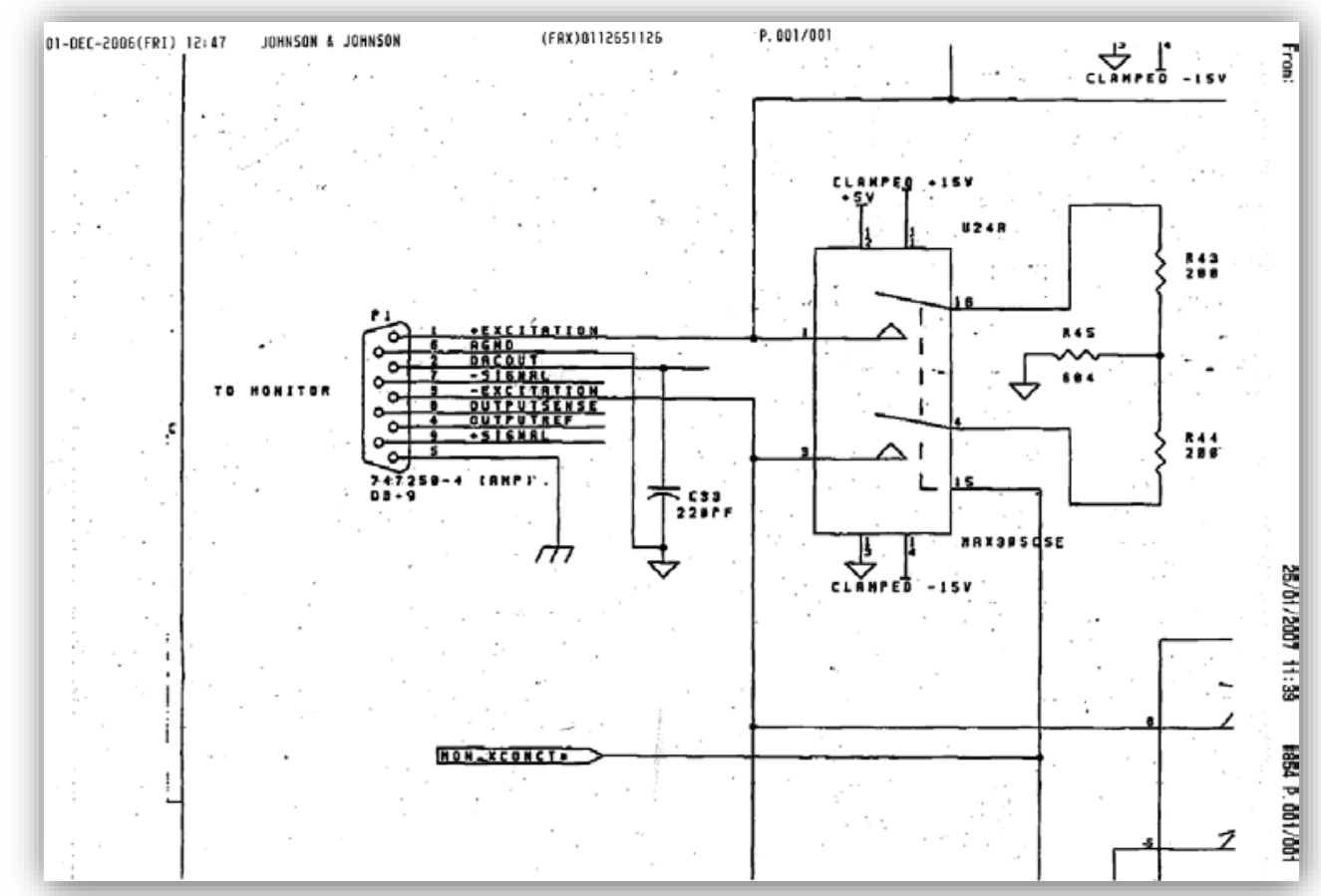

Figura 67 - Diagrama original digitalizado de conexão do CODMAN (JOHNSON \& JOHNSON, 2006).

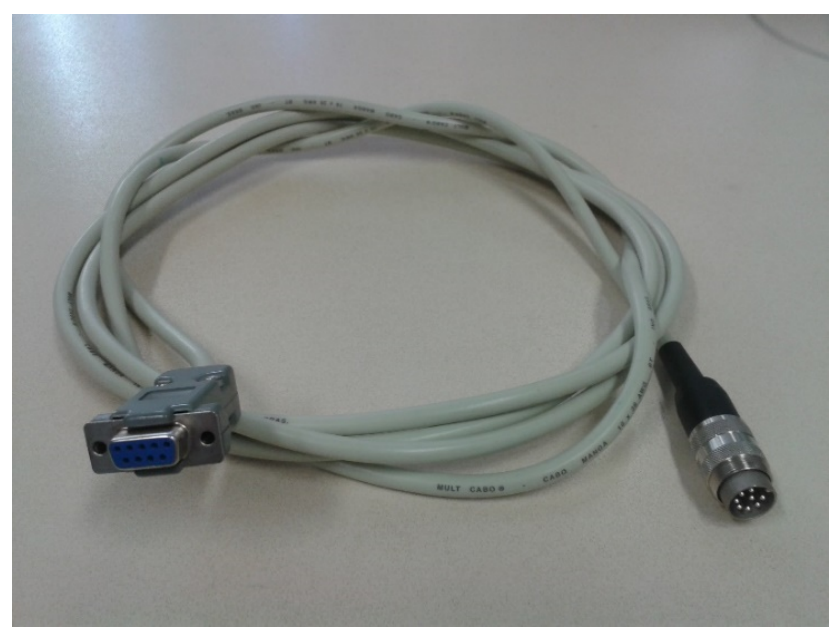

Figura 68 - Cabo de conexão Braincare-Codman

A Figura 69 mostra a pinagem do cabo de conexão entre os equipamentos. 


\begin{tabular}{|c|c|c|c|c|}
\hline COR & Braincare Signal & Codman Signal & Braincare & Codman DB-9 \\
\hline Vermelho & Vsensor & Exc+ & 1 & 1 \\
\hline Branco & - & DACOUT & 2 & 2 \\
\hline Laranja & Vin1 & Signal+ & 3 & 7 \\
\hline Marrom & GND & Exc- & 4 & 3 \\
\hline Amarelo & Vin2 & Signal- & 5 & 9 \\
\hline Verde & - & Output Sense & 6 & 8 \\
\hline Roxo & - & Output Ref & 7 & 4 \\
\hline Preto & AGND & AGND & 8 & 6 \\
\hline Cinza & Shield & Shield & Shield & 5 \\
\hline
\end{tabular}

Figura 69 - Pinagem Conexão Braincare-Codman

A Figura 70 mostra o sistema montado em conjunto pronto para realizar o monitoramento da PIC de forma não invasiva (Brainstrap) e invasiva (Codman) com aquisição simultânea.

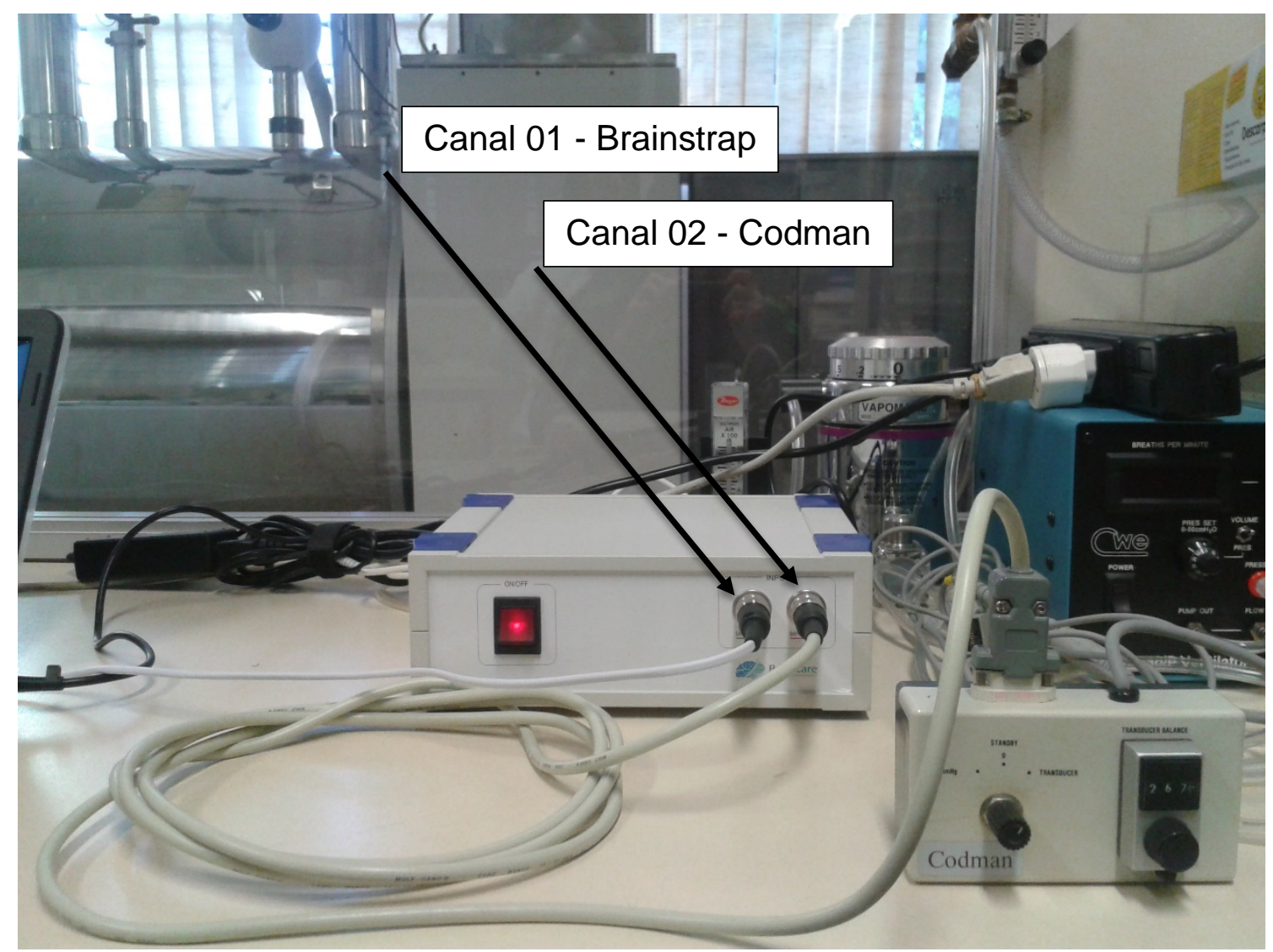

Figura 70 - Sistema Braincare de monitoramento da PIC (NI - Canal 01; Codman - Canal 02) 


\section{Materiais e Métodos}

\subsection{Simulação em Elementos Finitos}

Uma simulação foi realizada utilizando o método de elementos finitos simulando o comportamento da barra sensora antiga (com entalhe retangular) e da nova barra (com entalhe semicircular).

O Método dos Elementos Finitos (MEF) tem sido considerado uma das melhores soluções para a abordagem de problemas de projetos de engenharia, inclusive em mecnica dos sólidos. Com ele pode-se obter respostas estáticas ou dinâmicas desde estruturas simples, até as mais complexas.

O método foi utilizado como forma de aproximar, ilustrar e entender o comportamento das barras sensoras na região de concentração de tensão onde o extensômetro é colado de acordo com o entalhe feito. Como visto no capítulo 2.3, a tensão será concentrada na região do entalhe amplificando a deformação transferida ao extensômetro.

Foi utilizado o software ABAQUS versão 6.5-1 do Laboratório de Otimização de Processos de Fabricação (LOPF) para as simulações.

A Figura 71 mostra o desenho das barras sensoras já com as malhas definidas para a simulação.
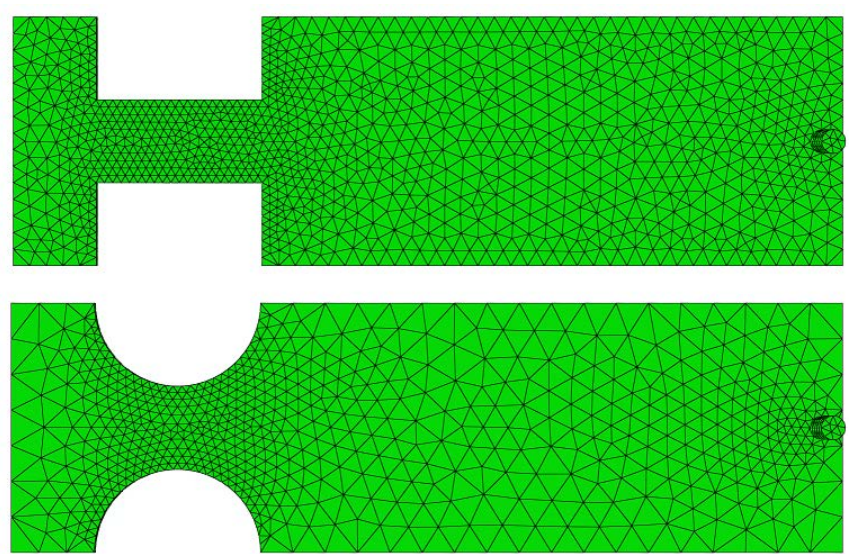

Figura 71 - Malhas das barras sensoras - Antiga com entalhe retangular (Superior) e atual com entalhe semicircular (Inferior) 
As propriedades do material Alumínio 2024 inseridas no software foram:

Tabela 6 - Tabela de propriedade do material Alclad Aluminum 2024 T3 de 0.4mm de espessura (MATWEB, 2013).

\begin{tabular}{|l|l|}
\hline Densidade & $2.78 \mathrm{~g} / \mathrm{cc}$ \\
\hline Módulo de Young & $73.1 \mathrm{GPa}$ \\
\hline Razão de Poisson & 0.33 \\
\hline Tensão Máxima de Escoamento & $270 \mathrm{MPa}$ \\
\hline
\end{tabular}

As condições de contorno para a simulação consideraram a borda direita das barras engastadas (encastre) e uma força concentrada nos pinos de $0.4 \mathrm{~N}$ (cada).

\subsection{Teste Mecânico do Sensor}

O Teste mecânico tem a função de conhecer e quantizar as características dos sensores desenvolvidos. Garantir que o sensor não está sofrendo deformações plásticas é essencial para uma boa linearidade e repetibilidade.

\subsubsection{Teste de repetibilidade}

A repetibilidade visa a confirmação de um resultado a partir de um experimento repetitivo de modo a garantir que os valores lidos se repitam sempre.

Neste teste, foram realizados 100 ciclos de 6 pequenos movimentos de $15 \mu \mathrm{m}$. Entre cada ciclo, a máquina realizava um movimento maior $(2 \mathrm{~mm})$ para simular a fixação do Sensor na cabeça do paciente/voluntário. Este teste recria as condições as quais o sensor fica exposto quando utilizado para realizar medições in vivo. O teste foi realizado com três sensores (Sensor 11, Sensor 13 e Sensor 21) e cada teste teve uma duração de aproximadamente 4 horas. 
Para realizar este experimento foi utilizado uma máquina CNC Hermle C800U, do Laboratório de Otimização de Processos de Fabricação (LOPF) da Escola de Engenharia de São Carlos onde experimentos e sensores (GUERRA,COELHO, 2009) já foram desenvolvidos utilizando a extensometria como princípio de medição. A Máquina CNC foi responsável por executar as movimentações com a precisão e resolução necessárias. A programação das movimentações foi realizada em código G no próprio CNC. A Figura 72 ilustra a Máquina Ferramenta utilizada nos testes.

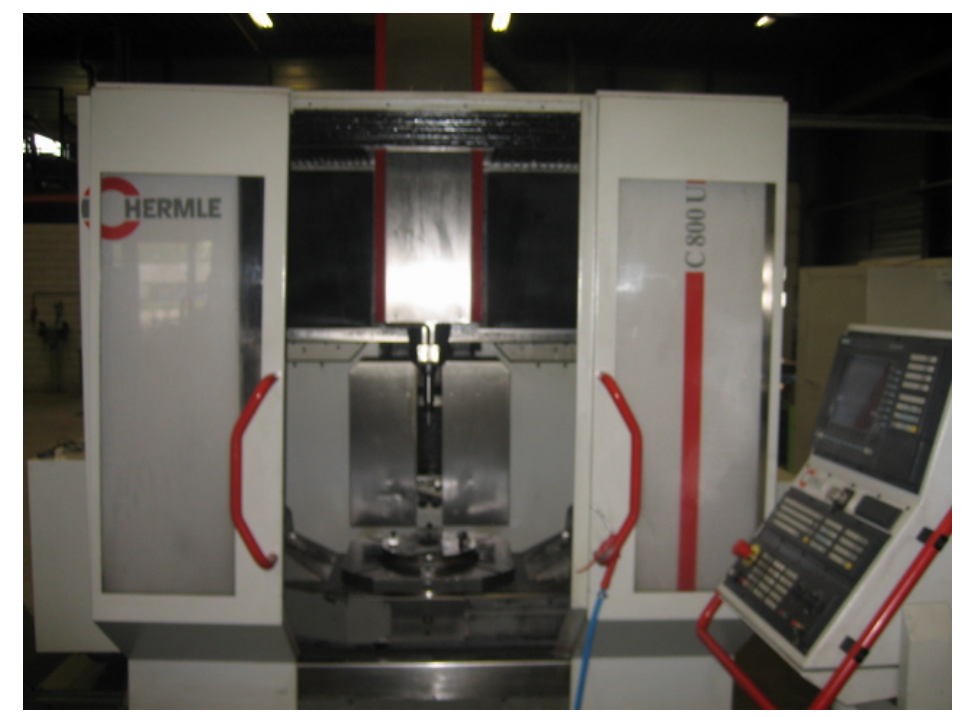

Figura 72 - Hermle modelo C 800 U

Para comparar o valor lido para os deslocamentos descritos acima, um sensor de posicionamento Heidenhain modelo MT 1200 foi utilizado. A Figura 73 mostra o sensor utilizado no teste para determinar o deslocamento que a barra exerce sobre o pino do sensor não invasivo. 


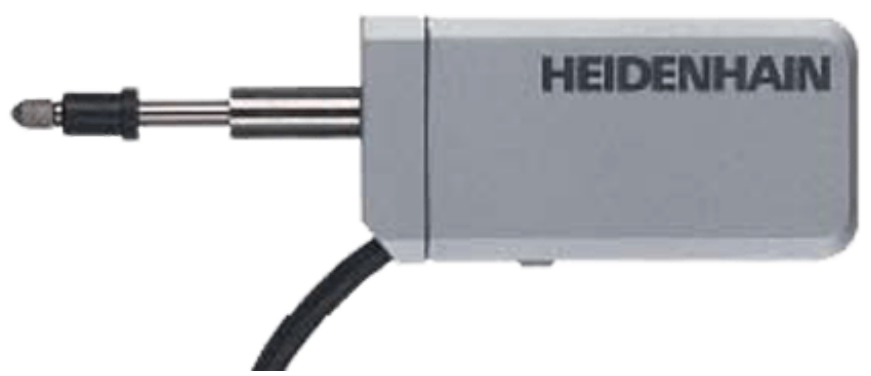

Figura 73 - Sensor de Posicionamento Heidenhain MT 1200

O sensor MT 1200 utiliza um módulo de leitura externo. Esse módulo possui comunicação RS-232 por onde pode ser enviado diversos valores, inclusive o valor da posição atual. Sendo assim, um software foi desenvolvido em ambiente LabVIEW para executar e leitura sincronizada do sensor não invasivo e do sensor MT 1200. A Figura 74 mostra o sistema montado para a aquisição dos sinais do teste.

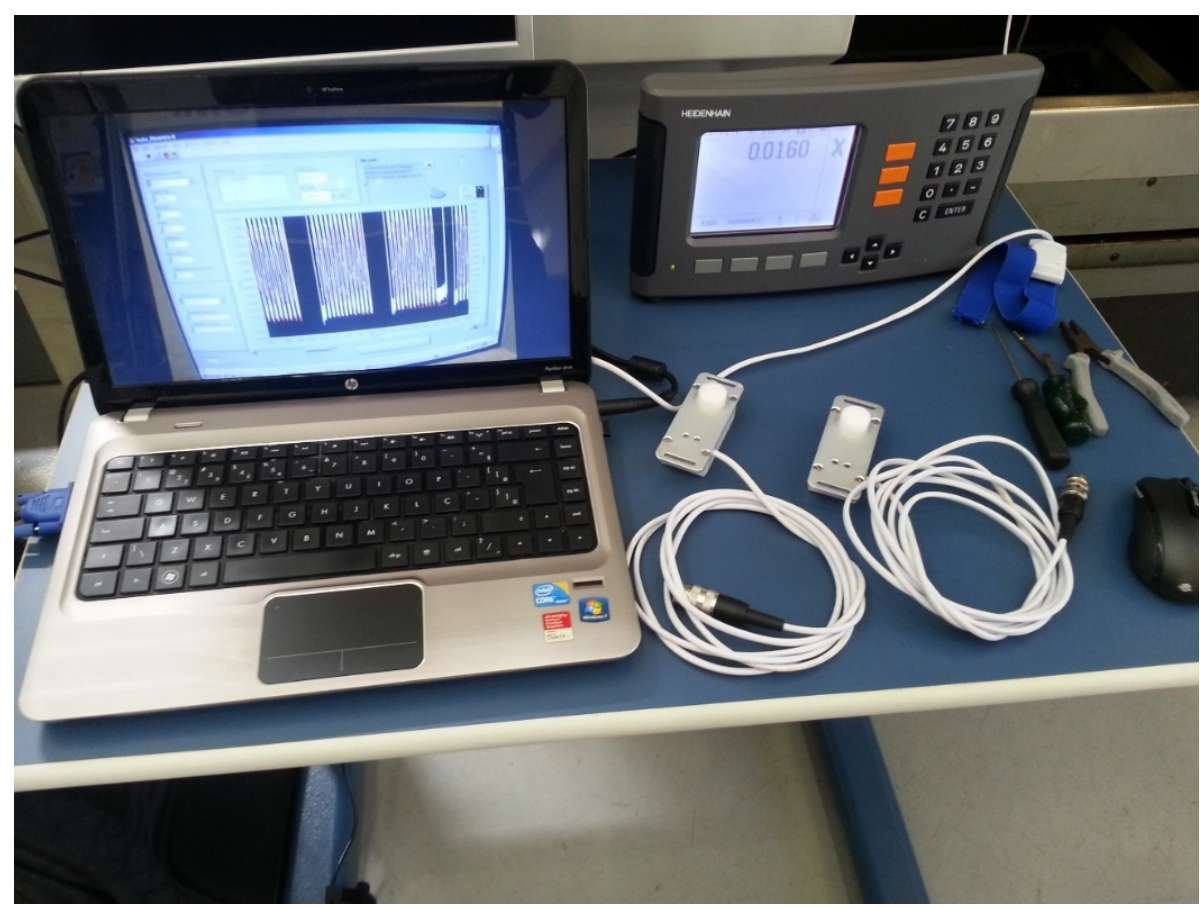

Figura 74 - Sistema de aquisição do sensor não invasivo e do sensor de deslocamento MT 1200.

Dentro da máquina ferramenta onde as manipulações foram executadas, foi necessária a usinagem uma barra para teste dinâmico (Figura 75) que conectada ao eixo manipulador do centro de usinagem, fosse responsável pela movimentação dos sensores simultaneamente. 


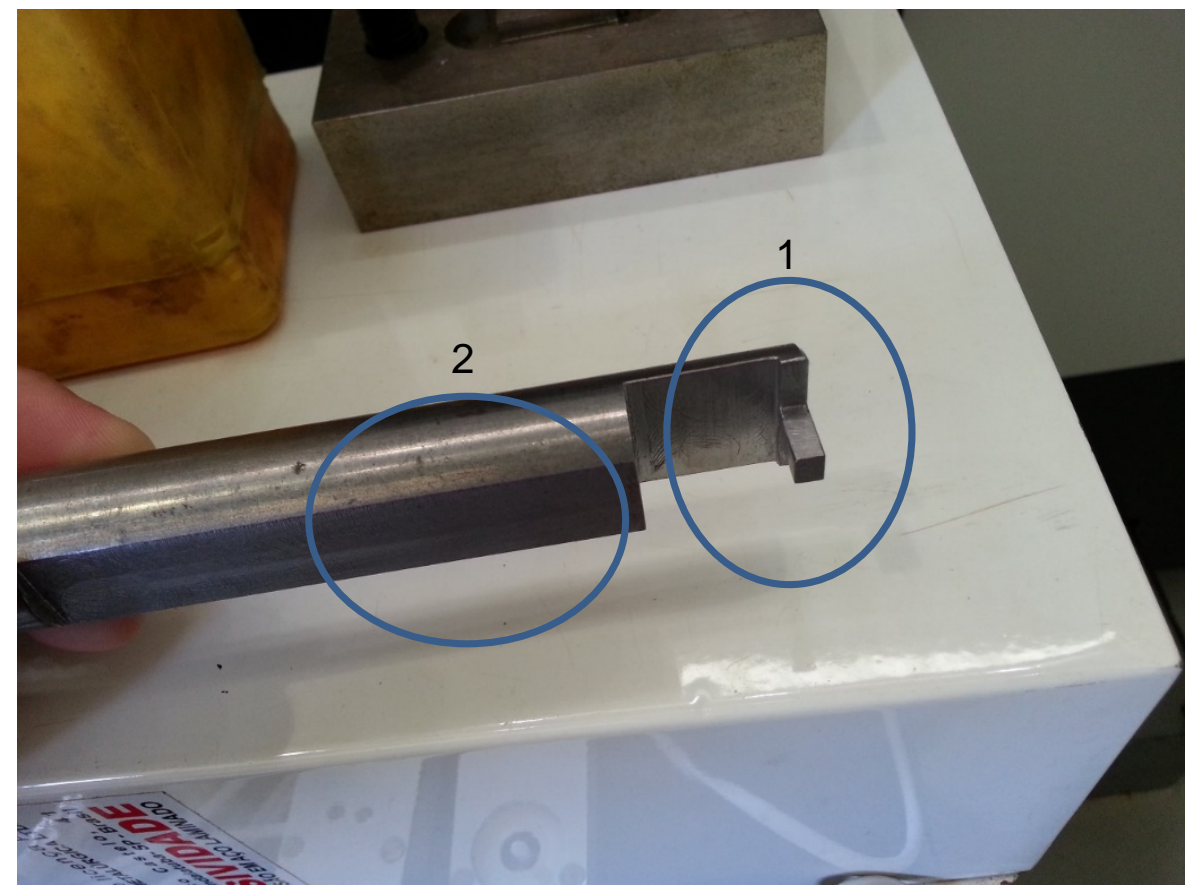

Figura 75 - Barra usinada usada para movimentar os dois sensores.

Essa barra foi conectada como uma ferramenta no centro de usinagem, na portaferramenta da máquina. Ela possui duas áreas (1 e 2) onde cada uma tocará seu respectivo sensor. Na extremidade da direita (1) é possível verificar um pino quadrado, o qual será responsável por movimentar o sensor não invasivo. E para movimentar o sensor de deslocamento, a região esquerda (2) da figura foi usinada deixando a superfície plana para o contato. As duas superfícies foram projetadas com a mesma altura para uma vez que os sensores estiverem paralelos entre sí (na direção de medição), a barra os toque ao mesmo tempo e produza o mesmo deslocamento em ambos.

A Figura 76 mostra o sistema montado e pronto para iniciar os testes. Uma morça é responsável por fixar o sensor não invasivo na mesa e o suporte magnético fixa o sensor Heidenhain. 


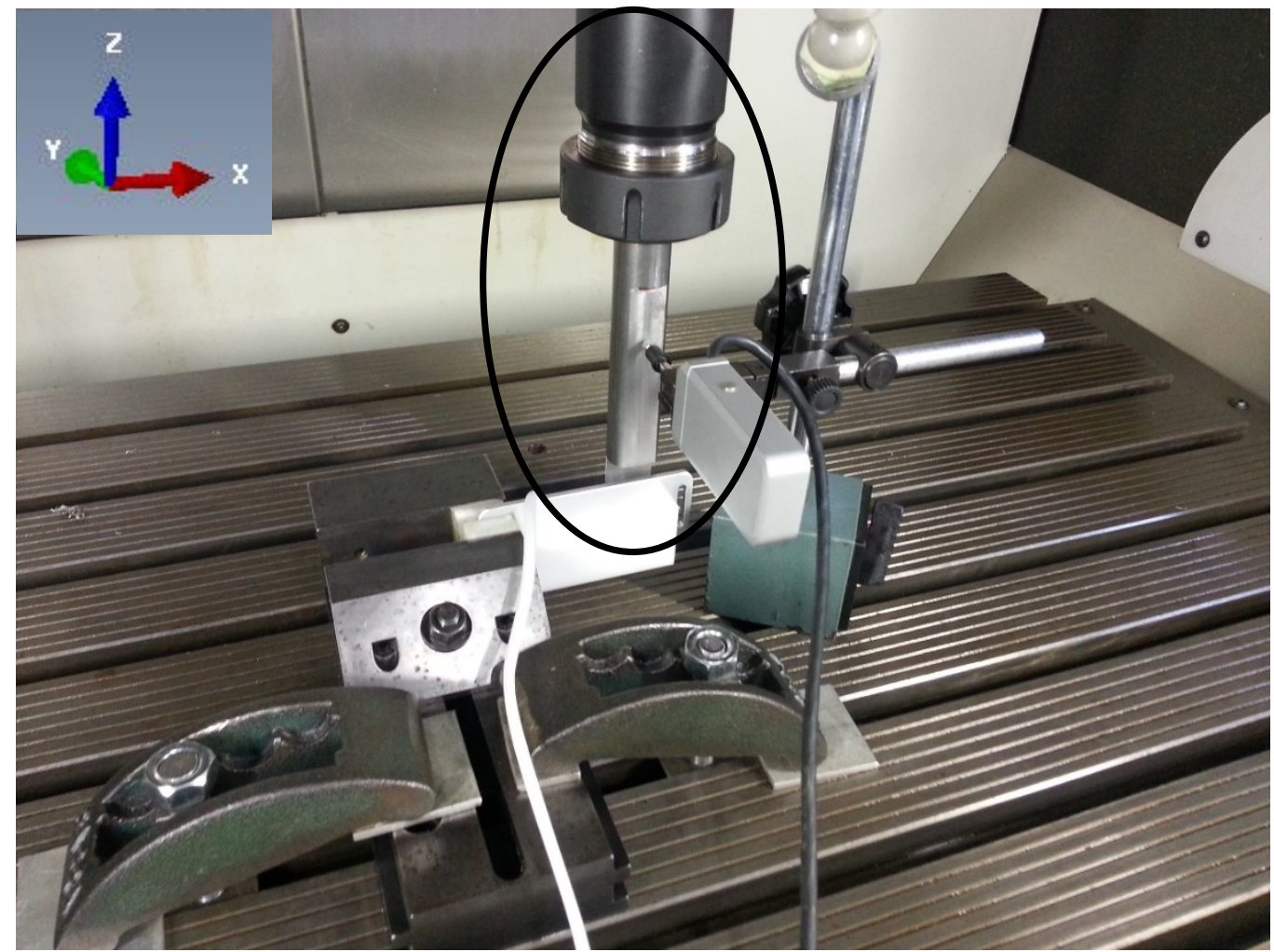

Figura 76 - Posicionamento dos Sensores no teste

Neste teste, a barra usinada fixada na porta-ferramenta foi programada para executar movimentações apenas na direção $Y$ da máquina ferramenta. Ambos os sensores estão fixos na mesa.

Para comparar os dados do sensor BrainStrap em relação ao deslocamento aquisitado pelo Heidenhein, foram escolhidos os sinais dos intervalos onde a ferramenta (Barra usinada) estava em repouso, ou seja, nos picos e vales dos ciclos de movimentações de $2 \mathrm{~mm}$ e $15 \mu \mathrm{m}$. Essa seleção foi feita para assegurar que os valores lidos de ambos os sensores fossem aquisitados na mesma posição da ferramenta.

O software desenvolvido em LabVIEW que realizou a análise dos dados aquisitados dos dois sensores (BrainStrap e Heidenhein) em relação ao tempo, foi desenvolvido da seguinte maneira:

Um algoritmo de detecção de limiar (Threshold detector) foi utilizado para identificar os picos e vales descritos acima. Posteriormente foi selecionado 100 pontos do centro de cada pico/vale e realizado uma média para obter um único 
valor médio para cada movimentação. Para determinar a amplitude de cada pulso, os valores médios dos picos foram subtraídos dos valores médios dos vales subsequentes. Sendo assim cada um dos 100 ciclos do teste de cada Sensor possui um pulso de $2 \mathrm{~mm}$ e 6 pulso de $15 \mu \mathrm{m}$.

Afim de comparar os valores dos dois sensores, no comportamento dos picos de $15 \mu \mathrm{m}$, o primeiro pulso é descartado e faz-se uma média dos outro 5 , tendo um valor médio do pulso de cada sensor para cada um dos 100 ciclos. Para cada ciclo, o valor aferido no Sensor BrainStrap é dividido pelo valor normalizado medido no Sensor de Deslocamento Heidenhain. O Resultado desse algoritmo é um gráfico do Sensor da PIC para deslocamentos normalizados. As análises e resultados estão dispostos no capítulo 0 . 


\subsection{Metodologia do Teste do Equipamento de Amplificação e Aquisição de Sinais}

O equipamento protótipo de amplificação e aquisição de sinais utilizado nesse trabalho, denominado MONA 1.5, necessita ser testado para definir os requisitos de projeto para o próxima versão do sistema, pois como se trata de um desenvolvimento de produto, o sistema passa por diversas modificações e evoluções afim de validar os componentes eletro-eletrônicos atendendo aos requisitos médicos e da Anvisa.

O projeto deverá ser feito sensível o suficiente para captar os traços da PIC (P1, P2 e P3) com alta relação sinal-ruído. Em paralelo a essa sensibilidade, o span do sensor deverá ser o suficiente para medir de 0 a 100 mmHg. Porém ainda não existem dados coletados com o sensor não invasivo em comparação com o invasivo (Codman por exemplo) em seres humanos para chegar a essa conclusão.

Sendo assim, baseou-se na literatura (WAGSHUL, EIDE,MADSEN, 2011), afim de comparar a intensidade dos pulsos da PIC dessas referências com o sistema não invasivo proposto (Braincare). Essa comparação é realizada apenas para título de conhecimento da ordem de grandeza da relação entre os sistemas.

Estudos ainda precisam ser realizados relacionando a PIC medida com sensores invasivos, com o sistema Braincare em diversos pacientes para diversas complacências distintas.

Baseado nessas especificações, monitoramentos fisiológicos e testes de ruído com o sensor em repouso foram realizados para avaliar a situação do sistema atual e assim, auxiliar fornecendo os requisitos eletrônicos e melhorias para a próxima versão do equipamento.

Os testes foram realizados com o equipamento MONA versão 1.5 com sua máxima amplificação e com uma frequência de aquisição de $200 \mathrm{~Hz}$. Os dados da função de transferência da PGA estão à seguir: 


\begin{tabular}{|c|c|c|c|c|c|c|}
\hline Vref & Mux & Coarse Offset & Front End Gain & Zero DAC & Gain DAC & Output Gain \\
\hline $5 \mathrm{~V}$ & -1 & $-17 \mathrm{mV}$ & 128 & $2.33803 \mathrm{~V}$ & 0.99999 & 9 \\
\hline
\end{tabular}

O Teste de ruído foi realizado com a leitura do sensor em repouso durante 3 minutos. O monitoramento fisiológico foi realizado durante 10 minutos com um voluntário em repouso com a finalidade de obter uma onda da PIC a ser comparada com a bibliografia. 


\subsection{Procedimento dos Testes In vivo}

Todos os teste citados foram aprovados por comissões de ética e os voluntários assinaram o termo de consentimento livre esclarecido (TCLE) antes da realização dos procedimentos.

\subsubsection{Metodologia de teste durante exercício físico}

Com o objetivo de avaliar o comportamento da PIC durante o exercício, o protocolo experimental foi dividido em dois grupos diferentes de pessoas: um grupo de sedentários com idades heterogêneas ( $27 \pm 6$ anos de idade) $(n=8)$, e um grupo de voluntários ativos de 19 anos originários de recrutamento militar $(n=8)$. Ambos os grupos foram instrumentados com o sensor não invasivo, fixado com uma cinta elástica sobre a região craniana parietal lateral, e com equipamentos adequados para o monitoramento frequência cardíaca (FC) e medição da pressão arterial (PA).

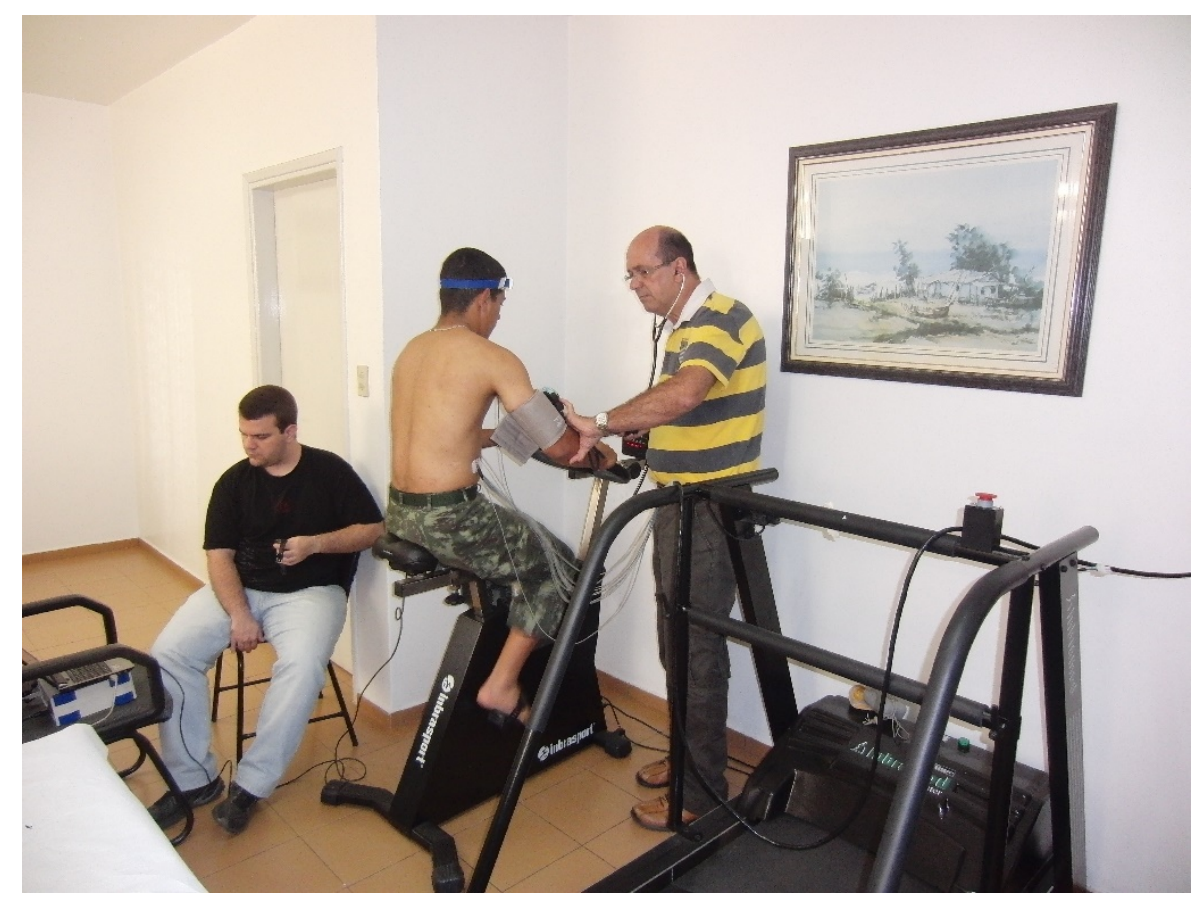

Figura 77 - Voluntário ativo durante atividade aeróbica em uma bicicleta ergométrica 
Os voluntários foram submetidos a monitoramentos de linha de base (repouso) da PIC, FC e PA, e em seguida, a atividade física aeróbica em uma bicicleta ergométrica, com intensidades variáveis de carga (elétrica bicicleta ergométrica IMBRAMED, modelo BRAND-CG04). PA e FC foram medidas a cada minuto, e a PIC foi monitorada continuamente durante o exercício, que durou até a frequência cardíaca do voluntário atingir o seu nível submáximo. A taxa cardíaca submáxima foi obtida calculando-se $85 \%$ da frequência cardíaca máxima, que é calculada a partir da subtração de 220 menos a idade da pessoa. Todos os procedimentos realizados durante a fase experimental foram analisados e aprovados pelo comitê de ética em pesquisa da Unicastelo, protocolo $n^{\circ} 3222$ 3442/10.

Dados da PA e FC foram anotados a cada minuto e todos os dados de monitorização da PIC, adquiridos a uma taxa de $100 \mathrm{~Hz}$, foram gravados em um computador para análises posteriores. No que se diz respeito à análise, apenas os dados PA e PIC foram considerados, uma vez que valores de FC foram necessários apenas para se determinar o fim do exercício para cada pessoa. Durante a análise, os dados da PIC passaram por um tratamento matemático que compreendeu de um filtro passa-baixa de $5 \mathrm{~Hz}$. Uma vez prontos, os dados foram organizados em tabelas e suas médias e erros médios quadráticos determinados. 


\subsubsection{Metodologia dos testes com sensor NI e sensor invasivo Codman em animais}

A proposta deste experimento compreende comparar, simultaneamente, 0 método não invasivo com um método já aceito na literatura médico-científica, o método invasivo intraparenquimatoso de monitoramento da pressão intracraniana, em ratos submetidos a procedimentos para variação da PIC. Tal comparação permitiu traçar parâmetros de correlação entre os métodos, na tentativa de se estabelecer no futuro, valores de calibração absoluta para os métodos minimamente invasivo e não invasivo em $\mathrm{mmHg}$, unidade padrão para a medição de pressão intracraniana.

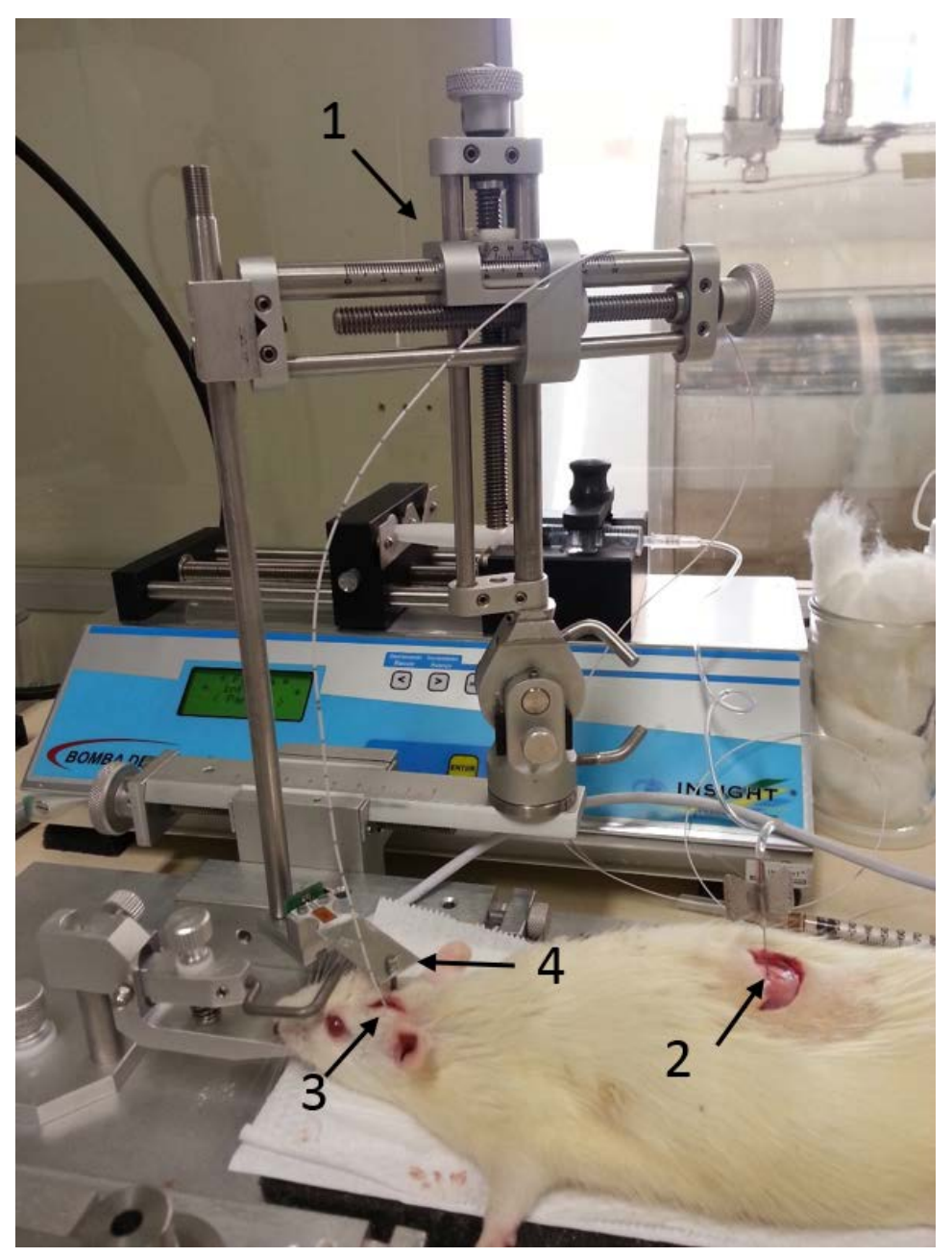

Figura 78 - Montagem do teste de infusão - (1) Haste Estereotáxica, (2) Agulha de infusão, (3) Sensor Invasivo CODMAN, (4) Sensor Não Invasivo 
Diferente do utilizado em humano, o sensor não invasivo para detecção ou monitoramento da PIC em ratos é constituído por um suporte para uma barra sensora, adaptada para estabilizar e fixar o sensor de deformação (strain gage), e em uma das extremidades da barra de detecção (sensora), existe um pino configurado para contato com a cabeça do animal. Essa diferença se dá pela impossibilidade de adequar o sensor Brainstrap na cabeça do rato. O desenho da barra sensora é o mesmo, porém a barra é engastada em um apoio estereotáxico. (Figura 79)(MASCARENHAS; VILELA, 2013).

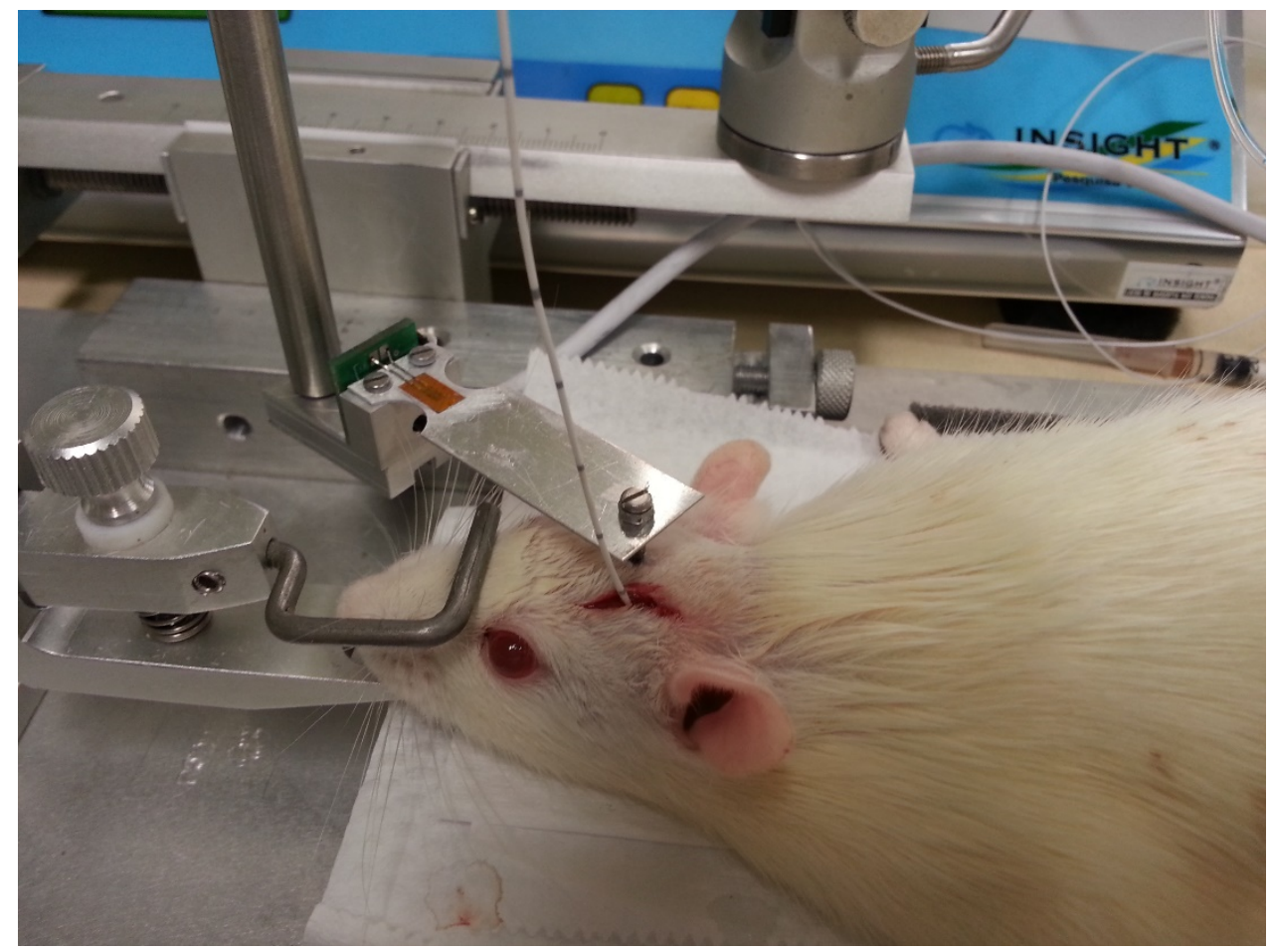

Figura 79 - Detalhe do posicionamento do SENSOR NI e do CODMAN na cabeça do Rato

\section{Animais}

Foram utilizados no protocolo experimental 4 ratos machos, adultos, da linhagem Wistar, com massa corporal entre 250 e 350 gramas, proveniente de biotério particular (ANILAB Animais de Laboratório, CNPJ 65.440.612/0001-40).

Os experimentos foram realizados no Centro de Imagens e Espectroscopia "in vivo" por Ressonância Magnética para Estudo de Modelos Animais (CIERMag), 
do Instituto de Física da USP de São Carlos. Os ratos permaneceram em biotério próprio do laboratório, acondicionados em grupos de cinco, sob as seguintes condições: regime de luz (12 horas claro e 12 horas escuro), temperatura controlada $\left(22^{\circ} \pm 2^{\circ} \mathrm{C}\right)$, alimentação com ração comercial e água ad libitum.

Todos os procedimentos seguiram os preceitos do Colégio Brasileiro de Experimentação Animal (COBEA), visando minimizar o sofrimento e dor, bem como reduzir o número dos animais necessários para a análise estatística confiável, e foram aprovados pelo comitê de ética no uso de animais da Universidade Federal de São Carlos (Protocolo número 016/2013). Imediatamente após o término dos experimentos, os animais foram eutanasiados por decapitação e as carcaças encaminhadas para serviço de coleta especializado em descarte de material biológico.

Antes dos procedimentos experimentais os ratos foram pesados e posteriormente anestesiados com quetamina, $95 \mathrm{mg} / \mathrm{kg}$ de massa corpórea e xilasina, $12 \mathrm{mg} / \mathrm{kg}$ de massa corpórea por via intramuscular. As etapas prévias à cirurgia de implantação dos sensores nos animais consistiram de tricotomia da região superior da cabeça, assepsia com clorexidina 2\% e aplicação de lidocaína (cloridrato de lidocaína 2\% com norepinefrina 1:50000) na região, utilizando uma dose de 0,5 mL/animal. A cirurgia consistiu de incisão com bisturi na região medial da cabeça dos animais no sentido anteroposterior, afastamento da camada de pele e periósteo com o auxílio de afastadores e exposição do osso craniano, somente da região de implantação dos sensores minimamente invasivo e invasivo, mantendo-se a região contralateral intacta. As regiões parietal e frontal de um dos hemisférios do osso craniano foram limpas e secas utilizando-se peróxido de hidrogênio.

Para a inserção do sensor intraparenquimatoso, foi feita uma trepanação no osso parietal paralelo ao lado da colagem do sensor minimamente invasivo em cada rato. O sensor não invasivo foi posicionado sobre a pele da cabeça, especificamente na região parietal, contralateralmente ao sensor invasivo, por meio de deslocamentos do braço da estrutura estereotáxica ao qual o sensor está acoplado. Posteriormente a estes procedimentos, foram realizados os monitoramentos da PIC simultaneamente, com os animais ainda anestesiados. 
Durante todos os procedimentos de monitoramento da pressão intracraniana, os animais também foram monitorados quanto à sua frequência cardíaca e saturação de oxigênio, com o auxílio de um oxímetro de pulso (SurgiVet ${ }^{\circ}$, modelo V9004), colocado em uma das patas traseiras do animal.

Uma vez que os dois sensores foram instalados nas suas devidas regiões, deuse início aos procedimentos de monitoramento da pressão intracraniana, que consistiram de dois protocolos: monitoramento de linha de base e monitoramento durante infusão escalonada de líquido no canal espinal.

O monitoramento de linha de base consiste na determinação de um padrão para a pressão intracraniana, e foi realizado um monitoramento de 5 minutos para cada animal, o qual permanece em decúbito ventral durante todo o período.

A infusão escalonada de líquido compreende a variação da pressão intracraniana por meio de injeções de solução salina 0,9\% no canal espinal dos animais, por meio de punção lombar. Durante a infusão, aumenta-se a quantidade de líquido na caixa craniana, o que leva ao aumento do volume intracraniano e consequentemente ao aumento da pressão intracraniana. $O$ protocolo de infusão escalonada foi realizado com o auxílio de uma bomba de infusão (Insight ${ }^{\circledR}$, modelo EFF 311), na qual foi acoplada uma seringa de $5 \mathrm{~mL}$, completamente preenchida com solução salina 0,9\%. A seringa foi ligada à uma cânula acoplada à uma agulha scalp butterfly (27G), que foi inserida no canal espinal dos animais entre as vertebras lombares $L 4$ e $L 5$, através de uma incisão lombar na pele. A infusão foi contínua, a uma taxa de 0,1 $\mathrm{mL} / \mathrm{min}$, e realizada três vezes para cada animal, injetando-se $1 \mathrm{~mL}$ em cada infusão. Previamente ao início das infusões, a pressão intracraniana foi monitorada por 5 minutos (monitoramento de linha de base), com intervalo de 5 minutos entre as infusões. Ao fim da última infusão, a pressão intracraniana foi monitorada por mais 5 minutos. 


\section{Resultados e Discussões}

\subsection{Análise da Simulação em Elementos Finitos}

A simulação foi realizada aplicando-se uma força de $0.4 \mathrm{~N}$ na base dos pinos na direção $Z$ de cada uma das barras.

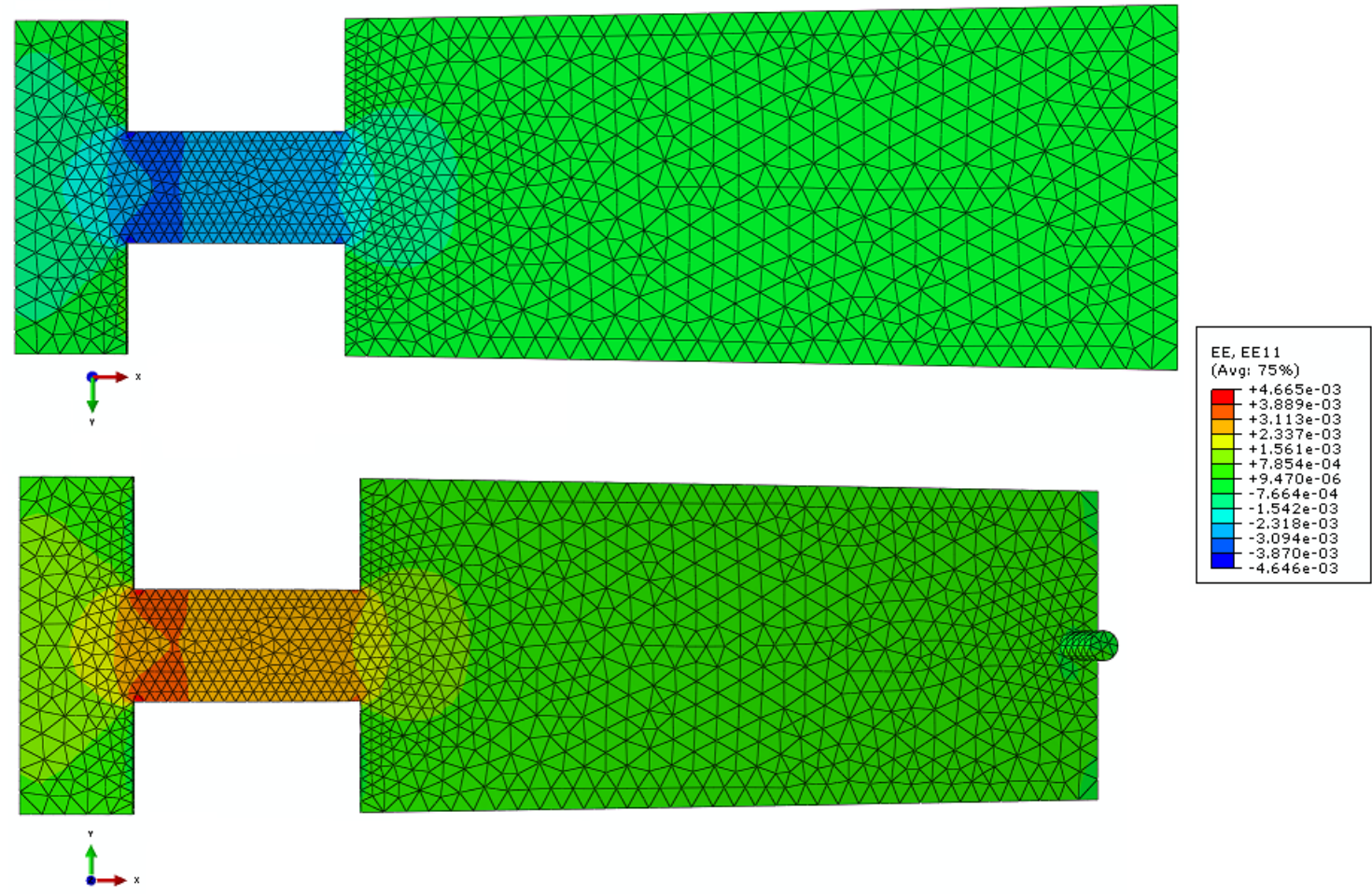

Figura 80 - Barra sensora com entalhe retangular - Análise da deformação no eixo X (E11).

A Figura 80 e a Figura 81 mostram o comportamento da deformação elástica dos dois modelos de barra sensora. 


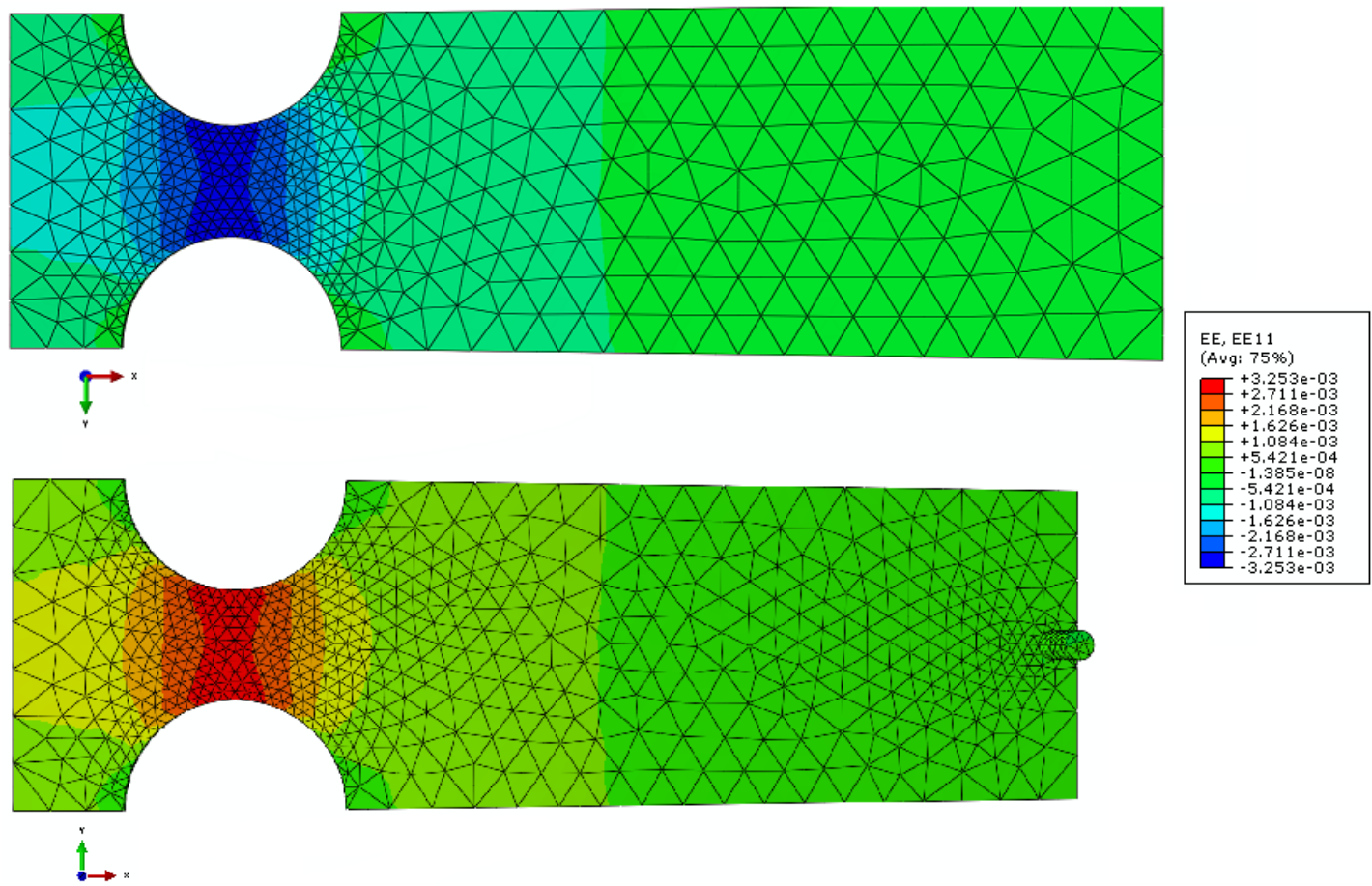

Figura 81 - Barra sensora com entalhe semicircular - Análise da deformação no eixo X (E11).

Percebe-se claramente que a nova barra (Figura 81) concentra as maiores deformações mais ao centro do entalhe. A barra antiga (Figura 80) gera uma concentração de tensões máximas nas quinas dos entalhes. Essas concentrações podem gerar fraturas comprometendo a medição ao longo do tempo.

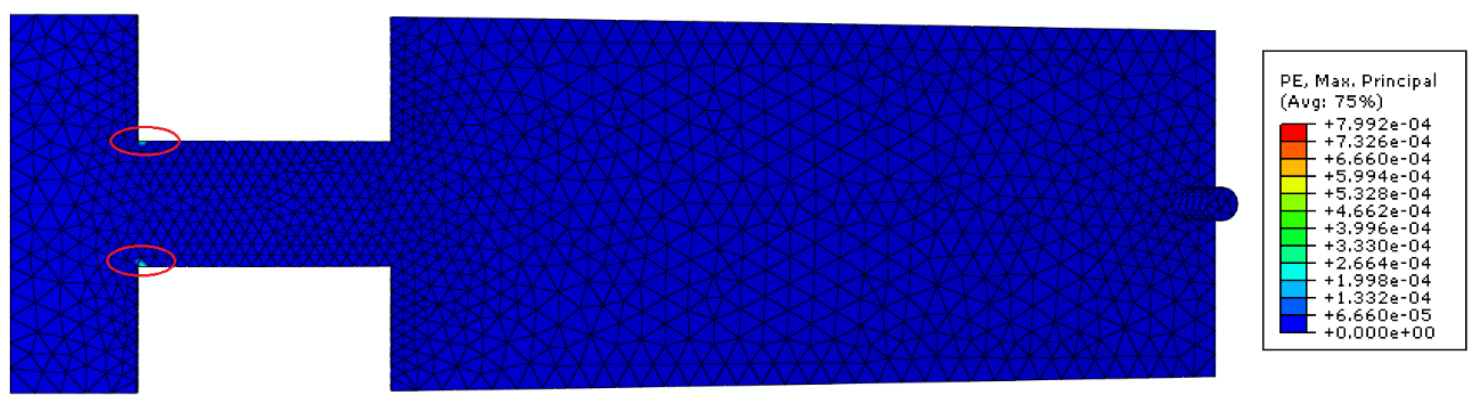

$\stackrel{\leftrightarrow}{\rightarrow}$

Figura 82 - Deformações Plásticas na barra com entalhe retangular.

A Figura 82 analisa a deformação plástica para a barra antiga. Percebe-se que ocorreu a deformação inelástica nas áreas selecionadas. A Figura 83 mostra o detalhe da deformação sofrida. 


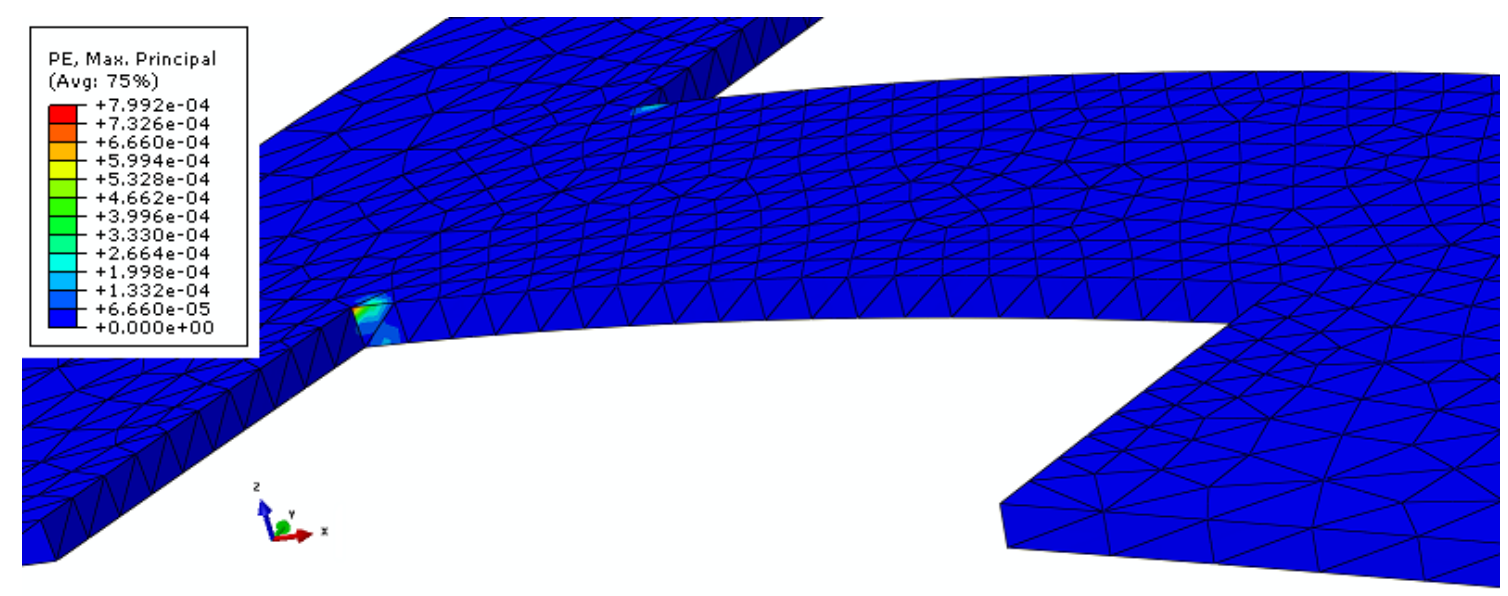

Figura 83 - Detalhe da deformação plástica.

A Figura 84 mostra a ausência de deformação plástica para a simulação da barra com entalhe semicircular.

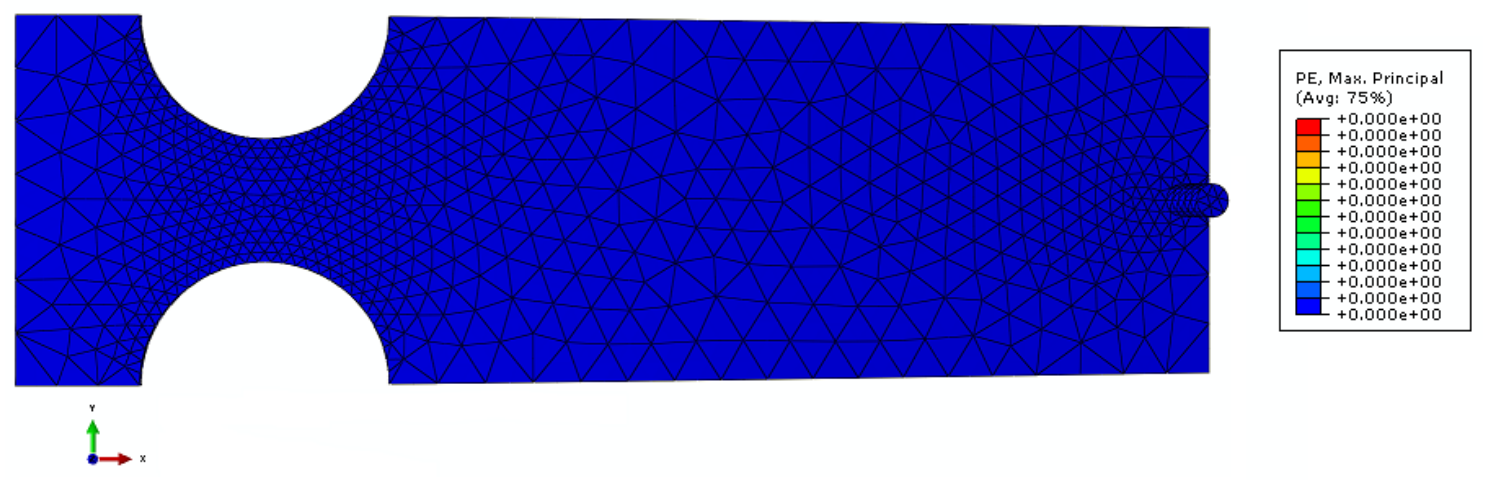

Figura 84 - Ausência de Deformação Plástica na nova barra sensora (entalhe semicircular).

Para a aplicação de $0.4 \mathrm{~N}$ de força no pino, a nova barra sensora não sofreu deformação plástica. A Figura 85 mostra o deslocamento simulado para essa força. 


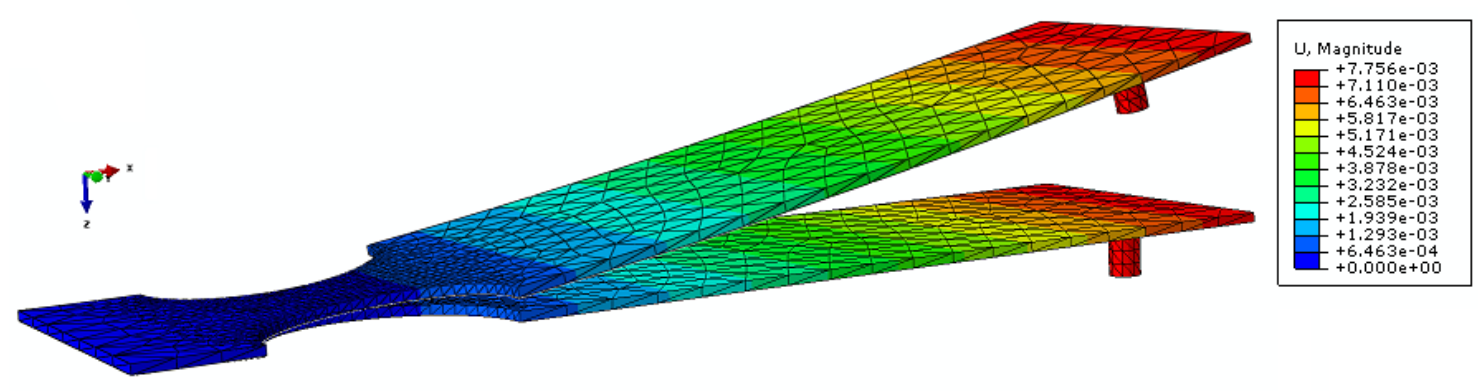

Figura 85 - Deslocamento da barra com entalhe semicircular.

A deflexão do pino foi de aproximadamente $7.75 \mathrm{~mm}$. Essa deflexão não gerou deformação plástica, o que indica que qualquer deslocamento abaixo desse valor também não deformará plasticamente a barra. Para proteção do sensor, o deslocamento máximo permitido dentro da caixa do sensor é limitado em aproximadamente $3 \mathrm{~mm}$. Esse valor é suficiente para o monitoramento da PIC no modelo atual.

A concentração de tensão da barra sensora foi revisada e projetada de forma semicircular dos dois lados a fim de concentrar as tensões no ponto de leitura do strain gauge. O entalhe antigo era retangular e não concentrava as maiores deformações na região onde o strain gauge é colado, além disso, muitos sensores perdiam a sensibilidade com pouco tempo de uso. Essa perda da sensibilidade pode estar ligada a deformações plásticas que foram vistas na Figura 83 e na Figura 84. 


\subsection{Análise mecânica do sensor}

A Figura 86 mostra os ciclos iniciais (1000 segundos) do teste dinâmico do Sensor 11. A máquina ferramenta alterna seis movimentos curtos de $15 \mu \mathrm{m}$ e um movimento longo de $2 \mathrm{~mm}$.

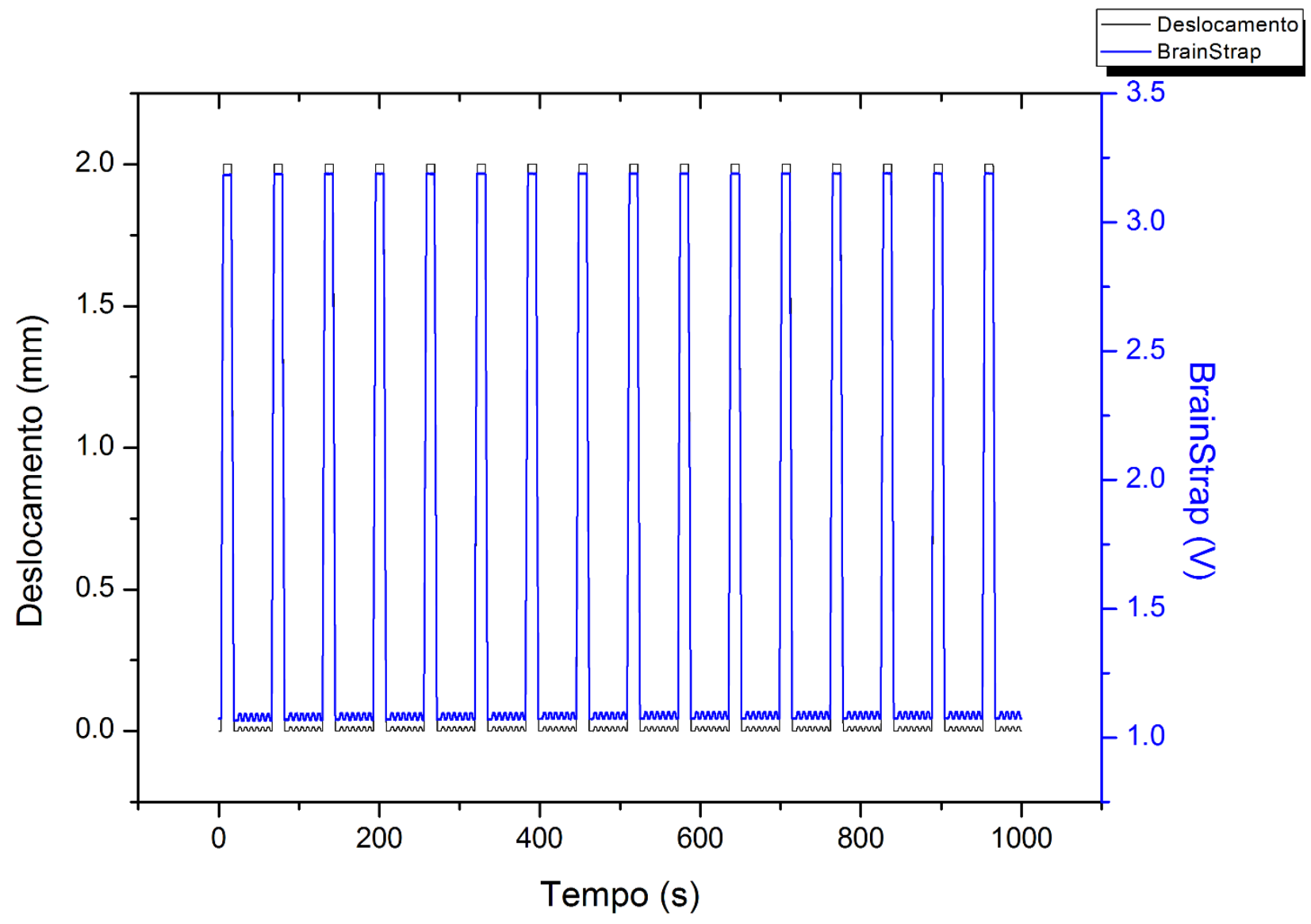

Figura 86 - Análise dos ciclos de teste Sensor Brain 11

As deflexões de $2 \mathrm{~mm}$ que simulam a retirada o sensor Brainstrap da cabeça, tiveram a função de estressar as barras sensoras para analisar experimentalmente se as mesmas sofreriam algum tipo de deformação plástica. A Figura 87 exibe o gráfico do teste proposto para os três sensores. 


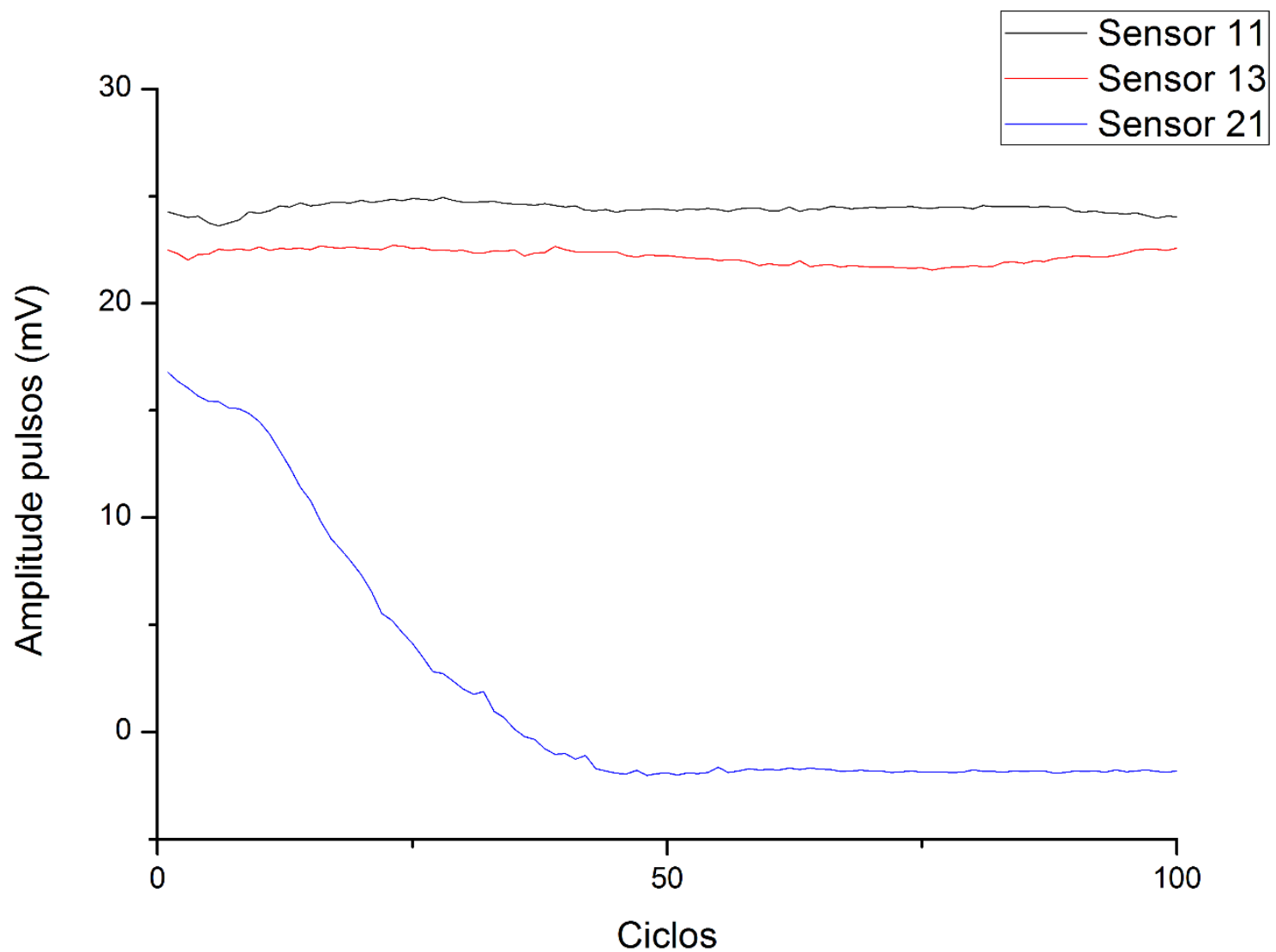

Figura 87 - Gráfico comparativo da média da amplitude dos pulsos por ciclo referentes às deflexões de 15 $\mu \mathrm{m}$ lidos dos três sensores BrainStrap.

No gráfico da Figura 87 pode-se perceber que um dos sensores (Sensor 21) perdeu a sensibilidade de leitura das pequenas deflexões de $15 \mu \mathrm{m}$ ao passar dos ciclos. O motivo não foi identificado, porém acredita-se que a barra sensora possa ter sido deformada plasticamente durante o corte, ou montagem do sensor. Por esse motivo seus dados não foram utilizados para os resultados estatísticos a seguir:

Tabela 7 - Resultados estatísticos do Teste dos Sensores BrainStrap

\begin{tabular}{|c|c|c|c|c|}
\cline { 2 - 5 } \multicolumn{1}{c|}{} & $\begin{array}{c}\text { Média Sensor } \\
\text { BrainStrap } \\
(\mathbf{m V})\end{array}$ & $\begin{array}{c}\text { Desvio Padrão } \\
\text { Sensor BrainStrap } \\
(\mathbf{m V})\end{array}$ & $\begin{array}{c}\text { Média de } \\
\text { Deslocamento } \\
(\mathbf{u m})\end{array}$ & $\begin{array}{c}\text { Média de } \\
\text { Sensibilidade } \\
(\mathbf{m V / u m})\end{array}$ \\
\hline Sensor 11: & 24.43 & 0,25 & 14,8 & 1,65 \\
\hline Sensor 13: & 22,20 & 0,33 & 14,8 & 1,50 \\
\hline
\end{tabular}


A Tabela 7 exibe os resultados estatísticos realizados com os dados do gráfico da Figura 87. A última coluna da tabela é referente à sensibilidade dos sensores em relação aos deslocamentos impostos.

A diferença de sensibilidade média percebida de um sensor para o outro $(1,65 \mathrm{x}$ $1,50)$ pode ser causada por diversos fatores, uma vez que a montagem dos sensores é feita de forma manual e ainda não se tem o controle de qualidade dos componentes e dos processos, que vão desde o corte da barra sensora, até a colagem e valores de resistência dos strain gauges. A calibração individual dos sensores é necessária devido aos fatores citados acima e pode ser feita de diferentes maneiras. Uma dessas maneiras seria por associação de trimpots na ponte que balanceariam a resistência inicial equivalente para todos os sensores (Técnica utilizada no codman). A segunda maneira (que pode ser realizada em conjunto com a primeira) é a calibração dos parâmetros da PGA309 para cada sensor, que calibrados previamente, teriam um código correspondente à calibração efetuada. O usuário entra com esse código e o equipamento se ajusta ao sensor (alterando os ganhos de amplificação e offsets).

De acordo com os resultados, percebeu-se que a repetibilidade ocorreu para os sensores que não apresentaram avarias mecânicas, com seus desvios padrões 
de $0,25 \mathrm{mV}$ para o sensor 11 e $0,33 \mathrm{mV}$ para o sensor 13. A Figura 88 mostra o histograma com a distribuição dos valores.

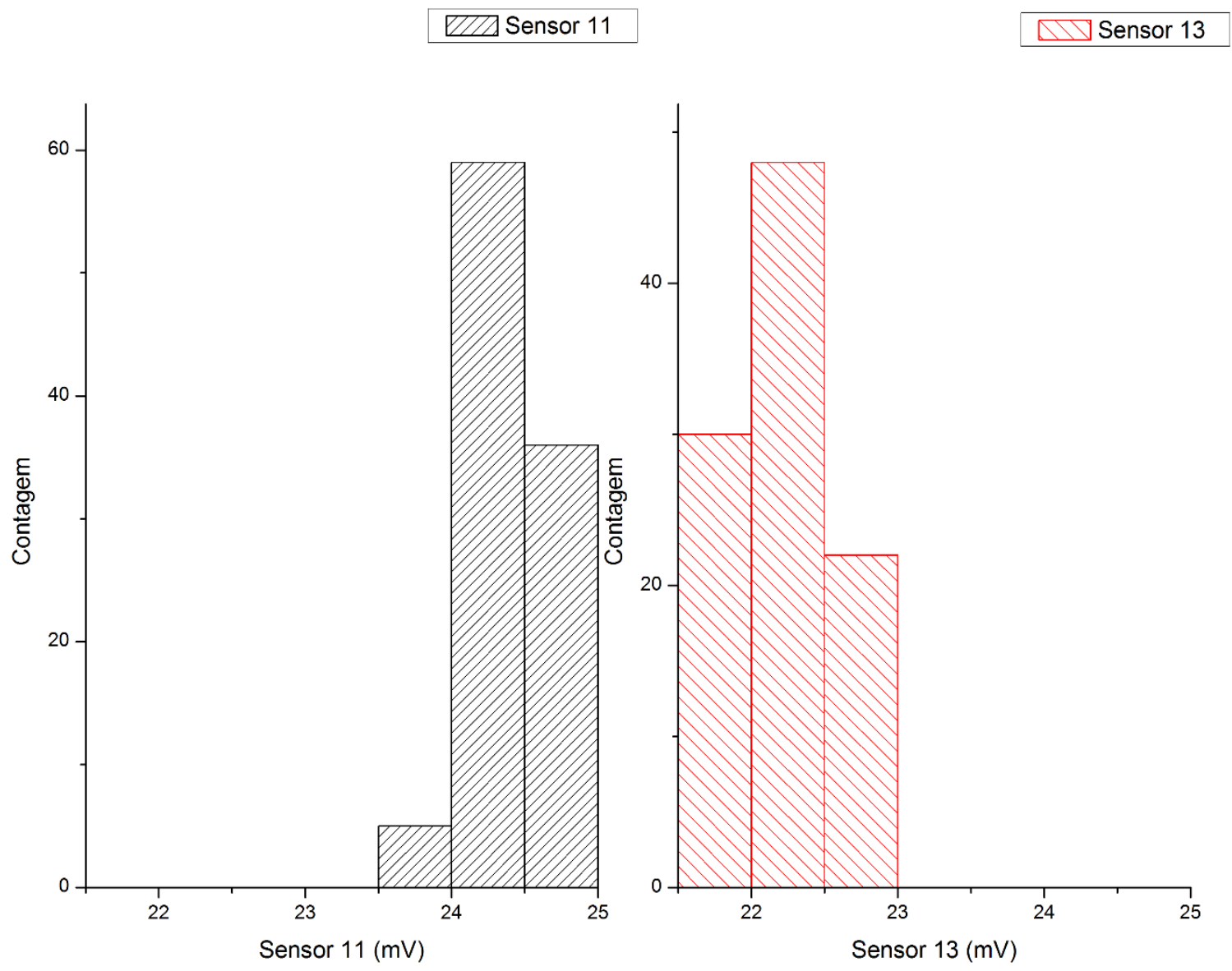

Figura 88 - Histograma da distribuição dos valores 


\subsection{Teste do Equipamento de Amplificação e Aquisição de Sinais}

A Figura 89 mostra uma janela de leitura de 4 segundos do monitoramento fisiológico realizado com o sensor não invasivo Brainstrap. O sinal preto é o sinal sem filtro e o vermelho é o com filtro de entrada. Foi selecionado um dos picos do sinal filtrado para realizar a comparação com a bibliografia.

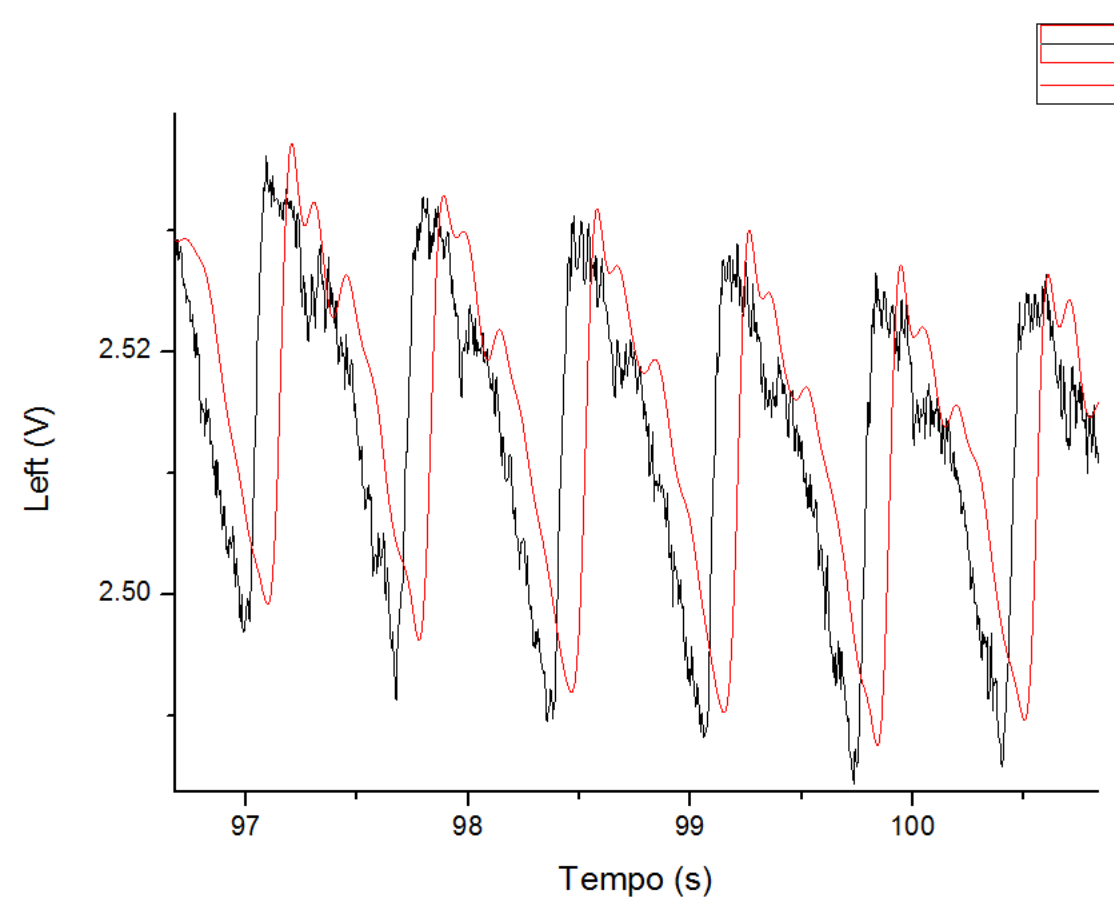

Figura 89 - Janela de leitura do monitoramento fisiológico com sensor não invasivo Brainstrap

A Figura 90 mostra o pulso da PIC com os traços (variações entre pulsos) conhecidos com P1, P2 e P3. 


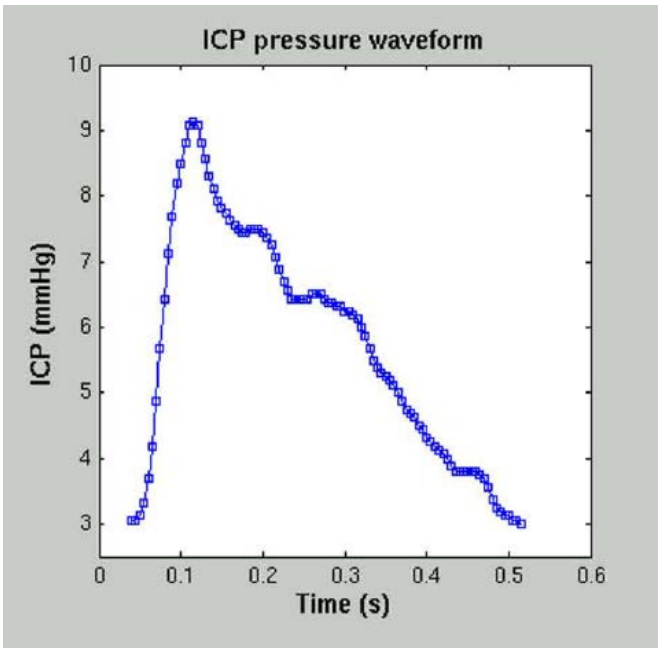

Figura 90 - Pulso da PIC medido invasivamente - PIC (mmHg) versus tempo (s) (WAGSHUL, EIDE,MADSEN, 2011)

De acordo com o gráfico da Figura 90 a amplitude (a variação da pressão intracraniana medida com sensor invasivo) do pulso P1é de aproximadamente 6 $\mathrm{mmHg}$. Sabe-se que esse valor não é exato e nem fixo, pois varia com a complacência cerebral e varia também de pessoa para pessoa devido a outros fatores. Mas com esse valor tem-se a ordem de grandeza para se chegar no span (mínimo e máximo) que o sistema deverá ser capaz de ler.
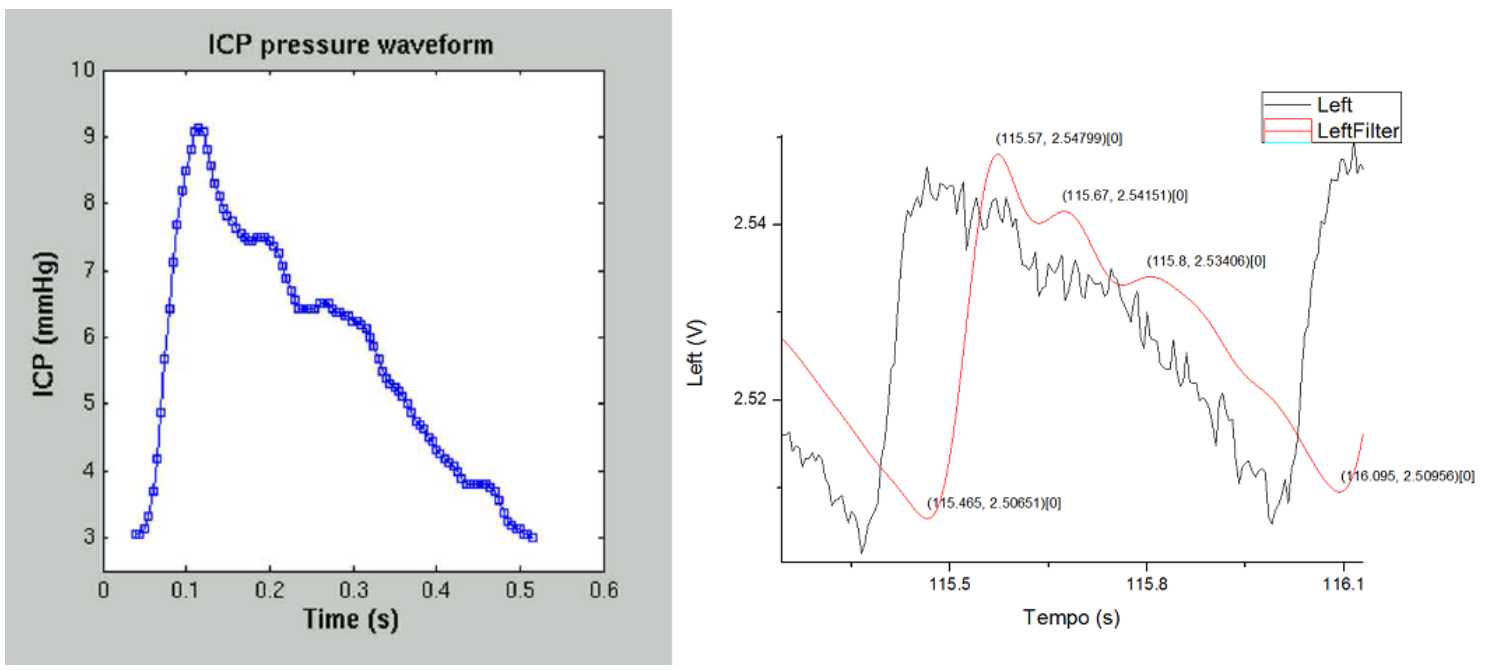

Figura 91 - Comparação entre as formas de onda do Sistema Invasivo (Esquerda) contra o Sistema Não Invasivo de monitoramento da PIC (Direita) de indivíduos distintos. 
Considerando que para cada pulso da PIC do sistema amplificado o valor do pulso P1 seja de 41.48 mV. Dividindo-se por 1152 (Ganho da PGA) e dividindo novamente por 5 (Tensão de entrada em Volts), o valor captado pelo sensor é de $7 \mu V / V$ para o pulso da PIC monitorado com o sistema Brainstrap.

Sabe-se que quanto maior a pressão intracraniana, menor a complacência cerebral e logo, maior a amplitude dos pulsos da PIC, porém idealizando o pior caso para o projeto da amplificação máxima necessária e considerando o pulso da PIC constante com $9 \mathrm{mmHg}$ de amplitude com o sensor invasivo e $35 \mu \mathrm{V}$ $\left(7 \frac{\mu V}{V} * 5 V\right)$ a amplitude do pulso da PIC monitorada pelo Brainstrap, a relação entre as medidas é de aproximadamente $3.89 \mu \mathrm{V} / \mathrm{mmHg}$.

Para a leitura no intervalo de 0 a 100 mmHg, o sensor terá como saída o valor de $389 \mu V$ de span. Para uma aquisição de 0 a 5 volts, a amplificação máxima necessária seria de 12858 vezes. A amplificação máxima atual do equipamento em desenvolvimento é de 1152 (Amplificação máxima da PGA309).

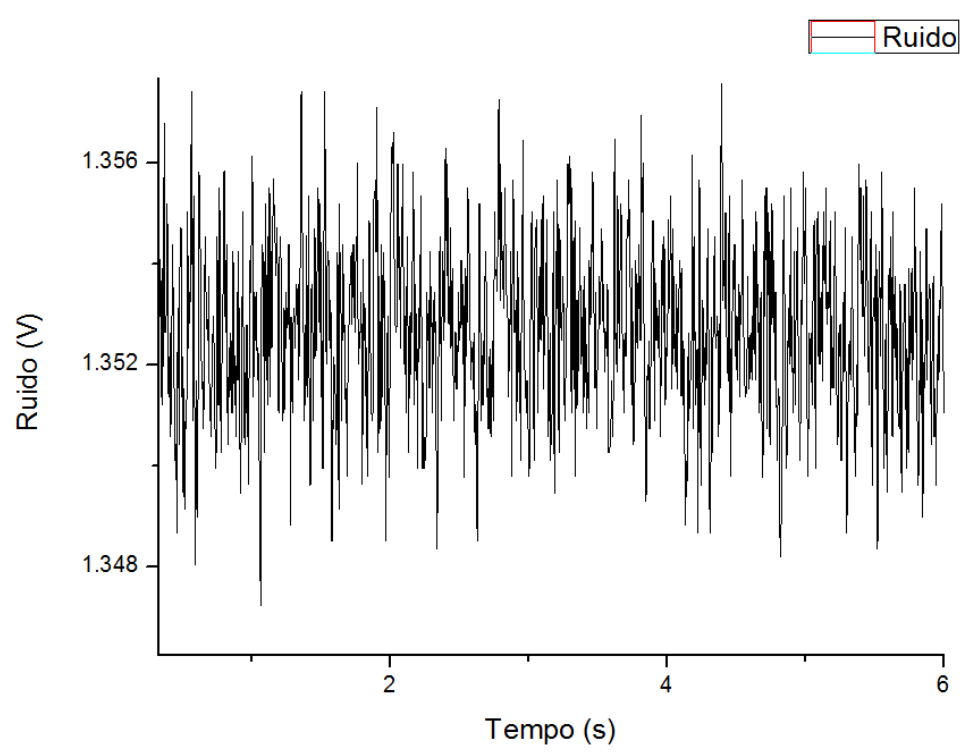

Figura 92 - Ruído de Zero Drift

A Figura 92 mostra o Zero Drift do sensor Brainstrap com o equipamento atual. Esse ruído é intrínseco ao amplificador e está na mesma ordem de grandeza dos 
traços da PIC como pode ser visto na Figura 91 com a forma de onda não filtrada (gráfico do lado direito - cor preta).

A relação atual entre a amplificação, ruído e a resolução de leitura, não é suficiente para detectarmos com segurança a morfologia dos traços da PIC pois estes estão muito próximos de ordem de grandeza do ruído do sistema. Apesar do sinal filtrado ser bem semelhante, o ruído pode estar interferindo na morfologia dos traços da PIC monitorados com o sistema não invasivo.

Com esses resultados, tem-se uma visão mais clara dos requisitos necessários para o projeto do próximo equipamento. Entretanto, vale ressaltar a grande importância que teve a primeira fase do projeto com o uso da PGA309. 


\subsection{Análise dos testes in vivo}

\subsubsection{Testes durante exercício físico}

As Figuras abaixo mostram as análises das pressões arteriais dos dois grupos.

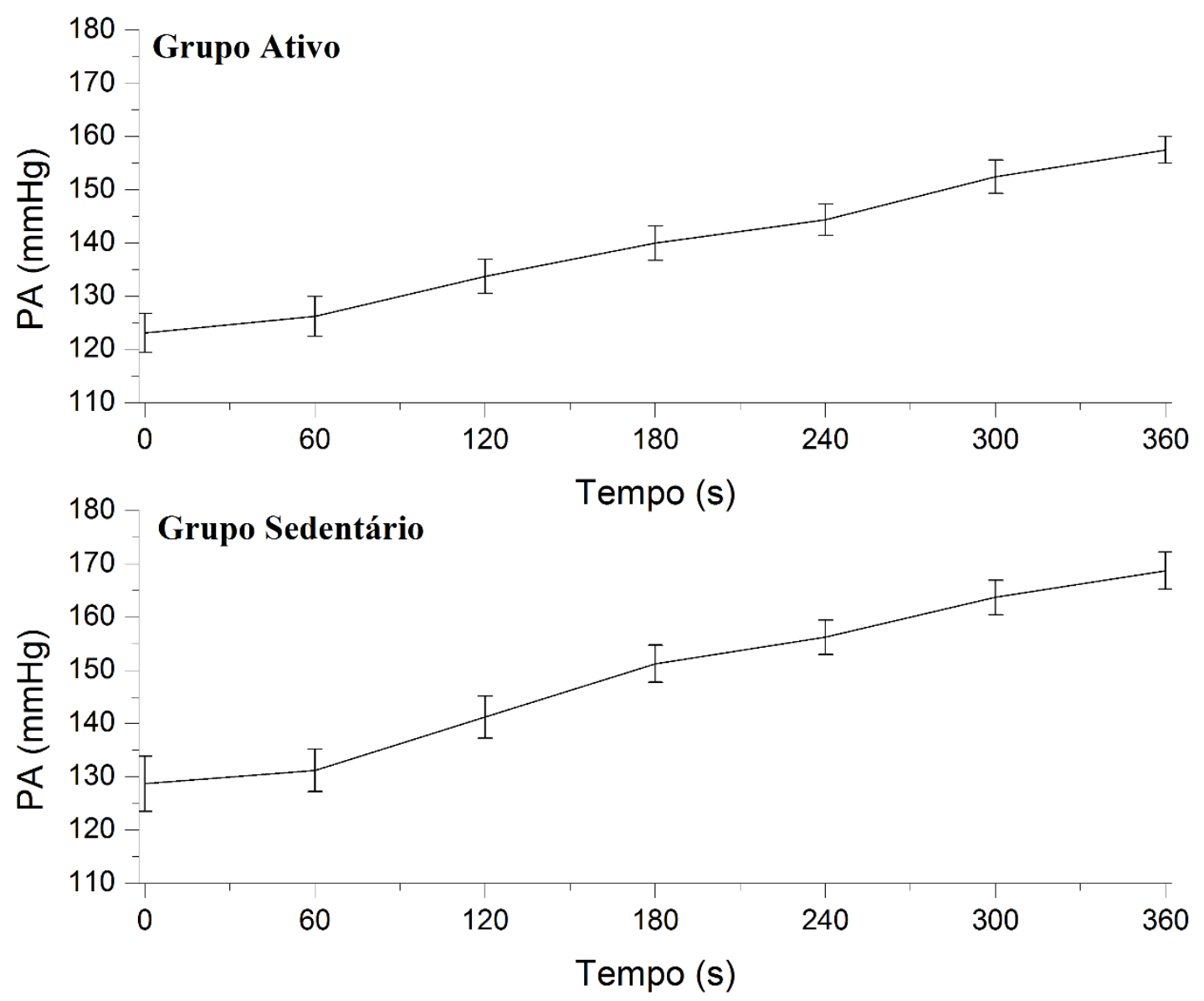

Figura 93 - Monitoramento da pressão arterial periférica durante exercício aeróbico. O Gráfico mostra a pressão sendo aferida a cada 60 segundos. A linha mostra a média e a barra mostra o erro quadrático entre os valores medidos da PA para os participantes de cada grupo. O primeiro gráfico mostra os resultados do grupo ativo (Militares de 19 anos de idade) e o segundo gráfico mostra o grupo dos sedentários (Homens de 27士 6 anos de idade).

O Sensor não invasivo Brainstrap, foi capaz de monitorar a pressão intracraniana durante o repouso e durante as atividades aeróbicas dos voluntários. A análise da pressão arterial mostra que a atividade física influencia esse parâmetro. Comparando os grupos, durante o repouso, a pressão sistólica média foi de 124 $\mathrm{mmHg}$ no grupo ativo, contra $129 \mathrm{mmHg}$ no grupo dos sedentários. Após 6 
minutos de exercício o grupo dos sedentários teve um aumento superior de 40 $\mathrm{mmHg}$, quando comparado ao aumento do grupo ativo (33 $\mathrm{mmHg}$ ).
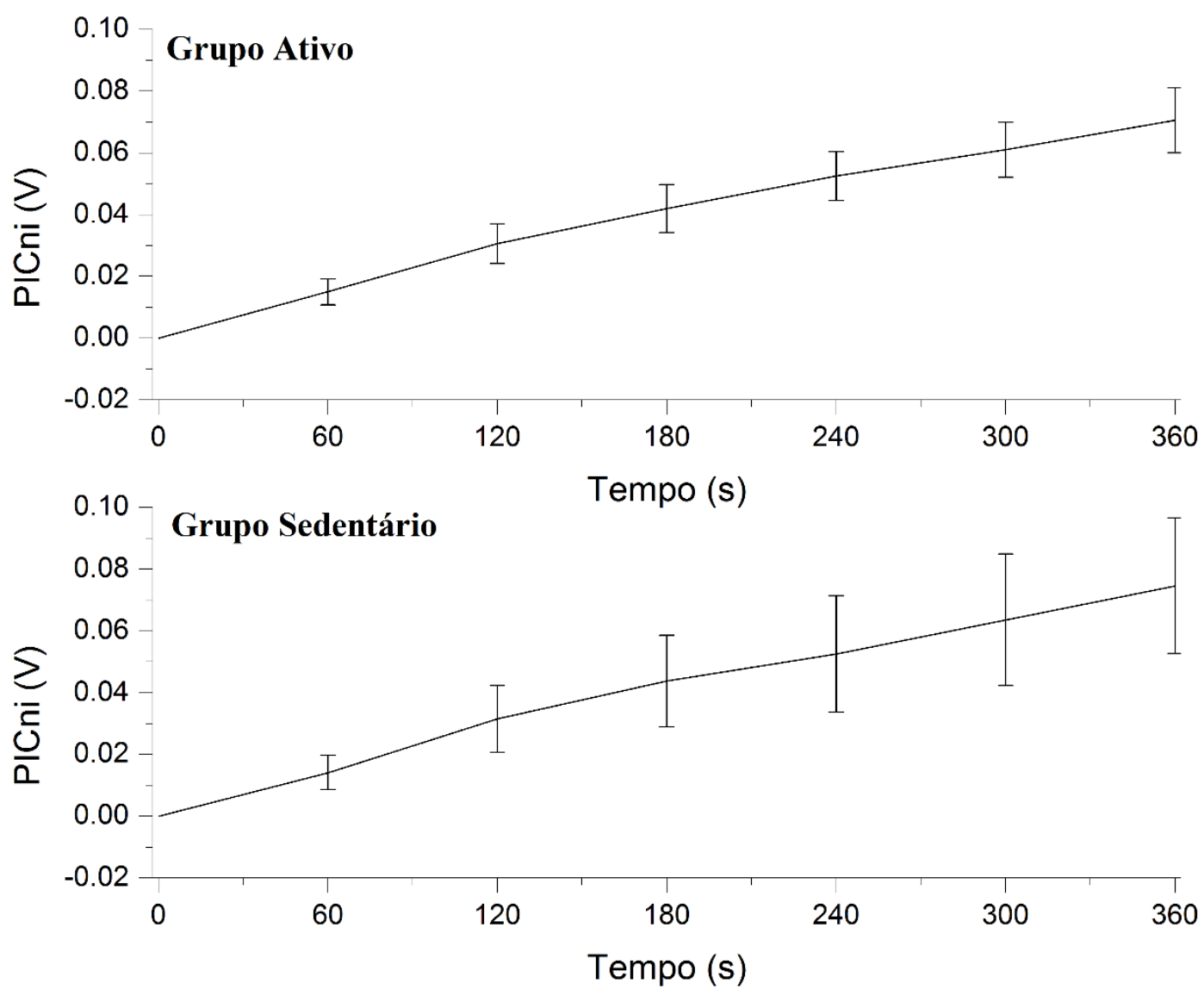

Figura 94 - Monitoramento da Pressão Intracraniana utilizando o sensor não invasivo BrainStrap. A linha mostra a média e a barra mostra o erro quadrático entre os valores medidos da PA para os participantes de cada grupo. O primeiro gráfico mostra os resultados do grupo ativo (Militares de 19 anos de idade) e o segundo gráfico mostra o grupo dos sedentários (Homens de $27 \pm 6$ anos de idade).

O monitoramento da PIC de forma não invasiva seguiu a tendência da pressão arterial observada nos exercícios aeróbicos. O grupo sedentário, semelhante ao acontecido com a pressão arterial, apresentou uma maior variação dos valores de monitoramento da PIC (75 mV), em comparação com o grupo ativo (71mV).

Além disso, analisando os dados do monitoramento da PIC, o grupo dos sedentários apresentou um maior erro quadrático quando comparado ao grupo ativo. Esse resultado era esperado devido à heterogeneidade de condicionamento físico e idade dos participantes do grupo. Esse erro foi aumentando conforme o aumento da atividade física, mostrando que o grupo de sedentários era bastante heterogêneo com relação ao condicionamento físico. 
5.4.2 Análise da comparação do sensor não invasivo com o CODMAN em animais

A análise dos quatro ratos estão dispostas nas imagens abaixo. As correções dos sinais, foram implementadas por uma média dinâmica de 10 segundos de janela.
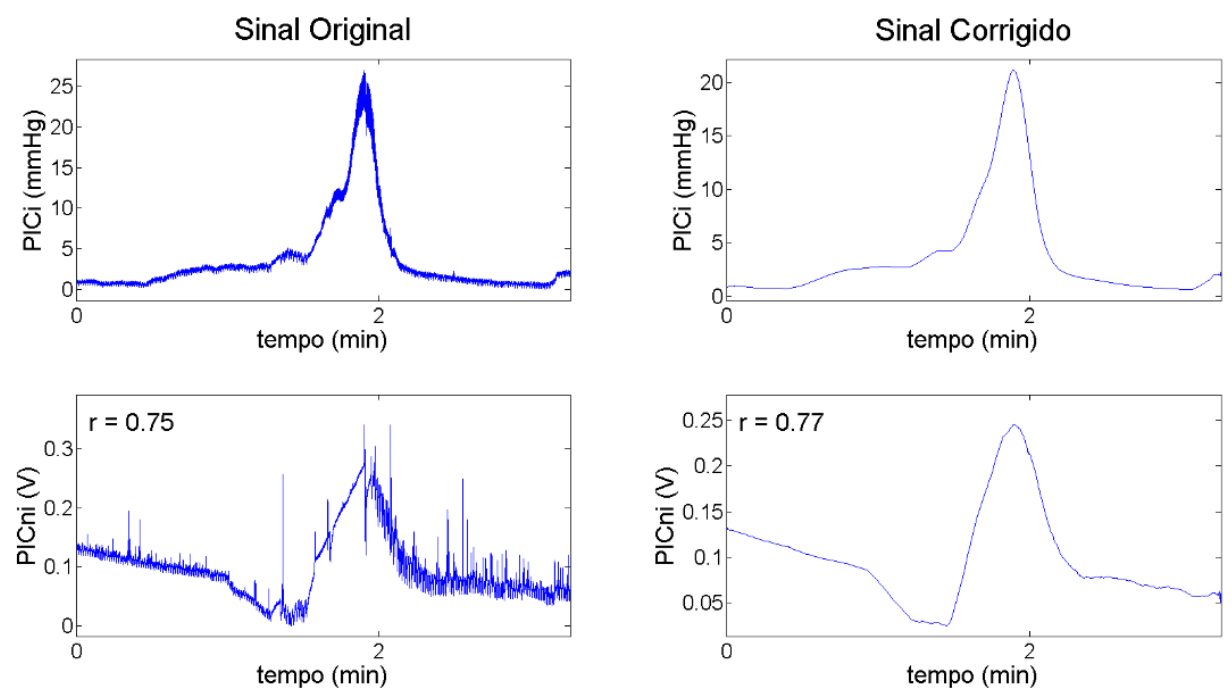

Figura 95 - Infusão aguda - Rato 01: Série temporal para a PICi ( $\mathrm{mmHg}$ ) e PICni (V) durante infusão aguda de solução salina. A correlação de Pearson foi calculada para o sinal original e para o sinal corrigido.

O sinal da PICni do Rato 01 possui muitos artefatos de origem mecânica, ou seja, o pino do sensor sofreu influência de movimentações do rato. Esses artefatos ocorrem geralmente quando o animal não se encontra completamente sedado e sua respiração causa uma movimentação do crânio do rato que muda o posicionamento do pino. Ainda assim a correlação foi boa apresentando um valor de 0.75 para o sinal bruto. 

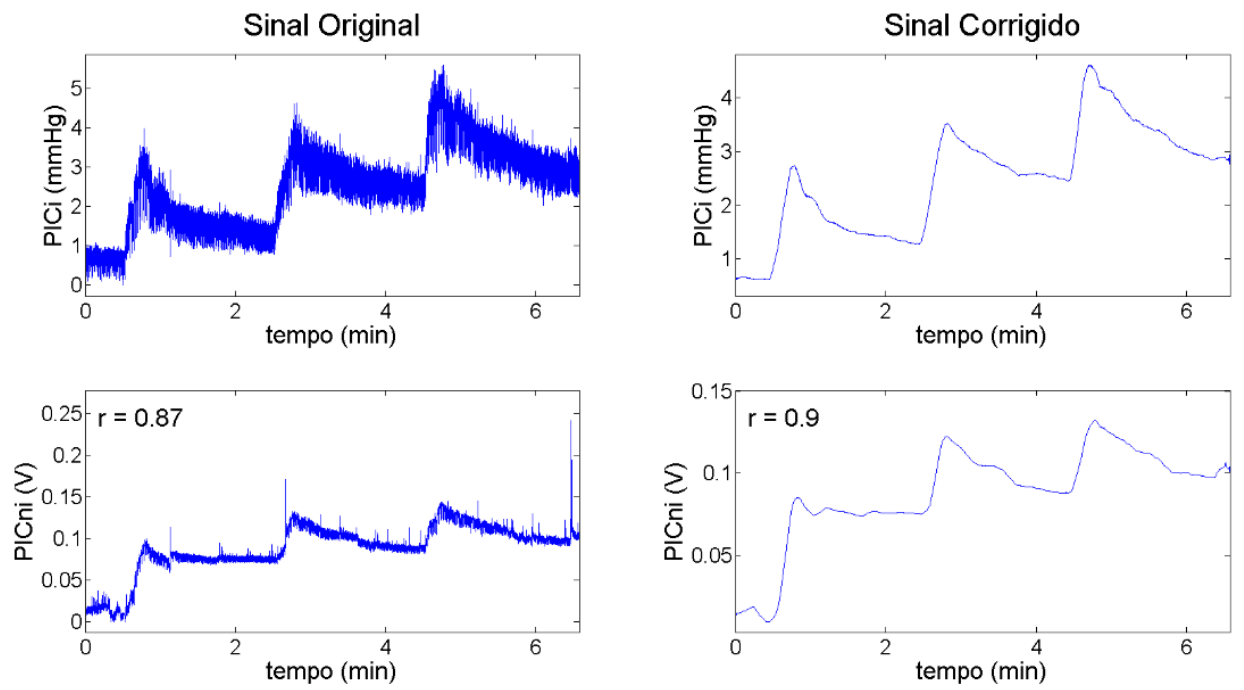

Figura 96 - Três infusões agudas - Rato 02: Série temporal para a PICi (mmHg) e PICni (V) durante sequência de infusões agudas de solução salina. A correlação de Pearson foi calculada para o sinal original e para o sinal corrigido.

A leitura da PICni do Rato 02 para as três infusões subsequentes, se mostrou muito boa, com uma correlação de 0.87 para o sinal bruto e 0.9 para o sinal corrigido. Neste Rato também houve muita interferência da movimentação devido a respiração, deslocando um pouco a linha de base em alguns instantes.
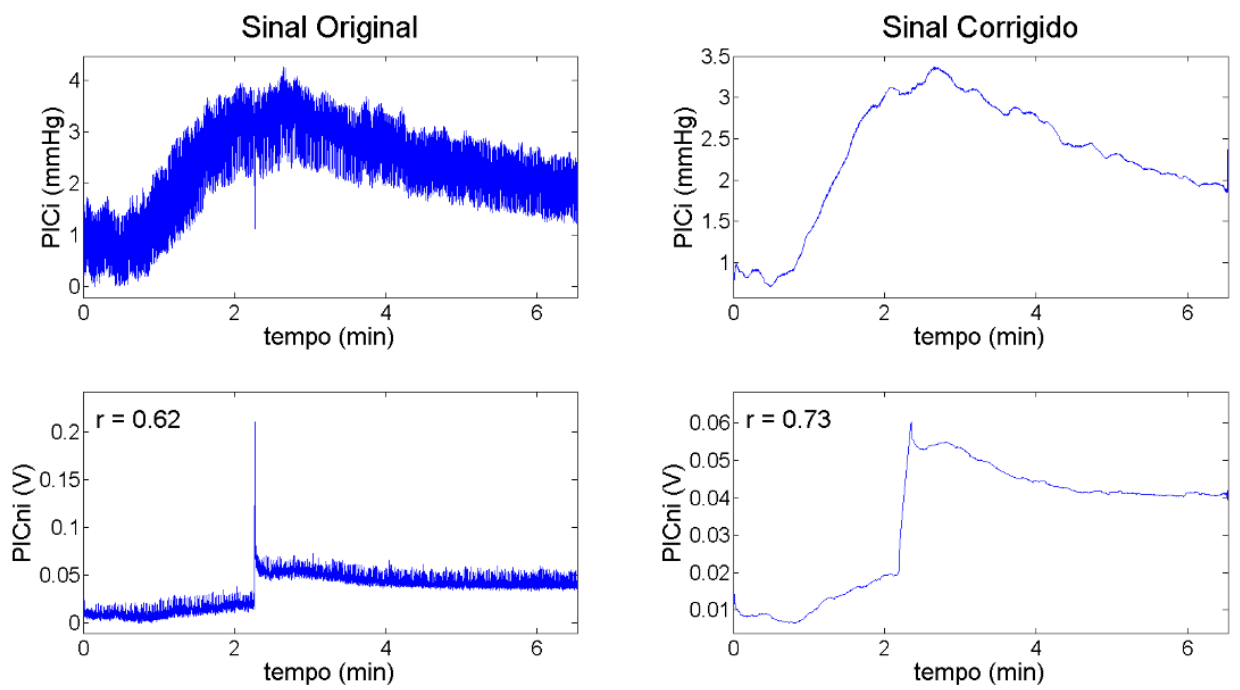

Figura 97 - Infusão aguda - Rato 03: Série temporal para a PICi (mmHg) e PICni (V) durante infusão aguda de solução salina. A correlação de Pearson foi calculada para o sinal original e para o sinal corrigido.

Para o Rato 03 uma infusão aguda foi feita e um erro de medição foi encontrado. Após dois minutos de monitoramento, o rato teve uma respiração profunda, o 
que movimentou e alterou a linha de base da medição, resultando obviamente em uma menor correlação (0.62) para o sinal bruto.
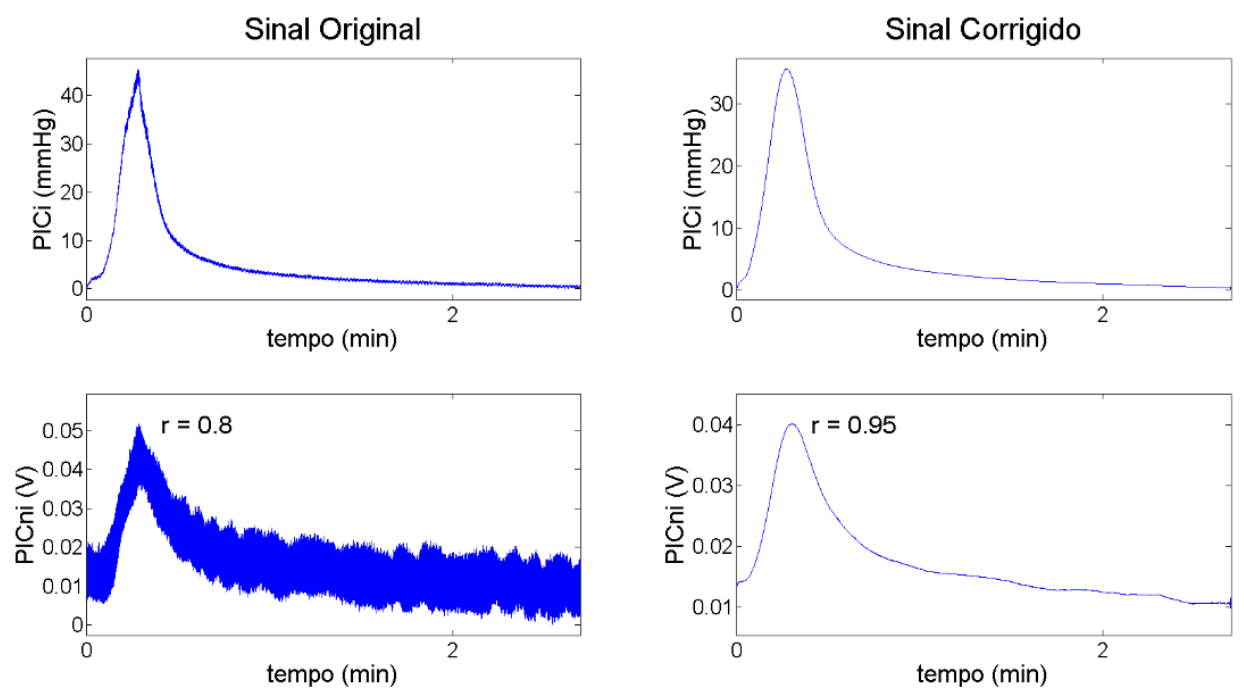

Figura 98 - Infusão aguda - Rato 04: Série temporal para a PICi (mmHg) e PICni (V) durante infusão aguda de solução salina. A correlação de Pearson foi calculada para o sinal original e para o sinal corrigido.

A Figura 98 mostra o melhor resultado do experimento. O Rato 04 permaneceu sedado durante a infusão. A linha de base não foi alterada, tendo como resultado um ótimo coeficiente de correlação de 0.95 para o sinal corrigido. 

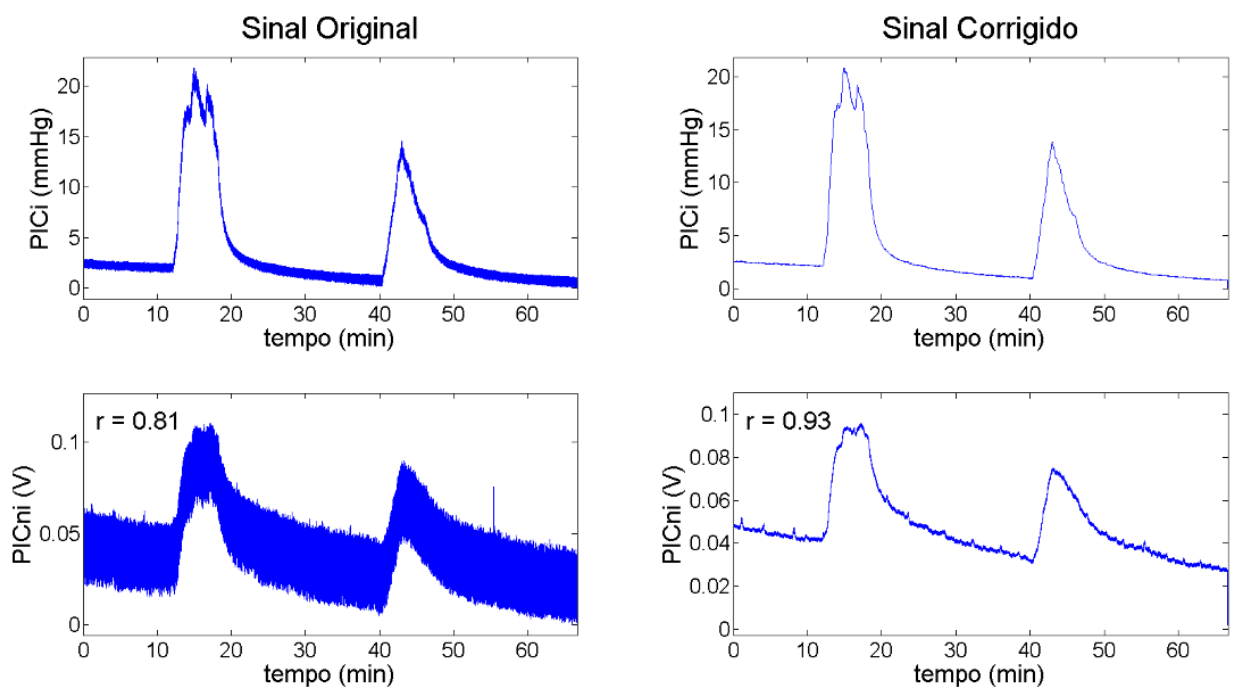

Figura 99 - Duas infusões agudas - Rato 05: Série temporal para a PICi $(\mathrm{mmHg})$ e PICni $(\mathrm{V})$ durante infusão aguda de solução salina. A correlação de Pearson foi calculada para o sinal original e para o sinal corrigido.

A Figura 99 mostra o gráfico de duas infusões realizadas no Rato 05. Esse rato também permaneceu em repouso durante a leitura. O Resultado foi uma correlação de 0.93 do sinal filtrado para mais de 60 minutos de leitura.

A respiração longa que interferiu nos resultados trata-se de um reflexo respiratório decorrente da supressão do sistema cardiopulmonar pelo anestésico administrado no experimento. A combinação de quetamina e xilazina é um potente depressor do sistema cardiorrespiratório, o que leva a uma redução das frequências cardíaca e respiratória. Devido a isto, o animal quando anestesiado tende a ficar privado da concentração de oxigênio ideal para os seus tecidos, logo ele apresenta esses reflexos respiratórios recorrentes para regular a saturação de oxigênio. 


\section{Conclusões e Perspectivas}

Apesar do valor absoluto da pressão intracraniana ser um parâmetro importante, sabe-se que a morfologia da onda transmite muitas informações essenciais do comportamento do sistema nervoso central. E mostrou-se que é possível monitorar a PIC tanto em humanos quanto em ratos utilizando o sensor não invasivo desenvolvido.

É importante que os sensores suportem as forças impostas exercidas sem ocorrer deformações plásticas que comprometam a repetibilidade. Para os testes mecânicos dos sensores foi visto que os sensores suportam o procedimento de fixação durante 100 ciclos sequenciais e a diferença de sensibilidade entre as amostras é aceitável para os protótipos e deverá diminuir consideravelmente ao melhorar o processo de montagem. Ainda assim, é importante calibrar os sensores individualmente para que os erros sejam minimizados.

Como sugestão inicial para as próximas melhorias no sensor, com relação à calibração, trimpots podem ser colocados na ponte que acompanha cada sensor, para compensar o erro entre os mesmos. Um equipamento de calibração pode ser desenvolvido, seja para gerar um código que será adicionado ao equipamento de leitura, seja para auxiliar nos ajustes dos trimpots. Esse equipamento poderá exercer um deslocamento conhecido e através das equações do Capítulo 2.8 os sensores podem ser calibrados.

O corte das barras sensoras deverá ser feitas de forma controlada, através de corte à laser por exemplo buscando uma otimização no processo de fabricação do sensor. A concentração de tensão pode ser otimizada de acordo com o gráfico da Figura 17 e utilizando a simulação em Elementos Finitos.

A fixação do sensor $\mathrm{NI}$ em humanos precisa ser aperfeiçoada. O problema da movimentação é recorrente e interfere principalmente em testes durante 0 exercício físico em movimentos abruptos. A diminuição do peso do sensor como um todo (cabo + sensor) deve ser implementado para diminuir a reação do sensor aos movimentos. A fixação através de presilhas ajustáveis semelhante 
às utilizadas em capacetes de ciclistas podem ser testadas em substituição ou associação à atual fita elástica.

O design da base do sensor deve ser criteriosamente analisado e melhorado de forma que a base não prejudique ou mascare o sinal captado pela barra sensora. Atualmente a base é muito plana e longa (cerca de $10 \mathrm{~cm}$ ), o que pode dificultar o posicionamento correto do sensor dependendo da forma do crânio do indivíduo.

O posicionamento incorreto do sensor na cabeça do indivíduo pode mascarar o sinal da PIC. Se o sensor for colocado em uma região onde contenha muitos músculos, como no caso da região temporal, o sensor estará susceptível a erros advindos da contração e circulação sanguínea nos músculos. Por isso o ideal é fazer o posicionamento do sensor na região parietal lateral, pois é uma região que não contém grupos musculares e é um ponto de fixação compatível com a geometria atual do sensor.

Sendo o sensor de monitoramento da PIC sensível a movimentações é interessante analisar a movimentação do indivíduo, principalmente os movimentos respiratórios (como no caso dos ratos) que causam deslocamento da barra sensora na cabeça que leva má interpretação do sinal com o deslocamento da linha de base.

A atual fixação do sensor em ratos é através de uma haste estereotáxica. E isto não permite que o sensor acompanhe os movimentos relativos do animal. Caso ocorra um deslocamento advindo, por exemplo, de uma longa respiração, o sensor capta essa respiração e geralmente volta fora da linha de base, dificultando um monitoramento preciso da PIC nos ratos. O desenvolvimento de um sensor semelhante ao utilizados em humanos poderá corrigir o problema, porém a dificuldade em miniaturizar o sensor, está ligado a diversos fatores, inclusive o tamanho do strain gauge. Uma outra solução é a utilização de outro tipo de anestésico. Esse outro anestésico seria uma combinação de uretana e alfa-cloralose, que são drogas que reconhecidamente (FLECKNELL, 2009) e (BAZIN, 1997) tem pouco efeito depressor do sistema cardiorrespiratório. Com isso, espera-se que os animais não apresentem esses movimentos respiratórios, reflexos esses que acabam comprometendo as medidas. 
O equipamento de leitura do sensor testado neste trabalho foi de extrema importância para o desenvolvimento do sensor. Entretanto alguns requisitos como fator de amplificação e ruído podem ser melhorados e estes estão intrínsecos ao amplificador PGA309. A resolução da conversão analógica digital também pode ser melhorada. Para garantir uma melhor qualidade do sinal, busca-se trabalhar com uma alta relação sinal-ruído, onde a escolha do amplificador e do conversor A/D devem ser feitas de acordo com a resolução de leitura escolhida. Esta resolução está diretamente ligada aos traços P1, P2 e P3 da PIC que atualmente são as menores grandezas desejadas.

Sobre o software, o design dos filtros é de extrema importância e deve ser mais bem estudado para análise do sinal e para a decomposição do mesmo para obter outros parâmetros como frequência cardíaca, frequência respiratória, ondas lentas, dentre outros parâmetros. O RAP (que é a correlação linear entre a amplitude de onda da PIC e o valor da PIC média) é um ótimo parâmetro para ser incorporado ao sistema em definitivo, pois ele depende apenas do monitoramento contínuo da pressão intracraniana utilizando o presente sensor não invasivo e seria uma ótima ferramenta para auxiliar no diagnóstico de doenças que interfiram na pressão intracraniana e na complacência cerebral.

Como conclusão final, os testes realizados mostraram que o sensor não invasivo respondeu com boa correlação quando comparado ao sensor invasivo. Novos testes precisam ser feitos, principalmente em humanos, para comparar o sensor NI desenvolvido, com os sensores Gold Standard invasivos. 
7 Sugestões para trabalhos futuros

- Modelagem do comportamento do sensor atual;

- Melhoria do design do sensor, contemplando menor peso e melhor sensibilidade, utilizando os fórmulas, técnicas e conceitos abordados neste trabalho;

- Implementação do parâmetro RAP no software;

- Desenvolvimento de um sensor wireless;

- Utilização e avaliação do sistema em humanos comparando com os sistemas invasivos para futura calibração.

- Modelagem da morfologia da forma de onda da pressão intracraniana 
ADAMS, J. P.,BELL, D.,MCKINLAY, J. Neurocritical care : a guide to practical management. London: Springer, 2010. ISBN 9781848820692 (pbk.)

9781848820708 (ebk.).

ANDOLFATO, R. C., JEFFERSON

BRITO, GILBERTO. Extensometria Básica. nepae, 2004. Acesso em: 25/06.

BAZIN, J. E. [Effects of anesthetic agents on intracranial pressure]. Ann Fr Anesth Reanim, v. 16, n. 4, p. 445-52, 1997. ISSN 0750-7658 (Print)

0750-7658 (Linking). Disponível em: < http://www.ncbi.nlm.nih.gov/pubmed/9750596 >.

BOWMAN, S. M.,ZEIND, J.,GIBSON, L. J.,HAYES, W. C.,MCMAHON, T. A. The tensile behavior of demineralized bovine cortical bone. J Biomech, v. 29, n. 11, p. 1497-501, Nov 1996. ISSN 0021-9290 (Print)

0021-9290 (Linking). Disponível em: < http://www.ncbi.nlm.nih.gov/pubmed/8894931 >.

CHEN, W.-F.,SALEEB, A. F. Constitutive equations for engineering materials. Rev. Amsterdam ; New York: Elsevier, 1994. ISBN 0444884084.

CZOSNYKA, M.,PICKARD, J. D. Monitoring and interpretation of intracranial pressure. J Neurol Neurosurg Psychiatry, v. 75, n. 6, p. 813-21, Jun 2004. ISSN 0022-3050 (Print)

0022-3050 (Linking). Disponível em: < http://www.ncbi.nlm.nih.gov/pubmed/15145991 >.

CZOSNYKA, M.,SMIELEWSKI, P.,PIECHNIK, S.,SCHMIDT, E. A.,AL-RAWI, P. G.,KIRKPATRICK, P. J.,PICKARD, J. D. Hemodynamic characterization of intracranial pressure plateau waves in head-injury patients. J Neurosurg, v. 91, n. 1, p. 11-9, Jul 1999. ISSN 0022-3085 (Print)

0022-3085 (Linking). Disponível em: < http://www.ncbi.nlm.nih.gov/pubmed/10389874 >.

DAVIS, J. R.,ASM INTERNATIONAL. Handbook of materials for medical devices. Materials Park, OH: ASM International, 2003. viii, 341 p. ISBN 087170790X. 
DELIJAICOV, S. Curso Extensometria HBM: HBM 2012.

FLECKNELL, P. A. Laboratory animal anaesthesia. 3rd ed. Amsterdam ; London: Academic, 2009. ISBN 9780123693761 (hbk.) : ${ }^{162.99}$

0123693764 (hbk.) : ${ }^{162.99 .}$

GERE, J. M. Mecânica dos Materiais. 5a Edição. São Paulo: CENGAGE Learning, 2003. ISBN 8522103135.

GIBRAIL, D. A. F. FISIOLOGIA E METABOLISMO CEREBRAL. 2013. Disponível em: < http://www.neurocirurgia-sc.com.br/ler artigo.php?id=4 >. Acesso em: 04-04-2013.

GIES, A. A.,CARTER, D. R. Experimental determination of whole long bone sectional properties. J Biomech, v. 15, n. 4, p. 297-303, 1982. ISSN 0021-9290 (Print)

0021-9290 (Linking). Disponível em: < http://www.ncbi.nlm.nih.gov/pubmed/7096384 >.

GUERRA, M. D.,COELHO, R. T. ESTUDO E DESENVOLVIMENTO DE SISTEMAS DE MEDIÇÃO EM PROCESSO PARA APLICAÇÕES EM USINAGEM COM MÁQ̧UINASFERRAMENTAS CNC. 2009. (Doutorado). Departamento de Engenharia Mecânica, Universidade de São Paulo, Escola de Engenharia de São Carlos.

HANNAH, R. L.,REED, S. E. Strain gage users' handbook. London ; New York Bethel, CT, USA: Elsevier Applied Science ;

Society for Experimental Mechanics, 1992. xiv, 476 p. ISBN 1851666869 (Elsevier)

0912053364 (SEM).

HBM. Apostila - Curso de Extensometria HBM 2006.

HIBBELER, R. C. Resistência dos Materiais. 5a Edição. 2004. ISBN 978-8587918-67-3.

HOFFMANN, K. An introduction to measurements using strain gages. Darmstadt: Hottinger Baldwin Messtechnik, 1989. 
INSTRUMENTS", N. The NI TDMS File Format. 2012. Disponível em: < http://www.ni.com/white-paper/3727/en >. Acesso em: 06/05/2013.

JODAL, M.,HALLBACK, D. A.,SVANVIK, J.,LUNDGREN, O. A method for the continuous study of net water transport in the feline small bowel. Acta Physiol Scand, v. 95, n. 4, p. 441-7, Dec 1975. ISSN 0001-6772 (Print)

0001-6772 (Linking). Disponível em: < http://www.ncbi.nlm.nih.gov/pubmed/1970 $>$.

JOHNSON \& JOHNSON, I. Diagrama Conexão CODMAN 2006.

KYOWA, I. Catálogo de Extensômetros metálicos. 2013. Acesso em: 13/02.

LAMBERT, K. L. The weight-bearing function of the fibula. A strain gauge study. J Bone Joint Surg Am, v. 53, n. 3, p. 507-13, Apr 1971. ISSN 0021-9355 (Print). Disponível em: < http://www.ncbi.nlm.nih.gov/pubmed/5580009 >.

LANYON, L. E.,BAGGOTT, D. G. Mechanical function as an influence on the structure and form of bone. J Bone Joint Surg Br, v. 58-B, n. 4, p. 436-43, Nov 1976. ISSN 0301-620X (Print)

0301-620X (Linking). Disponível em: < http://www.ncbi.nlm.nih.gov/pubmed/1018029 >.

LITTLE, E. G.,FINLAY, J. B. Perspectives of strain measurement techniques, in Strain Measurement in Biomechanics. In: (Ed.). Strain measurement in biomechanics. London; New York: Chapman \& Hall, 1992. ISBN 0412432706.

MACHADO, A. Neuroanatomia Funcional. 2a Edição. 2004.

MASCARENHAS, S., VILELA, G. H.,CARLOTTI, C.,DAMIANO, L. E., SELUQUE, W.,COLLI, B.,TANAKA, K.,WANG, C. C.,NONAKA, K. O. The new ICP minimally invasive method shows that the Monro-Kellie doctrine is not valid. Acta Neurochir Suppl, v. 114, p. 117-20, 2012. ISSN 0065-1419 (Print)

0065-1419 (Linking). Disponível em: < http://www.ncbi.nlm.nih.gov/pubmed/22327675 >.

MATWEB. Material Property Data. 2013.

MILES, A. W.,TANNER, K. E. Strain measurement in biomechanics. London ; New York: Chapman \& Hall, 1992. ISBN No price. 
MILLER, J. D.,STANEK, A.,LANGFITT, T. W. Concepts of cerebral perfusion pressure and vascular compression during intracranial hypertension. Prog Brain Res, v. 35, p. 411-32, 1972. ISSN 0079-6123 (Print)

0079-6123 (Linking). Disponível em: < http://www.ncbi.nlm.nih.gov/pubmed/5009562 >.

MONRO, A. M. D. S. O. T. N. Observations on the structure and functions of the Nervous System, etc. Edinburgh, 1783.

OLIVEIRA, S. M. V., G. H. F. NON-INVASIVE INTRACRANIAL PRESSURE SYSTEM. United States: Sérgio Mascarenhas Oliveira: 35 p. 2013.

OLIVEIRA, V. C. M. P., A. A.

OLIVEIRA, E. J. V.

TESSER, J. A.

FERNANDES, R. G.,PIRES, T. M. F. MANUAL PARA REGULARIZAÇÃO DE EQUIPAMENTOS MÉDICOS NA ANVISA: ANVISA 2010.

PAGE, A. E.,ALLAN, C.,JASTY, M.,HARRIGAN, T. P.,BRAGDON, C. R.,HARRIS, W. H. Determination of loading parameters in the canine hip in vivo. J Biomech, v. 26, n. 4-5, p. 571-9, Apr-May 1993. ISSN 0021-9290 (Print)

0021-9290 (Linking). Disponível em: < http://www.ncbi.nlm.nih.gov/pubmed/8478358 >.

PEARCE, J. M. Queckenstedt's manoeuvre. J Neurol Neurosurg Psychiatry, v. 77 , n. 6 , p. 728, Jun 2006. ISSN 1468-330X (Electronic)

0022-3050 (Linking). Disponível em: http://www.ncbi.nlm.nih.gov/pubmed/16705195

http://jnnp.bmj.com/content/77/6/728 >.

PETERSON, R. E. Stress concentration factors; charts and relations useful in making strength calculations for machine parts and structural elements. New York,: Wiley, 1974. xiv, 317 p. ISBN 0471683299. Disponível em: < Contributor biographical information http://www.loc.gov/catdir/enhancements/fy0607/73009834-b.html

Publisher http://www.loc.gov/catdir/enhancements/fy0607/73009834-d.html

description 
Table

of

contents

only

http://www.loc.gov/catdir/enhancements/fy0607/73009834-t.html >.

PITLYK, P. J.,PIANTANIDA, T. P.,PLOEGER, D. W. Noninvasive intracranial pressure monitoring. Neurosurgery, v. 17, n. 4, p. 581-4, Oct 1985. ISSN 0148396X (Print)

0148-396X

(Linking).

Disponível

em:

$<$

http://www.ncbi.nlm.nih.gov/pubmed/4058693 >.

RABOEL, P. H.,BARTEK, J., JR.,ANDRESEN, M.,BELLANDER, B. M.,ROMNER, B. Intracranial Pressure Monitoring: Invasive versus Non-Invasive Methods-A Review. Crit Care Res Pract, v. 2012, p. 950393, 2012. ISSN 20901313 (Electronic)

2090-1305 (Linking). Disponível em: < http://www.ncbi.nlm.nih.gov/pubmed/22720148 >.

ROBERTS, V. Strain-gage techniques in biomechanics. Experimental Mechanics, v. 6, n. 3, p. 19A-22A, 1966/03/01 1966. ISSN 0014-4851. Disponível em: < http://dx.doi.org/10.1007/BF02326147 >.

ROSSBERG, M. I. B., A. ; HURN, P. D.; KIRSCH, J. R. . Principles of Cerebroprotection. In: MURRAY, M. J. E. A. (Ed.). Critical Care Medicine. $2^{\mathrm{a}}$. Philadelphia: Williams \& Wilkins, 2002. cap. 19, p.225 - 235. ISBN 9780781729680.

RYDELL, N. W. Forces acting on the femoral head-prosthesis. A study on strain gauge supplied prostheses in living persons. Acta Orthop Scand, v. 37, p. Suppl 88:1-132, 1966. ISSN 0001-6470 (Print)

0001-6470 (Linking). Disponível em: < http://www.ncbi.nlm.nih.gov/pubmed/5937976 >.

VILELA, G. H. F. Desenvolvimento de um sistema minimamente invasivo para monitorar a pressão intracraniana. 2010. 126 (Doutorado). Instituto de Física de São Carlos, Universidade de São Paulo, IFSC/USP.

WAGSHUL, M. E.,EIDE, P. K.,MADSEN, J. R. The pulsating brain: A review of experimental and clinical studies of intracranial pulsatility. Fluids Barriers CNS, v. 8, n. 1, p. 5, 2011. ISSN 2045-8118 (Electronic)

2045-8118 (Linking). Disponível em: < http://www.ncbi.nlm.nih.gov/pubmed/21349153 >. 